\title{
Assessment of risk factors for HIV infection among men who have sex with men in the metropolitan area of Campinas City, Brazil, using respondent-driven sampling
}

Maeve de Mello

Population Council

Adriana de Araujo Pinho

Population Council

Magda Chinaglia

Population Council

Waimar Tun

Population Council

Aristides Barbosa Junior

Follow this and additional works at: https://knowledgecommons.popcouncil.org/departments_sbsr-hiv Part of the Demography, Population, and Ecology Commons, Gender and Sexuality Commons, Health
See next page for additional authors

Policy Commons, Immune System Diseases Commons, International Public Health Commons, Medicine

and Health Commons, Public Health Education and Promotion Commons, and the Virus Diseases

Commons

How does access to this work benefit you? Let us know!

\section{Recommended Citation}

de Mello, Maeve, Adriana de Araujo Pinho, Magda Chinaglia, Waimar Tun, Aristides Barbosa Junior, Maria Cristina F.J. Ilario, Paulo Reis, Regina C.S. Salles, Suzanne Westman, and Juan Diaz. 2008. "Assessment of risk factors for HIV infection among men who have sex with men in the metropolitan area of Campinas City, Brazil, using respondent-driven sampling," Horizons Final Report. Washington, DC: Population Council. 


\section{Authors}

Maeve de Mello, Adriana de Araujo Pinho, Magda Chinaglia, Waimar Tun, Aristides Barbosa Junior, Maria Cristina, F.J. Ilario, Paulo Reis, Regina C.S. Salles, Suzanne Westman, and Juan Diaz 
Assessment of Risk Factors for HIV Infection Among Men Who Have Sex With Men in the Metropolitan Area Of Campinas City, Brazil, Using Respondent-Driven Sampling
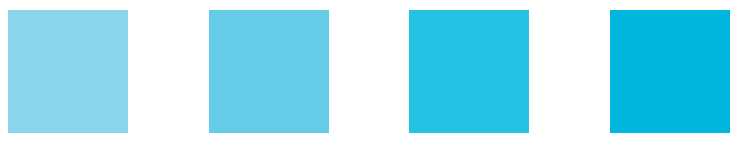

Horizons Program/Population Council

National STD/AIDS Program/Brazil

STD/AIDS Program of Campinas

Municipal Reference Centre for Gays, Lesbians, Transsexuals, Transvestites and Bisexuals of Campinas

Municipal Laboratory of Campinas 


\section{Assessment of Risk Factors for HIV Infection Among Men Who Have Sex With Men in the Metropolitan Area Of Campinas City, Brazil, Using Respondent-Driven Sampling}

Maeve de Mello ${ }^{1}$, Adriana de Araujo Pinho ${ }^{1}$, Magda Chinaglia ${ }^{1}$, Waimar Tun ${ }^{2}$, Aristides Barbosa Júnior ${ }^{3}$, Maria Cristina F. J. Ilário ${ }^{4}$, Paulo Reis ${ }^{5}$, Regina C. S. Salles ${ }^{6}$, Suzanne Westman ${ }^{7}$, and Juan Díaz ${ }^{1}$

(-) USAID HRrizons Ministério
da Saúde
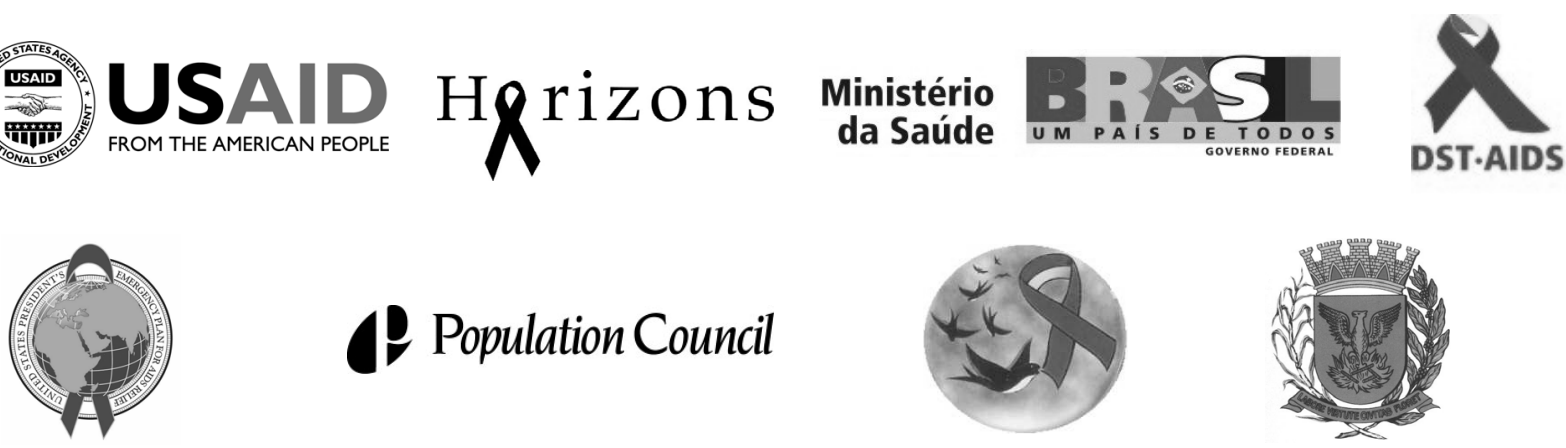

12 Population Council
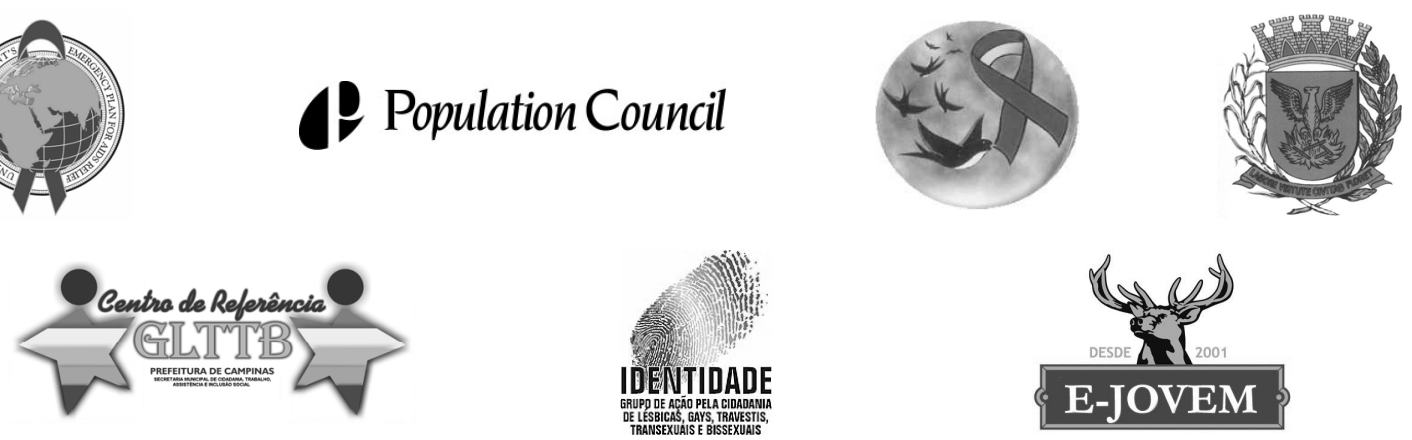

Staff affiliations:

${ }^{1}$ Population Council

${ }^{2}$ Horizons Program/Population Council

${ }^{3}$ Ministry of Health, National STD/AIDS Program/Brazil

${ }^{4}$ STD/AIDS Program of Campinas

${ }^{5}$ Municipal Reference Centre for Gays, Lesbians, Transsexuals, Transvestites and Bisexuals of Campinas ${ }^{6}$ Municipal Laboratory of Campinas

${ }^{7}$ World Health Organization, South-East Asia Regional Office 


\section{Acknowledgments}

The authors thank the project staff in Campinas: Adriana Amador, Andréa Rabelo, Cássia Siqueira, Cláudio Ferreira, Janaína Nicomedes, Leyla Demucci, Maria Aparecida Cardoso, Maria de Fátima Martins, Rosângela Montemor, Shirlei Sousa, Silvio Amaral, Tiago Duque, and Vicente Pisani Neto.

A special thanks to Mariângela Simão, director of the National STD/AIDS Program of Brazil; Ivo Brito, responsible for the Prevention Unit of the National Program; Michael Burkly and Jaime Rojas, from the USAID Mission in Brazil; William Brady, former Director of CDC/GAP-Brazil; Francisco Aoki from the State University of Campinas; and Maria do Carmo Ferreira, from Campinas Sanitary Surveillance Department for their support of the project. This study could not have been implemented without the strong support from the local NGOs who fight for lesbian, gay, bisexual, transvestite, transsexual and transgender rights in the region, especially Grupo Identidade and E-jovem.

We are indebted to Keith Sabin (CDC/GAP) who was always prompt in providing technical support for implementing respondent-driven sampling. Other technical assistance was also kindly provided by Julie Pulerwitz, Sheri Lippman, Alex Carballo-Diéguez, Carl Kendall, Ligia Kerr, Gláucia Marcondes, Camilo Albuquerque de Braz, Francisco Aoki, Johannes van Dam, and Paul Hewett. We are especially thankful for LeeAnn Jones's significant input in writing this report.

We also appreciated the collaboration of the trainers: Bárbara Menezes, Carmem Soares, Denise Serafim, Francisco Cabral, Janaína Lima, Margarita Díaz, Maria do Carmo Ferreira, Rosângela Montemor, Tânia Ferroni, Valdete Queiroz, and Valéria Almeida.

Additional thanks to Population Council staff, including Lúcia Brito, Silvana Muller, Simone Rodrigues, João de Carvalho, André Galiano, Elizabeth Maciel de Albuquerque, Sidnei Sousa, and Dário Silva. We are also thankful to Marcelo Coutinho for the development of the coupon management system and Victor Zubeldia for the artistic design of all communication materials.

The authors are especially appreciative of study volunteers who were willing to dedicate their time to participate in the study.

\footnotetext{
This study and final report were made possible by the President's Emergency Plan for AIDS Relief and the generous support of the American people through the United States Agency for International From THE AMERICAN PEOPIE Development (USAID) under the terms of Cooperative Agreement No. HRN-A-00-97-00012-00. The USAID or the United States Government. contents are the responsibility of the Horizons Program and do not necessarily reflect the views of
}

Published in June 2008.

\footnotetext{
(1) Population Council

The Population Council is an international, non-profit, nongovernmental institution that seeks to improve the well-being and reproductive health of current and future generations around the world and to help achieve a humane, equitable, and sustainable balance between people and resources. The Council conducts biomedical, social science, and public health research and helps build research capacities in developing countries. Established in 1952, the Council is governed by an international board of trustees. Its New York headquarters supports a global network of regional and country offices.

Copyright $@$ C 2008. The Population Council Inc.
}

Suggested citation: de Mello, Maeve, Adriana de Araujo Pinho, Magda Chinaglia, Waimar Tun, Aristides Barbosa Júnior, Maria Cristina F. J. Ilário, Paulo Reis, Regina C. S. Salles, Suzanne Westman, and Juan Díaz. 2008. "Assessment of risk factors for HIV infection among men who have sex with men in the metropolitan area of Campinas city, Brazil, using respondent-driven sampling," Horizons Final Report. Washington, DC: Population Council.

This document may be reproduced in whole or in part without permission of the Population Council provided full source citation is given and the reproduction is not for commercial purposes. 


\section{Table of Contents}

\section{Abbreviations}

Executive Summary 1

$\begin{array}{ll}\text { Introduction } & 6\end{array}$

HIV and AIDS among Brazilian men who have sex with men (MSM) 6

High-risk behaviors and vulnerabilities to HIV/STI transmission $\quad 6$

$\begin{array}{ll}\text { Respondent-driven sampling as a strategy to reach hard-to-reach populations } & 7\end{array}$

$\begin{array}{ll}\text { Study objectives } & 8\end{array}$

$\begin{array}{ll}\text { Methods } & 9\end{array}$

$\begin{array}{ll}\text { Study design } & 9\end{array}$

$\begin{array}{ll}\text { Formative research } & 9\end{array}$

Study site and staff $\quad 9$

$\begin{array}{ll}\text { Sample size } & 10\end{array}$

$\begin{array}{ll}\text { Data collection } & 10\end{array}$

Qualitative assessment of the recruitment 13

$\begin{array}{ll}\text { Ethical issues } & 13\end{array}$

Main study variables $\quad 13$

Data analysis $\quad 15$

$\begin{array}{ll}\text { Results } & 16\end{array}$

Recruitment process 16

$\begin{array}{ll}\text { Characteristics of social network } & 22\end{array}$

$\begin{array}{ll}\text { Sociodemographic characteristics of MSM } & 24\end{array}$

Self-reported sexual orientation and attraction $\quad 26$

Disclosure and openness about sexual attraction $\quad 27$

Exposure to HIV prevention activities 28

Experience of homophobic abuse $\quad 29$

$\begin{array}{ll}\text { Childhood sexual abuse } & 29\end{array}$

$\begin{array}{ll}\text { Alcohol and illicit drug use } & 30\end{array}$

HIV testing behavior $\quad 31$

HIV and syphilis seroprevalence estimates $\quad 32$ 
Self-reported STI symptoms

Sexual behavior

Commercial sex work

Factors associated with URAI

Low levels of disclosure of sexual orientation $\quad 43$

Importance of participation in HIV prevention activities and access to condoms 44

History of HIV testing and self-perception of risk 44

Sexual behavior and condom use $\quad 45$

HIV status of sex partners $\quad 46$

$\begin{array}{ll}\text { Male sex workers } & 47\end{array}$

$\begin{array}{ll}\text { Experience of homophobic abuse } & 47\end{array}$

$\begin{array}{ll}\text { Alcohol and drug abuse } & 48\end{array}$

$\begin{array}{ll}\text { HIV and syphilis prevalence } & 48\end{array}$

$\begin{array}{ll}\text { Concluding remarks } & 50\end{array}$

References $\quad 52$

$\begin{array}{ll}\text { Appendix } 1 \text { Recruitment Coupon } & 59\end{array}$

$\begin{array}{ll}\text { Appendix } 2 \text { Tables of Full Results } & 60\end{array}$ 


\section{Abbreviations}

ACASI Audio computer-assisted self-interview

AIDS Acquired immunodeficiency syndrome

LGBTTT Lesbian, gay, bisexual, transvestite, transsexual and transgender

HIV Human immunodeficiency virus

MSM Men who have sex with men

NGO Non-governmental organization

RDS Respondent-driven sampling

STI Sexually transmitted infections

UIAI Unprotected insertive anal intercourse

URAI Unprotected receptive anal intercourse

UAI Unprotected anal intercourse

UVI Unprotected vaginal intercourse

UAVI Unprotected anal or vaginal intercourse

VCT Voluntary counseling and testing

VDRL Venereal diseases research laboratory

RDSAT RDS Analysis Tool

MRC Metropolitan Region of Campinas

AOR Adjusted odds ratio

IQR Interquartile range

IBGE Instituto Brasileiro de Geografia e Estatística

FGD Focus group discussion 



\section{Executive Summary}

\section{Background}

In 2006, male homosexual/bisexual transmission of HIV accounted for 28 percent of the AIDS cases in Brazilian men ages 13 years and older (Brasil 2006a). Studies conducted in major metropolitan areas in southern Brazil suggest high HIV prevalence rates among men who have sex with men (MSM), ranging from 11 percent in the city of São Paulo (Brasil 2000) to 24 percent in the city of Rio de Janeiro, which also included male commercial sex workers and transvestites (Sutmoller et al. 2002).

While MSM clearly represent an important group in the HIV epidemic in Brazil, the scientific literature on the subject is still limited. There is a growing evidence base in the literature of sexual risk factors for HIV infection among populations of MSM, including unprotected sex with steady partners, experience of discrimination and violence due to sexual orientation (i.e., homophobia), disclosure, and sociodemographic diversity. These studies indicate the need to consider aspects such as sexual identities, discrimination and violence suffered by MSM, commercial sex, drug use, and access to prevention activities in order to understand the vulnerability of these populations to HIV/STIs.

The Population Council, in collaboration with Brazil Ministry of Health, the Municipal Program of STD/AIDS of Campinas, and U.S. Centers for Disease Control and Prevention/Global AIDS Program/Brazil, conducted a study to characterize the sociodemographic, behavioral, and environmental factors associated with subgroups of MSM who are most at risk for HIV infection in the metropolitan area of Campinas, in the state of São Paulo, to inform future HIV prevention and treatment programs. This research is the first Brazilian study to provide population-based estimates for HIV, syphilis, and HIVrelated risk behaviors using an innovative sampling technique, respondent-driven sampling (RDS), to reach members of the target population.

\section{Methods}

A total of $658 \mathrm{MSM}$, at least 14 years old, lived in the metropolitan area of Campinas, and willing to undergo a syphilis test were recruited into the study between October 2005 and October 2006 through RDS, a method based on participants recruiting their peers into the study. Men who had engaged in oral or anal sex with a man within the last six months were eligible to participate in the study. Data collection consisted of an audio computer-assisted self-interview (ACASI), a face-to-face interview about the participant's social network, and blood collection to test for syphilis and HIV (optional) using rapid tests. The ACASI included questions about perceptions and behaviors related to HIV, sexual self-identity, HIV/STI testing and diagnosis history, condom use, drug and alcohol use, homophobic violence, and exposure to HIV prevention activities.

Preliminary data analysis consisted of examining network structures and recruitment patterns based on key attributes of respondents, using NetDraw 2.3.1, a network illustration program, and RDS Analysis Tool version 5.6 (RDSAT) to assess whether the sample reached equilibrium, resulting in a sample that allows the calculation of unbiased population-based estimates. All sociodemographic, behavioral, and environmental measures are presented with population-based estimates with 95 percent confidence intervals (CI), which are adjusted for personal network size and recruitment patterns by RDSAT. 


\section{Hgrizons}

Differences between subgroups were considered statistically significant at the $p<0.05$ level if the 95 percent $\mathrm{CI}$ of the population-based estimates did not overlap.

Logistic regression was conducted using STATA 9.1 $1^{\mathrm{TM}}$ to determine factors associated with unprotected receptive anal intercourse (URAI) with male and transvestite partners in the past two months. This was selected as the dependent variable, as URAI is most likely the behavior that makes the study population most at risk for STI and HIV infection. Stepwise procedure was performed to eliminate variables with pvalues $\geq 0.05$, with the exception of important confounders. The fit of the final model was tested using STATA $9.1^{\mathrm{TM}}$.

\section{Recruitment Process}

Ten "seeds" (initial recruiters) were enrolled into the study. Seeds were selected based on their high level of motivation to participate in the study, self-reported large social network size, and potential to influence peers in the gay community. Twenty additional seeds were enrolled later in the study to boost recruitment. It took 12 months to enroll 658 subjects into the study. An examination of the recruitment process revealed that 46 percent of participants did not successfully recruit anyone into the study. Compared to those who successfully recruited other participants into the study, non-recruiters belonged to a higher socioeconomic class, had fewer peers who disclosed their sexual orientation to their families, had smaller network sizes, and had sex with a higher proportion of members from their reported social network. Nonrecruiters were also less likely to belong to gay NGOs or participate in HIV-related educational talks in the past 12 months compared to those who did recruit at least one participant.

When participants returned to the study site to redeem their reward for recruiting peers, they responded to a self-administered survey about their own experience with the recruitment process. Survey data indicated that the opportunity for taking an HIV test (72 percent), interest in participating in a study specifically about MSM (45 percent), and interest in taking a syphilis test (43 percent) were the most common motivations to participate.

A qualitative assessment was conducted to identify and understand the reasons for the slow recruitment process. This assessment indicated that while getting a free HIV rapid test was an attractive feature for some, it may have deterred others from participating out of fear of taking the HIV test and potentially having to face a positive result. Additionally, the fear of disclosing their sexual orientation remained a strong barrier to participation.

\section{Characteristics of MSM in the Campinas Metropolitan Area}

An estimated one-quarter were between the ages of 14 and 19 years and another quarter were 35 years or older. Nearly one-third reported having had some or completed college, and the majority were either white (55 percent; CI: 50-60) or mulatto/brown (36 percent; CI: 32-41). About one-quarter (26 percent; CI: 21-30) identified themselves as bisexual, and 70 percent (CI: 65-75) as homosexual. Almost all MSM reported having disclosed their sexual attraction to men to another person. 


\section{Key Study Findings}

\section{Sexual behaviors and condom use}

It was estimated that in the two months prior to the survey, one-third of all MSM had only one sex partner (31 percent; CI: 25-35), about half had 2-5 sex partners (46 percent; CI: 42-52), and nearly 20 percent had six or more partners (18 percent; CI: 14-21). Ninety percent (CI: 87-94) had male sex partners, 11 percent (CI: 7-14) transvestite partners, and 16 percent (CI: 11-21) female partners in the last two months. Among those who had male or transvestite sex partners in the last two months, 30 percent (CI: 26-35) were estimated to have had unprotected receptive anal intercourse (URAI) with one partner and 7 percent (CI: 4-10) with more than one partner. Despite these low rates of condom use, 50 percent (CI: 46-56) of MSM perceived themselves to be at low or no risk for HIV infection. In fact, one-third (34 percent; CI: 28-41) of those who perceived themselves to be at low or no risk for HIV infection reported having had at least one experience of URAI in the past two months.

An estimated 16 percent (CI: 11-22) of MSM had sex with both men and women in the last two months. Among those who had vaginal or anal sex with female partners, it was estimated that 75 percent (CI: $37-$ 91) had practiced unprotected anal or vaginal sex with female partners at least once in the past two months.

Multivariate analysis revealed that ever having suffered homophobic psychological abuse was an important predictor of URAI in the past two months along with having a greater number of sexual partners, lower education, and living with a male or transvestite partner. Thirty-eight percent of those living with a male or transvestite partner had engaged in unprotected sex with more than one partner in the previous two months. Additionally, having participated in HIV prevention activities in the past 12 months was also found to be associated with lower odds of unprotected sex.

\section{Commercial sex work}

Approximately 15 percent (CI: 11-19) of MSM reported having received payment (money, drugs, or gifts) in exchange for sex in the past two months and approximately 8 percent (CI: 5-12) declared themselves to be commercial sex workers. MSM who had received payment for sex in the past two months were more likely to have less education, be mulatto/brown, use alcohol and drugs, engage in URAI and unprotected insertive anal intercourse (UIAI), test positive for syphilis, have suffered psychological and physical violence and violence from police in the past 12 months, and have experienced sexual abuse as a child, compared to those who did not sell sex. However, MSM who received payment for sex were less likely to identify themselves as homosexuals.

\section{HIV testing and self-perception of HIV risk}

Forty-two percent (CI: 36-48) of all MSM had never been tested for the HIV. Sixty-two percent (CI: 5071) of MSM aged 14-19 years had never been tested for HIV, and 46 percent (CI: 32-70) of these individuals had URAI in the past two months. Additionally, it was observed that about half perceived themselves to be at low risk for HIV infection despite the fact that 34 percent (CI: 28-41) of them had engaged in URAI in the last two months. 


\section{Hgrizons}

\section{Estimates of HIV and syphilis prevalence}

Seroprevalence of HIV was estimated to be 7 percent (CI: 5-11) among MSM. Among the youngest MSM (aged 14-19), the estimated seroprevalence was 4 percent (CI: 1-9). Seroprevalence of syphilis infection (current or past infection) among MSM was estimated to be 9 percent (CI: 6-12).

\section{Drug use and alcohol consumption}

It was estimated that 32 percent (CI: 27-37) of all MSM had used illicit drugs in the past six months; marijuana was the most commonly used drug, followed by cocaine. One percent (CI: $0-3)$ was estimated to have ever injected drugs. Seventeen percent (CI: 13-22) were estimated to be heavy drinkers (consuming alcohol many times a week or everyday). Twenty-nine percent (CI: 14-46) were estimated to have drunk or used any drug during URAI and 15 percent (CI: 7-25) during UIAI.

\section{Homophobic abuse}

A high proportion reported having suffered homophobic violence at least once in their lifetime (85 percent; CI: 80-88), as well as in the past 12 months (70 percent; CI: 65-75). Psychological abuse (61 percent; CI: 56-67) was the most common form of homophobic violence experienced in the past 12 months, followed by sexual harassment (31 percent; CI: 26-36) and physical abuse (20 percent; CI: 1625). Some (9 percent; CI: 6-13) MSM reported having experienced homophobic abuse from the police at least once in their lifetime. Among those who ever experienced physical abuse or sexual harassment, 11 percent (CI: 6-17) sought medical help and only 6 percent (CI: 3-9) reported the abuse to the police.

\section{Condom distribution and HIV/STI educational activities}

A high proportion (78 percent; CI: 73-82) were estimated to have received free condoms in the previous 12 months. Sex workers received more free condoms in the past 12 months than non-sex workers, but also engaged more in URAI and UIAI. Although participation in HIV/STI prevention activities was found to be associated with condom use in receptive anal sex, only 30 percent (CI: 26-35) of MSM in the region were estimated to have participated in HIV/STI prevention activities in the previous 12 months.

\section{Concluding Remarks}

The study was designed to characterize patterns of sexual behavior associated with risk for HIV infection, taking into account the diversity within this population. The study was successful in providing insights into the identification of most-at-risk "sub-populations," as well as identifying other underlying factors that increase the vulnerability of MSM. The results indicate that the sub-populations of MSM who are most at risk include younger MSM, those who engage in sex work, MSM in stable partnerships (living with a male or transvestite partner), and those who have been victims of homophobic violence.

This study found an HIV seroprevalence of 7 percent among MSM in the metropolitan area of Campinas. An important finding of this study was the high percentage of MSM who did not know their HIV status, 
with 70 percent of those who tested HIV-positive being unaware of their infections. Additionally, of those who tested positive, 37 percent had previously tested negative for HIV. The findings suggest the importance of increasing the uptake of HIV testing among MSM.

HIV prevalence, especially for very young MSM (age 14-19) was strikingly high for the Brazilian context. Considering that the median age of first sexual contact was 13 years old, adolescent males who have sex with men should be a priority group for prevention activities in the country. Prevention programs for young MSM must also take into account sexuality and gay identity, as this study found that younger men were less likely to identify themselves as homosexual than older men.

MSM who engage in commercial sex work were also identified as a high-risk group in this study. These MSM are more socially vulnerable due to their lower socioeconomic status, lower levels of education, ethnicity, and history of homophobic abuse, which makes them even more susceptible to HIV infection.

Prevention programs must also address high-risk sexual behaviors within stable partnerships. The findings from this study indicate that MSM who are in stable partnerships are five times more likely to have unprotected receptive anal sex than those who are not in stable relationships, and 38 percent of those in stable partnerships were estimated to have engaged in unprotected sex with more than one partner in the previous two months. In light of these findings, prevention strategies must also address safer sex in the context of steady relationships.

The astonishingly high levels of homophobia found in this study provide strong evidence for prioritizing and supporting initiatives of NGOs for gay men and for the Brazilian Federal Government's plan to reduce homophobia and discrimination against gays, lesbians, transgenders, and bisexuals. Societal homophobia is a major barrier for MSM to accessing prevention services. Advocacy for greater acceptance by all sectors of society is urgently needed.

Our data suggest the importance for HIV prevention programs to address not only sexual risk reduction, but also other social and cultural factors such as their vulnerability to homophobic violence, social construction of sexual identity, and social norms regarding sexuality and condom use within their social networks.

The findings from this study clearly indicate the importance of the population of MSM in the HIV epidemic and the need for targeted interventions, particularly for the risky sub-populations in Campinas. Progress is being made in this area. The Brazilian government has made MSM a key target group in the fight against HIV, as highlighted by the high priority given to young MSM during the official 2007 AIDS Day prevention campaign. Together these are important steps towards comprehensive coverage of MSM and its sub-groups with HIV prevention programs. Lastly, the implementation of this study contributed substantially to the development of the guidelines for the implementation of the national HIV surveillance in high-risk populations. 


\section{Hgrizons}

\section{Introduction}

\section{HIV and AIDS among Brazilian Men Who Have Sex with Men (MSM)}

In 2006, male homosexual/bisexual transmission accounted for 28 percent of the AIDS cases among Brazilian men (Brasil 2006a). Studies conducted in major metropolitan areas located in southern Brazil suggest high HIV prevalence and incidence rates among MSM. In a cohort study carried out in the city of São Paulo, researchers documented an 11 percent seroprevalence rate of HIV among MSM (Brasil 2000). In another study carried out in the city of Rio de Janeiro, a higher seroprevalence rate of HIV (24 percent) was found among homosexuals and bisexuals, which also included commercial sex workers and transvestites (Sutmoller et al. 1997). In the city of Belo Horizonte, researchers observed a high incidence of sexually transmitted infections (STIs), including HIV (0.358/100 people/month for HIV), among MSM (Lignani et al. 2000).

MSM clearly represent an important group in the HIV epidemic in Brazil. However, as Luna and Veras (2002) point out in a review, the scientific literature on the Brazilian epidemic and MSM is still limited in terms of the number of publications and in their approach to the dynamics of the HIV epidemic. The literature reflects the views of lesbian, gay, bisexual, transvestite, transsexual and transgender (LGBTTT) organizations by pointing to the need to consider aspects such as sexual identities, discrimination and violence suffered by MSM, commercial sex, drug use, and access to prevention activities to understand the vulnerability of the population to HIV/STIs.

\section{High-risk Behaviors and Vulnerabilities to HIV/STI Transmission}

Several studies have suggested that MSM engage in sexual risk behaviors such as unprotected receptive anal intercourse (URAI). A study carried out in a southern Brazilian city showed that nearly 40 percent of MSM between the ages of 18 and 30 years had not used condoms during receptive anal intercourse with a steady or occasional partner in the past six months (da Silva et al. 2005). A similar proportion was found in a Brazilian northeastern city, where 44 percent of respondents between the ages of 14 and 64 years reported having unprotected anal sex in the previous one year (receptive or insertive) (Kerr-Pontes et al. 1999). Studies outside Brazil also have reported high rates of unsafe sexual practices and high HIV prevalence rates, especially among young MSM (Waldo et al. 2000; Celentano et al. 2006). The perceived low risk for HIV infection among young men has been found to be an important factor associated with unsafe sexual practices (MacKellar et al. 2005, 2006). Furthermore, among Brazilian MSM, optimistic perceptions about HIV and AIDS have been shown to be associated with unprotected sex (da Silva et al. 2005); these are possibly due, in part, to universal free access to antiretroviral therapy and other drugs for Brazilian HIV-positive patients, which has substantially reduced the morbidity associated with HIV (Marins et al. 2003).

Studies carried out in Brazil and elsewhere also have shown a strong association between unprotected sex and having a steady partner (Brasil 2000; da Silva et al. 2005; MacKellar et al. 2005), and a number of studies suggest that a large majority of new infections among younger MSM might be attributed to transmission from steady sexual partners (Davidovich et al. 2001; Xiridou et al. 2003). 
Additionally, recent research has shown the high vulnerability of MSM to discrimination and homophobic violence and the association of such experiences with high-risk sexual behaviors (Thiede et al. 2003; Koblin et al. 2006). Data from police departments and LGBTTT organizations also indicate high rates of discrimination and homophobic violence against Brazilian MSM (Carrara 2005; Mott 2006).

Some studies have found that young MSM who disclosed their sexual orientation were more likely to suffer discrimination and violence experiences, which in turn may lead to problems of depression, low self-esteem, anxiety, suicidal thoughts, greater drug and alcohol consumption, and high-risk sexual behaviors (Díaz et al. 2001; Ortiz-Hernández and Torres 2005; Rosário et al. 2006). On the other hand, non-disclosure of homosexuality may increase the likelihood of engaging in unsafe sexual behaviors with women (CDC 2003). Some studies observed that Latino bisexually active men, particularly those who did not identify themselves as gay or bisexual, were more likely to have high-risk anal sex than those who did, likely as a result of not perceiving themselves to be at risk for HIV infection (Jarama et al. 2005). However, bisexuality remains a phenomenon that is sparsely investigated both in Brazil and elsewhere.

It is imperative to determine the sociodemographic and behavioral factors associated with HIV infection in order to better guide design of innovative interventions for HIV and STI prevention and treatment specifically tailored for the population of MSM in Brazil. Further, given that male-to-male sexual interactions occur for various reasons and under different social contexts, it is essential to also characterize patterns of sexual behaviors associated with the risk of HIV infection, taking into account the socio-cultural diversity and context within this group, in order to determine the vulnerability of "subgroups" within the larger population.

\section{Respondent-driven Sampling as a Strategy to Reach Hard-to-reach Populations}

The limited scientific research about MSM in Brazil is in part due to the difficulties of sampling such a highly stigmatized and often hidden population in a representative way. Past studies among Brazilian MSM have used convenience sampling, despite its inherent biases (Sudman et al. 1988; Lepkowski 1991). On the other hand, traditional probability-based sampling methods require the development of a sampling frame, which is challenging for hard-to-reach or "hidden" populations (Robinson et al. 2006). To minimize selection bias, researchers have started using a new sampling alternative among populations such as MSM, commercial sex workers, and injection drug users. This sampling method, respondentdriven sampling (RDS) (Heckathorn 1997, 2002), is a type of chain-referral sampling, or snowball sampling, and "is based on the recognition that peers are better at locating and recruiting other members of a hidden population than outreach workers and researchers" (Semaan et al. 2002). A dual compensation system, whereby a respondent is compensated for participating in the study and for recruiting his/her peers, is used. Moreover, proponents of RDS claim that this sampling method can produce probability samples of the target population and reduce several sources of bias found in chainreferral methods (Heckathorn 1997, 2002; Semaan et al. 2002). The population-based estimates are based on a model that takes into account the network size of participants and recruitment patterns (Heckathorn 1997; Salganik and Heckathorn 2004; Thompson and Frank 2000).

This research is the first Brazilian study to use RDS to provide population-based estimates for HIV and syphilis prevalence, together with HIV-related risk behaviors, among men who have sex with men. The study also provides detailed information on how RDS can be implemented among MSM in Brazil. 


\section{Hgrizons}

Lessons learned from the implementation of RDS provide critical information to the Ministry of Health who plan to use RDS as a sampling strategy for national surveillance of HIV and associated risk behaviors among MSM and other vulnerable populations.

\section{Study Objectives}

\section{Primary objective}

The primary objective of this research was to characterize the sociodemographic, behavioral, and environmental factors associated with subgroups of MSM who are most at risk for HIV infection in the metropolitan area of Campinas to inform future HIV prevention and treatment programs.

\section{Secondary objectives}

1) Characterize subgroups of MSM by different levels of risk for HIV infection, using sociodemographic, behavioral, and environmental factors in the metropolitan area of Campinas;

2) Characterize the network of MSM in the metropolitan area of Campinas, including the interconnections within subgroups and among other populations;

3) Determine the proportion of MSM reached by different prevention activities developed by NGO or public health services in the metropolitan area of Campinas and determine levels of exposure to these prevention activities; and

4) Estimate HIV and syphilis prevalence in the population of MSM in the metropolitan area of Campinas. 


\section{Methods}

\section{Study Design}

This study employed a cross-sectional design, recruiting MSM through RDS. Data was collected using an audio computer-assisted self-interview (ACASI) and blood collection to test for syphilis and HIV seropositivity. Interviews and blood sample collection were undertaken (at the same time-point) between October 2005 and October 2006.

\section{Formative Research}

Formative research was first conducted with members of the population of MSM and stakeholders who work with this population to guide study implementation and facilitate participation. Trained facilitators conducted nine short, semi-structured interviews and five focus group discussions (FGDs) to gather information regarding: interest in participating in the research project; feasibility of recruitment through RDS; need for and nature of compensation for participating in and for recruiting peers into the study; and choice of educational materials and preferences for study logistics and procedures (location, hours, study staff characteristics, selection of initial participants to start the recruitment process, recruitment coupons, return procedures, and referrals). According to participants of the formative research, using RDS with a dual compensation system (i.e., for participation and for recruitment of peers) would work well within the target community. In addition, the possibility of having rapid HIV testing was identified to be the most attractive aspect of the study.

\section{Study Site and Staff}

The study site was in Campinas City, which is located in southeastern Brazil and has a population of approximately 1 million residents. Reasons for undertaking the study in Campinas included that it had a gay community that was willing to collaborate with the study organizers, there was a well-organized AIDS municipal program, it had a good history of collaborative projects with the municipal program, researchers' knowledge of the city, and the large number of AIDS cases reported in the city. In addition, Campinas city is considered a referral pole for health care for its surroundings and is at the geographical center of its metropolitan area, which is composed of 19 municipalities encompassing approximately 3,600 square kilometers and home to 2.33 million inhabitants, according to the 2000 Census (IBGE 2000).

A rented house in an area that was easily accessible for the target population was selected, with input from local gay NGO members, as the study site. Participant flow at the study site was designed to provide maximum privacy and minimize their exposure to any other study participants. The site was open from $1 \mathrm{pm}$ to $8 \mathrm{pm}$ (Monday to Friday) and from $10 \mathrm{am}$ to $5 \mathrm{pm}$ on Saturdays. The office was supervised by the Regulatory Agency of the local public health department (COVISA) and staffed at all times by a supervisor (a medical biologist trained in public health), a lab technician, two counselors, a receptionist, and a security officer. Participants who tested positive for syphilis and/or HIV were referred to the Municipal STI/AIDS Program Health Center for treatment and follow-up care. 


\section{Hgrizons}

\section{Study population}

MSM were eligible to participate in this study if they fulfilled all of the following inclusion criteria:

- Had not participated in the study previously.

- Was 14 years of age or older.

- Resided in of one of the 19 municipalities of the metropolitan area of Campinas.

- Had oral or anal sex with a man within the last 6 months.

- Was willing to comply with study protocol (this included responding to the questionnaire and collecting a blood sample for syphilis testing; HIV testing was optional).

- Was able to understand and willing to sign the informed consent form.

- Arrived at the study site with a valid study recruitment coupon.

- Was not obviously under the influence of drugs and/or alcohol at the time of enrollment.

In this study a man who has sex with men was considered anyone who was born with a penis and had engaged in oral or anal sex with a man within the past six months. Therefore, transvestites (i.e., crossdressers) were also eligible to participate. Overall, $658 \mathrm{MSM}$ were recruited (including seeds) between October 2005 and October 2006, of which 3.4 percent were transvestites.

\section{Sample Size}

The sample size was calculated to estimate HIV and syphilis prevalence. A previous Brazilian study with MSM (Brasil 2000) estimated the prevalence of syphilis at 10.7 percent and HIV at 10.8 percent. A target sample size of 1,800 was determined based on the ability to estimate syphilis and HIV prevalence with an error of \pm 1.5 percentage points (or with an error of \pm 1 percentage point using a more conservative estimate of HIV prevalence in MSM of 4.5 percent) (Szwarcwald et al. 2000). The sample size achieved was $658 \mathrm{MSM}$, with which it was possible to estimate, with a 95\% CI, a prevalence of syphilis and HIV with an error of \pm 2.4 percentage points.

\section{Data Collection}

Recruitment of respondents was conducted using RDS. RDS recruitment starts with "seed" participants, who were selected non-randomly. The seeds were selected by partner NGOs in the gay movement and during the Gay Pride Parade based on their high level of motivation to recruit, their enthusiasm for the study, their large social network, and sociodemographic and behavioral diversity. Each seed received three unique, non-replicable, recruitment coupons (see Appendix 1) to give to peers who also fit the eligibility criteria for the study. Individuals who came to the study venue with a recruitment coupon and met the eligibility criteria gave informed consent. After completing the interview and giving a blood sample, they also received coupons to invite their peers to participate in the study. This process was repeated for one year. Respondents received compensation for participating in the study and for each of their recruits who subsequently enrolled in the study.

After the eligibility check and informed consent procedures, participants completed the AudioComputerized Assisted Self Interview (ACASI) in a private room. A study staff member gave instructions on how to use the computer-based questionnaire and was available at all times to provide assistance. The questionnaire included information regarding: i) Sociodemographic characteristics; ii) Sexual orientation 
and sexual identity; iii) Self-esteem; iv) Disclosure; v) Exposure to HIV prevention activities; vi) Experiences with anti-gay and transvestite violence and victimization; vii) History of sexual abuse; viii) Sexual behaviors with transvestites, men, and women; ix) Participation in or with commercial sex; $x$ ) STI symptoms; xi) Past HIV testing behavior; xii) Drug use; xiii) Incarceration history; and xiv) Acceptability of the use of rapid tests and ACASI.

\section{Pre-test counseling}

Upon completion of the survey, participants went through individual pre-test counseling before the blood sample collection, in order to ensure that they were aware of the risks and benefits of being tested for syphilis and HIV and the meaning of rapid test results ${ }^{1}$. Study participants were also offered vaccination against the Hepatitis B virus; the risks and benefits of the vaccination were also explained.

\section{Laboratory procedures}

After the counseling session, the participants received the first dose of the Hepatitis B vaccine, if accepted, and received a vaccination card to present to any public health clinic in the municipality of Campinas to receive the remaining two doses. The lab technician also took biometric measures (height, forearm length, and wrist width), which was part of the protocol to minimize potential multiple participation. In addition, facial recognition was used by staff members.

The nurse technician then performed rapid tests for syphilis and HIV for those who agreed. Participants were asked to provide a blood sample for the rapid tests. The HIV test was conducted according to the Ministry of Health's (MoH) HIV rapid test procedures guideline. Two approved rapid tests by the $\mathrm{MoH}$ were used: Determine ${ }^{\mathrm{TM}}$ HIV 1/2 test (Abbott Laboratories) and Rapid Check HIV 1 and 2 (NDI). In case of discordance between the two test results, the Uni-Gold ${ }^{\mathrm{TM}}$ HIV test (Trinity Biotech) or the Teste Rápido HIV- 1/2 (Bio-Manguinhos, FIOCRUZ) was used as a tiebreaker. For syphilis detection, the rapid test Determine ${ }^{\mathrm{TM}}$ syphilis Treponema palidum (TP) test (Abbott Laboratories) was used. Whole blood was used in all tests according to manufacturer instructions for each diagnostic test. For all positive syphilis rapid tests, the blood sample was sent to the Municipal clinic for a quantitative VDRL (Venereal Disease Research Laboratory) to facilitate physicians' decision on treatment and follow-up procedures.

Participants were also asked if they would be willing to provide a blood sample to be stored and used for more detailed STI testing in future studies. If they agreed, the nurse technician drew two tubes (13 ml) of blood from the participant's arm, and, using the same puncture, drew an additional $2 \mathrm{ml}$ of whole blood in a special tube containing anti-coagulant (EDTA) to be used to perform the rapid tests according to manufacturer instructions. Participants who refused to provide a sample for future testing had the option of a finger puncture for the performance of the two rapid tests.

\footnotetext{
${ }^{1}$ Counseling was based on the Ministry of Health's National Guidelines for Pre- and Post-test Counseling for HIV. In addition, the Centers for Disease Control's (CDC) Revised Guidelines for HIV Counseling, Testing, and Referral (CDC 2001) and the Protocol for Rapid Test Intervention Session (CDC 1999) were reviewed to ensure coverage of all possible components of counseling and testing for STI/HIV, including discussion of safer sex practices, HIV/STI diagnosis and care, and partner notification.
} 


\section{Hgrizons}

\section{Recruitment coupons and compensation}

While waiting for test results, the counselor administered a face-to-face interview with the participant about the participant's personal network. Questions were related to the size of their personal network, the characteristics of members of the network, and the relationship between the participant and his recruiter. The participant was then given three recruitment coupons to use to invite eligible acquaintances to participate in the study. Participants were compensated for enrolling in the study ${ }^{2}$ and for each eligible man they successfully recruited into the study ${ }^{3}$. Free condoms, lubricant gel, and educational materials were given to all who came to the study site. Participants arriving at the study site to redeem the secondary incentive of their second or third coupon were asked to complete a brief self-administered questionnaire about their experience in recruiting their peers, including the number of refusals by MSM they had tried to recruit and their reasons for refusing.

\section{Post-test counseling and referral}

Approximately 20 to 30 minutes after sample collection, participants received their test results and posttest counseling. Participants with a positive rapid test for syphilis and who had provided a venous blood sample were told that their serum would be sent to the Municipal Laboratory of Campinas, where a quantitative VDRL would be performed to guide the treatment decision and the clinical management of the infection. Those participants who had provided blood drops to perform the rapid tests were asked to provide a tube $(5 \mathrm{ml})$ of blood to be sent to the Municipal Laboratory so that the quantitative VDRL could be performed. These VDRL results were returned to the study site within 10 days and the counselor offered a scheduled appointment with the doctor at the study site. If active syphilis was diagnosed, the first dose of Penicillin Benzathine was given at the study site, and the doctor made a referral to the municipality STI clinic for completing the treatment and monitoring free of charge.

Participants who tested positive for HIV underwent all MoH pre-established voluntary counseling procedures. The counselor provided a written referral to the municipal STI/AIDS reference center, where study participants were able to enroll for free treatment and monitoring.

\section{Ending recruitment and closing the study site}

The expiration date of all recruitment coupons given after September 2006 was October $21^{\text {st }} 2006$, and the expiration date of payment coupons was October $31^{\text {st }} 2006$. Participants who tested positive for syphilis with the rapid test were able to retrieve their VDRL results until October $31^{\text {st }}$. During this period, secondary incentives could be redeemed and the Hepatitis B vaccination was available to those enrolled (for first, second, or third shots). Participants who came after October $21^{\text {st }}$ looking for HIV testing were referred to the Reference Center for STD/AIDS of Campinas, which offers VCT and free treatment.

\footnotetext{
${ }^{2}$ Participants could choose their compensation among: two cinema tickets, two VIP gay nightclub entrance passes, two meal vouchers, a hair cut, manicure and pedicure, a clothing store gift, and a t-shirt.

${ }^{3}$ Extra compensation included one cinema ticket, a VIP nightclub entrance pass, a meal voucher, and a manicure or pedicure service.
} 


\section{Qualitative Assessment of the Recruitment}

In order to understand the recruitment process, in-depth interviews were conducted with 31 MSM who had participated in the study and four MSM who had received the coupon but did not enroll. Interviewees were invited to take part in the qualitative assessment by study seeds or by partner NGO staff who knew participants, or MSM who had accepted a coupon but did not participate in the survey. Interview questions were related to reasons for participating or not in the study, for delivering their coupons or not, the influence of the complexity of study procedures, and the use of rapid tests for HIV and syphilis in a RDS study on participation and recruitment. Analyses of the qualitative data consisted of an initial reading of all the interview transcripts by two researchers. They determined a series of key themes or codes considering all aspects of the interview guidelines. These codes were inserted into the interviews and searched afterwards by the software ZYindex ${ }^{\circledR}$, which identified the specific excerpt (interviewee's speech) to assist with the content analysis of the material. Analyses were stratified by age and schooling degree.

\section{Ethical Issues}

The protocol was approved by the Institutional Review Board of the Population Council in the U.S. and by the ethics committee of the Campinas State University (Unicamp) and the National Ethics Committee, Conselho Nacional de Ética em Pesquisa (CONEP) in Brazil. Written informed consent was obtained for all study participants. For individuals between 14 and 17 years of age, parental consent as well as consent of the adolescent was obtained. If the adolescent felt that requesting his parental permission would cause any harm to his well-being, parental consent was not required. Consent forms were kept separately from questionnaires, recruitment coupons, and biological samples so names could not be linked to any study data collected. All interviews were conducted in private rooms. Study documents, including ACASI data and specimens, were identified using unique ID numbers for each participant to maintain confidentiality. All electronic data were downloaded and deleted from every rented computer used in the study site. Frozen biological samples are kept at the Municipal Laboratory of Campinas, following procedures described in the study protocol.

A Local Ethics and Advisory Committee was established to ensure protection of human subjects. The Committee met at the municipal Reference Center for gays, lesbians, bisexuals, and transgenders and included representatives from municipal AIDS programs, NGOs involved in the gay movement in Campinas, and a representative of Population Council/Brazil. Participants were given a free phone number to call the Committee in case of any complaints or infraction of rights.

\section{Main Study Variables}

HIV infection was defined as a positive result on the HIV rapid test following the Ministry of Health HIV rapid test procedures guideline.

Syphilis infection (including recent or past syphilis infection) was defined as positive result for syphilis rapid test. A positive result using this test indicates either recent or past syphilis infection. 


\section{Hgrizons}

Sexual orientation and sexual attraction were self-reported measures. Participants indicated their sexual orientation during the face-to-face interview as homosexual, bisexual, or heterosexual. Definitions of sexual identity or sexual orientation were not provided to participants. Participants indicated their sexual attraction during the ACASI interview as attracted to only men; men and women; or other combinations of men, women, and/or transvestites.

Brazilian Criteria of Purchase Power was adopted as a proxy for participant's economic status. This indicator is constructed based on number of household goods, as well as the educational degree of the household head (available at www.abep.org).

A social network was defined as all MSM living in the metropolitan area of Campinas that the participant knew by first name, that the participant could contact personally or by phone, and with whom they had talked in the previous month. Members of the participant's restricted social network were a subset of individuals from the social network who the participant was willing to invite to participate in the study.

Homophobic violence was examined in three different ways: psychological, physical, and sexual. Participants were asked if they had experienced any form of abuse perceived as homophobic both in their lifetime and during the previous twelve months. Psychological abuse was defined as experiences of being cursed, threatened to be beaten, pursued in the street, or having personal objects broken because the participant was either gay or transvestite. Physical abuse was defined as any act of being hit, spat upon, slapped, kicked, or beaten because the participant was gay or transvestite. Sexual abuse was defined as someone insisting to have any sexual contact in a disrespectful manner with the participant or against the participant's will because the participant was either gay or transvestite.

Childhood sexual abuse was defined as any sexual contact before the age of 13 with someone at least 4 years older. Those participants were also asked whether they had considered that experience sexual abuse or not.

Drug use was defined as use of any illicit drugs, including marijuana, amphetamines, cocaine, crack, methylenedioxymethamphetamine (ecstasy), inhalants, and any drug injected into the vein. The participant was classified as an "infrequent user" if he had consumed the specific drug less than once a week and a "regular user" if he had consumed it once a week or more.

Commercial sex was assessed by asking participants about whether they had received money, drugs, or gifts in exchange for sex with men, transvestites, and/or women and whether they had paid (women, transvestites, or men) for sex. Participants were also asked if they identified themselves as sex workers.

Sexual behavior was examined through assessment of frequency and types of sexual acts, types of partners, the number of different types of partners, condom use with them, perception of partners' serostatus, places where participants met sex partners, and frequency of engaging in sex in groups. The term male partner in this study includes both men and transvestites.

An STI symptom was defined as having any sores or warts in the anal or genital area, discharge or burning upon urination, or discharge or burning at the anus. If a participant indicated a positive answer, he was asked whether he still had the STI symptom(s) at the time of the interview. 


\section{Data Analysis}

Preliminary data analysis consisted of examining network structures and recruitment patterns based on key attributes of respondents using NetDraw 2.3.1, a network illustration program, and RDS Analysis Tool version 5.6 (RDSAT). The researchers assessed whether the sample reached equilibrium, resulting, therefore, in a sample which should allow the calculation of unbiased population-based estimates. The parameters used to calculate the RDS population-based estimates were 15,000 bootstraps and imputation of 5 percent of the outliers in both extremes for the restricted network size. The number of recruitment waves required was calculated in RDSAT for all independent and key dependent variables. Almost all variables reached equilibrium between the second and fourth recruitment waves, and the remaining at the maximum of eight waves. Continuous variables were examined for normality and categorized using STATA $9.1^{\mathrm{TM}}$ before conducting the analysis in RDSAT. Sociodemographic variables are presented as both sample proportions and population-based estimates with $95 \%$ confidence intervals (CI) weighted for personal network size and recruitment patterns based on RDSAT. However, for all other variables, only population-based estimates are presented in the main report. (See Appendix 2 for the comparison of the sample and population-based estimates.) The text reporting the results is written based on populationbased estimates.

The research team also evaluated differences between participants who had received payment for sex in the past two months and those who did not, by some sociodemographic and risk behaviors characteristics. Differences in these characteristics between the two groups were considered significant if the $95 \%$ CIs of the estimates did not overlap. In addition, because of previously documented sexual risk taking, the transvestite category was included in the descriptive analysis, although there were too few transvestites recruited for more detailed analysis.

The researchers explored factors associated with URAI with male partners in the past two months. Analysis was done in two stages. The first stage encompassed bivariate analysis using Chi Square tests to determine independent associations with URAI. All variables moderately associated $(p<0.20)$ in the bivariate analyses were included in the second stage of the analysis, logistic regression modeling. The full model was produced by stepwise elimination of variables with $p$-values $\geq 0.05$, with the exception of important confounders based on previous research. We assessed the fit of the final model using the Hosmer and Lemeshow goodness-of-fit test (Hosmer and Lemeshow 1989). These analyses were performed using STATA 9.1 ${ }^{\mathrm{TM}}$. The analysis was not based on weights from RDSAT results.

This report describes the social and sexual network characteristics of study seeds and compares network size medians between participants who were successful and not successful at recruiting their peers into the study using STATA $9.1^{\mathrm{TM}}$. 


\section{Hgrizons}

\section{Results}

\section{Recruitment Process}

\section{Description of seeds and recruitment from these seeds}

A total of thirty seeds (initial participants who started the recruitment process) were enrolled into the study. The initial recruitment started with 10 seeds that were selected during formative research, as well as by partner NGOs. Seven additional seeds identified by partner NGOs were added 4-6 months after the study started due to slow recruitment. During the Campinas Gay Pride Parade, where information about the study was disseminated, another six seeds were added (eight months after the study started). Additionally, seven potential participants who arrived after the $10^{\text {th }}$ month at the study site without a coupon were treated as seeds.

The diverse characteristics of the seeds are shown in Table 1. Seeds were selected based on their high level of motivation to participate in the study, self-reported large social network size, and potential to influence peers in the gay community. Seeds that were enrolled midway through the study were chosen based also on having characteristics of a poorly represented group in the sample at the time of enrollment (i.e., being 30 or older, male sex workers, and living in other municipalities outside of Campinas).

Seed network size was determined based on their response to a question that asked how many MSM they knew that met the following criteria:

- you think they have had sexual intercourse (anal or oral) at least once with a man,

- they live in the metropolitan region of Campinas,

- you know how to contact them, and

- you have talked to them in the last month.

The median network size was 10 people (interquartile range [IQR]: 5-20). For the purpose of the analysis for RDS, a more restricted definition of network size was used. This restricted network size included only the people in the respondent's social network who they would consider recruiting into the study. The median restricted network size was six people (IQR: 4-10).

Table 1 Characteristics of the seed participants in the study $(n=30)$

\begin{tabular}{lr}
\hline Age & $\mathbf{n}$ \\
$14-19$ & 6 \\
$20-24$ & 6 \\
$25-34$ & 10 \\
$\geq 35$ & 8 \\
Schooling degree & 13 \\
$\quad$ Some or completed primary or secondary & 5 \\
At least some or completed high school & 12 \\
At least some or completed college & \\
\hline
\end{tabular}


Table 1 Characteristics of the seed participants in the study $(n=30)$ (continued)

\begin{tabular}{|c|c|}
\hline & $\mathbf{n}$ \\
\hline \multicolumn{2}{|l|}{ City of residence } \\
\hline Campinas & 27 \\
\hline Hortolândia & 1 \\
\hline Itatiba & 1 \\
\hline Valinhos & 1 \\
\hline \multicolumn{2}{|l|}{ Brazilian Criteria for Purchase Power } \\
\hline Class A (Highest) & 3 \\
\hline Class B & 13 \\
\hline Class C & 11 \\
\hline Class D/E (Lowest) & 3 \\
\hline Median monthly income (in Reais) (IQR) & $950(350-2,300)$ \\
\hline Median monthly income (in USD) (IQR) & $437(161-1,058)$ \\
\hline \multicolumn{2}{|l|}{ Type of job } \\
\hline Formal & 16 \\
\hline Informal & 9 \\
\hline Was not working & 5 \\
\hline \multicolumn{2}{|l|}{ Skin color } \\
\hline White & 18 \\
\hline Black & 4 \\
\hline Brown/Mulatto & 8 \\
\hline \multicolumn{2}{|l|}{ Sexual orientation (self-reported) } \\
\hline Homosexual & 24 \\
\hline Heterosexual & 1 \\
\hline Bisexual & 5 \\
\hline \multicolumn{2}{|l|}{ Sexual attraction (self-reported) } \\
\hline Men only & 25 \\
\hline Men and women & 2 \\
\hline Other & 3 \\
\hline \multicolumn{2}{|l|}{ Member of NGO for gay men } \\
\hline Yes & 11 \\
\hline No & 19 \\
\hline \multicolumn{2}{|l|}{ Consider self as sex worker } \\
\hline Yes & 3 \\
\hline No & 27 \\
\hline \multicolumn{2}{|l|}{ Self-reported HIV status } \\
\hline Positive & 1 \\
\hline Negative & 19 \\
\hline Not reported & 10 \\
\hline
\end{tabular}

IQR: Inter-quartile range

Eight of the 30 seeds were unproductive, that is, they did not recruit a single participant. Nine seeds recruited one participant, six recruited two, and seven recruited three participants. From these initial recruited participants, the recruitment chains were very different, as observed in Figure 3. The chains of 


\section{Hgrizons}

12 of the seeds led to the recruitment of 1-10 participants, eight seeds led to the recruitment of 10-40 participants, and two seeds, who were recruited at the beginning of the study, led to the recruitment of 175 and over 200 participants each (see Figure 1).
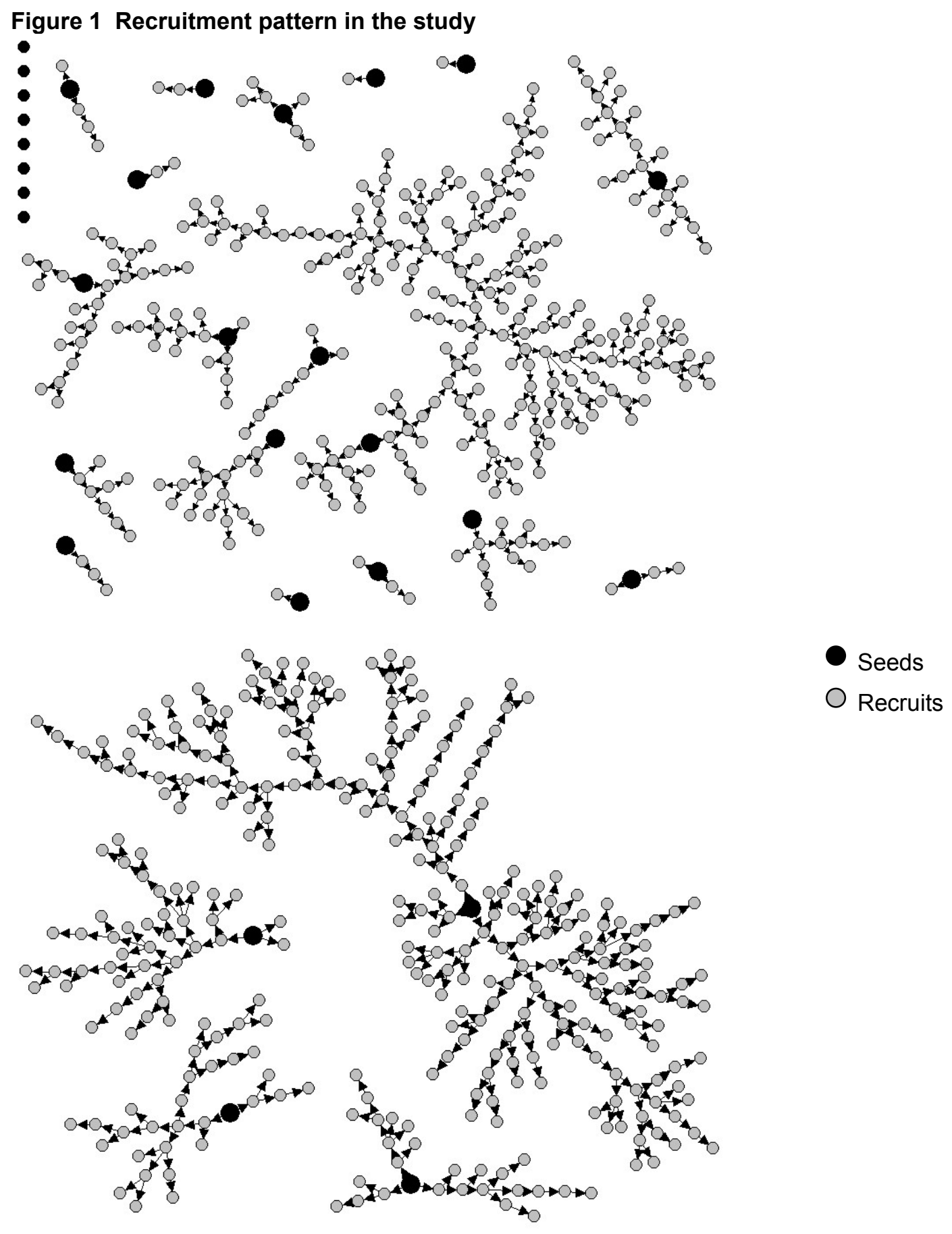


\section{Ineligibility, refusals, and drop-outs}

Overall, 658 MSM were recruited (including seeds) between October 25, 2005 and October 21, 2006. A total of 1,974 coupons were handed out to participants to recruit their peers, and 689 were retrieved from subsequent participants. Of the 689,28 (4 percent) were ineligible to participate in the study for reasons listed in Table 2. Only two eligible participants refused to participate and one dropped out of the study, leaving a total of 658 participants in the study.

Table 2 Eligibility, refusals and drop-outs

\begin{tabular}{lrc}
\hline & $\#$ & $\%$ \\
\hline Persons arriving at the study site & 689 & 100 \\
Ineligible to participate & 28 & 4 \\
Reasons for ineligibility & & \\
$\quad$ Did not have sex with men in past 6 months & 14 & 50 \\
$\quad$ Have never had sex with men & 5 & 18 \\
$\quad$ Born woman & 4 & 14 \\
Lived outside the MRC* & 4 & 14 \\
$\quad$ Under influence of alcohol or drugs & 1 & 0.3 \\
Refusals & 2 & - \\
Reasons for refusals & & \\
$\quad$ Did not want to collect blood sample & 1 & 0.1 \\
$\quad$ Did not want to talk about himself & 1 & \\
Enrollments & 658 & \\
Drop-outs (refused to take syphilis test) & 1 & \\
\hline
\end{tabular}

${ }^{*} \mathrm{MRC}=$ Metropolitan region of Campinas

Participants indicated that they had seen their recruiter a median of 10 times (IQR: 3-30) in the past month. Table 3 indicates the relationship of participants with recruiters. Most of the recruiters were friends/acquaintances ( 54 percent) or a best friend ( 24 percent). Only 2 percent were recruited by a stranger. No participants reported paying for coupons.

Table 3 Relationship of participants with recruiters $(n=626)$

\begin{tabular}{lc}
\hline & $\%$ \\
\hline Friend or acquaintance & 54 \\
Best friend & 24 \\
Boyfriend or spouse & 11 \\
Work colleague & 5 \\
Occasional sex partner & 2 \\
Relative & 2 \\
Stranger & 2 \\
Friend of friend/friend of boyfriend & 0.5 \\
\hline
\end{tabular}




\section{Hgrizons}

The median speed of recruitment, measured as the interval (in days) between the recruiter's participation in the study and the enrollment of his recruit in the study, was nine days (IQR: 3-25). Of the 658 participants, 302 (46 percent) did not recruit new participants, 160 (24 percent) recruited one, 121 (19 percent) recruited two, and 75 (11 percent) had three recruits enrolled. Among those with at least one recruit enrolled $(n=356)$, a total of 277 (78 percent) participants returned to the study site to collect their secondary incentive for recruiting their peers.

\section{Characteristics of recruiters}

The characteristics of participants who recruited at least one new participant were compared to those who did not recruit new participants. Those who did not recruit new participants had a smaller median network size, greater purchase power, fewer friends or acquaintances who disclosed their sexual orientation to family, and were more likely to report having had sex (anal or oral) with friends or acquaintances who were part of their reported social network. They were also less likely to be affiliated with NGOs for gay men or to have participated in HIV-related workshops in the past 12 months (see Table 4). There were no significant differences between these two groups in age, self-reported sexual orientation, education, skin color, religious affiliation, city of residence, income, commercial sex worker status, number of sexual partners, condom use, drug use, or HIV or syphilis test results (data not shown).

\section{Reasons for recruiting and participating}

Of the 176 study participants who completed the follow-up questionnaire about their recruitment experience, which was administered to those who returned to collect their secondary incentive, 143 (81 percent) successfully gave away all the recruitment coupons received from the study. Reasons for not being able to hand out all coupons included not being able to find the person they wanted to recruit (77 percent) and not knowing anyone eligible for the study (7 percent). Seventeen percent of the participants reported that some of the people they tried to recruit rejected the coupons for various reasons including lack of interest, being too busy to participate, fear of disclosure of sexual orientation, and fear of confidentiality of test results. Participants were also asked about their reasons for enrolling in the study. The opportunity to take a free HIV test was the most reported reason (72 percent), followed by wanting to be a part of a study for MSM (45 percent) and the possibility of taking a syphilis test (43 percent). Four percent reported wanting to receive information about STIs or homosexuality. The distribution of incentives was reported only by 2 percent of the sample as their main reason for enrolling in the study.

The reasons for participating in the study were also investigated through a qualitative evaluation of the recruitment process at the end of the study. The results of this qualitative assessment reinforced those found in the survey, with the rapid HIV test being one of the main reasons for enrolling in the study. However, the rapid HIV test was also a disincentive for some men who did not want to participate in the study due to a fear of learning their HIV test result (even though the HIV test was optional). Qualitative data also suggested that the study site was perceived by the local gay community to be a place mainly for STI testing. 
Table 4 Comparison of the characteristics of recruiters who did not successfully recruit participants and those who successfully recruited at least one participant into the study

\begin{tabular}{|c|c|c|}
\hline & \multicolumn{2}{|c|}{ Number of recruits who enrolled } \\
\hline & $\begin{array}{c}\text { None } \\
(n=302)\end{array}$ & $\begin{array}{c}1-3 \text { recruits } \\
(n=356)\end{array}$ \\
\hline Median network size* $(I Q R)(n=658)$ & $8(4-16)$ & $10(5-20)$ \\
\hline $\begin{array}{l}\text { Median of restricted social network considering only those who could } \\
\text { be invited to the study (IQR)* }\end{array}$ & $5(3-10)$ & $7(4-15)$ \\
\hline \multicolumn{3}{|l|}{ Brazilian Criteria for Purchase Power $(n=589)^{*}$} \\
\hline Class A & 8 & 6 \\
\hline Class B & 40 & 34 \\
\hline Class C & 46 & 49 \\
\hline Class D/E & 5 & 18 \\
\hline \multicolumn{3}{|l|}{$\begin{array}{l}\text { Percentage of respondents' friends/acquaintances who disclosed } \\
\text { sexual attraction to family }(n=653)^{\star *}\end{array}$} \\
\hline 0 & 17 & 8 \\
\hline $1-49 \%$ & 29 & 32 \\
\hline $50-99 \%$ & 29 & 39 \\
\hline $100 \%$ & 25 & 22 \\
\hline \multicolumn{3}{|l|}{$\begin{array}{l}\text { Percentage of respondents' friends/acquaintances with whom } \\
\text { respondent had sex }(n=657)^{*}\end{array}$} \\
\hline 0 & 41 & 49 \\
\hline $1-49 \%$ & 14 & 9 \\
\hline $50-99 \%$ & 0 & 0 \\
\hline $100 \%$ & & \\
\hline Member of NGO for gay men $(n=643)^{* *}$ & 5 & 14 \\
\hline Participated in any AIDS talks/workshops in past 12 months $(n=643)^{*}$ & 29 & 38 \\
\hline
\end{tabular}

IQR: Inter-quartile range; * $p<0.05 ;{ }^{* *} p<0.01$

Participants reported recruiting close peers with whom they had some degree of intimacy. Also, many reported trying to recruit peers who they believed practiced risky sexual behaviors and needed safer sex counseling. Additionally, participants mentioned that because this study required them to invite peers to join a study with STI testing, it tended to make peers curious about each others' STI test results and potentially created distrust and misconceptions about each other's risky sexual behaviors. Further, although many participants found the study site to be a friendly environment to discuss personal experiences concerning homosexuality and STI/HIV, the fear of having to disclose their sexual orientation appeared to have been a stronger barrier to participation.

Lastly, differences in quality and/or characteristics of the counseling also seemed to have affected recruitment. The research team compared the proportion of participants who successfully recruited someone (at least one peer) into the study stratified by counselor, and found that some counselors were two times more effective in getting their participants to successfully recruit peers into the study. 


\section{Hgrizons}

\section{Characteristics of Social Network}

For the purpose of this study, social network size was defined as the number of MSM who:

i. the respondent believes has had sex with a man;

ii. lives in the metropolitan area of Campinas;

iii. the respondent could contact personally or by phone; and

iv. the respondent had spoken with in the previous month.

Approximately one-third of respondents had a network of five or fewer MSM while 18 percent had a network greater than 20 individuals (see Table 5).

To understand the interconnections within the study population, respondents were asked about the number of their MSM peers that knew each other. Half of the respondents reported that all of their acquaintances knew each other, indicating that the respondent and all his peers belonged to the same social network (see Table 5). Only 4 percent reported that none of their acquaintances knew each other.

Participants were also asked about some of the characteristics of those in their network. Twenty-three percent of respondents reported that all MSM in their social network had disclosed their sexual attraction to men to their family members, while 12 percent reported that none of their peers had done so. Twothirds reported that none of their acquaintances were HIV-positive. When asked about the number of people with whom the respondent had had sex within his own social network, 57 percent reported having had sex with at least one member of their social network, and 43 percent reported not having had sex with anyone in their network. 
Table 5 Characteristics of social networks of MSM in Campinas

\begin{tabular}{|c|c|}
\hline & $\begin{array}{c}\text { Sample } \\
\%\end{array}$ \\
\hline \multicolumn{2}{|c|}{ Social network size $(n=658)$} \\
\hline$\leq 5 \mathrm{MSM}$ & 32 \\
\hline $6-10 \mathrm{MSM}$ & 28 \\
\hline 11-20 MSM & 22 \\
\hline$>20 \mathrm{MSM}$ & 18 \\
\hline \multicolumn{2}{|c|}{ Percentage of members in respondent's social network who knew each other $(n=640)$} \\
\hline 0 & 4 \\
\hline $1-49 \%$ & 14 \\
\hline $50-99 \%$ & 32 \\
\hline $100 \%$ & 50 \\
\hline \multicolumn{2}{|c|}{$\begin{array}{l}\text { Percentage of members in respondent's social network who disclosed sexual attraction } \\
\text { to a family member }(n=653)\end{array}$} \\
\hline 0 & 12 \\
\hline $1-49 \%$ & 31 \\
\hline $50-99 \%$ & 34 \\
\hline $100 \%$ & 23 \\
\hline \multicolumn{2}{|c|}{ Percentage of members in respondent's social network who were HIV-positive $(n=639)$} \\
\hline 0 & 66 \\
\hline $1-49 \%$ & 30 \\
\hline $50-99 \%$ & 4 \\
\hline $100 \%$ & 0 \\
\hline \multicolumn{2}{|c|}{$\begin{array}{l}\text { Percentage of members in respondent's social network with whom respondent had sex } \\
(n=657)\end{array}$} \\
\hline 0 & 43 \\
\hline $1-49 \%$ & 46 \\
\hline $50-99 \%$ & 11 \\
\hline $100 \%$ & 0 \\
\hline
\end{tabular}

Note: Sample sizes vary slightly because of missing data.

The median network size of MSM was also examined by some of the respondents' characteristics. The median network size was found to be similar by age, self-identified sexual orientation, involvement in sex work, and drug use. Significant differences in network sizes were found within four categories examined: Larger network sizes were found among those reporting more sex partners in the last two months, those who were a member of a gay NGO, and those who had disclosed their sexual orientation to their mother. Network size was also found to vary by the proportion of network members with whom the respondent had had sex (see Table 6). 


\section{Hgrizons}

Table 6 Size of social networks ${ }^{\dagger}$ of MSM in Campinas region

\begin{tabular}{|c|c|}
\hline & Sample median network size (IQR) \\
\hline \multicolumn{2}{|c|}{ Number of male partners last 2 months $(n=641)^{\star *}$} \\
\hline None & $10(4-15)$ \\
\hline 1 partner & $10(5-15)$ \\
\hline 2-3 partners & $10(5-18)$ \\
\hline$>3$ partners & $12(6-30)$ \\
\hline \multicolumn{2}{|c|}{ NGO member $(n=642)^{\star *}$} \\
\hline Yes & $15(10-30)$ \\
\hline No & $10(5-20)$ \\
\hline \multicolumn{2}{|c|}{ Disclosure sexual orientation to mother $(n=589)^{*}$} \\
\hline Yes & $10(6-20)$ \\
\hline No & $8(4-15)$ \\
\hline \multicolumn{2}{|c|}{ Percentage of friends in network with whom had sex $(n=657)^{\star *}$} \\
\hline 0 & $6(4-11.5)$ \\
\hline $1-49 \%$ & $15(9.5-30)$ \\
\hline $50-100 \%$ & $6(3-20)$ \\
\hline
\end{tabular}

Note: Sample sizes vary slightly because of missing data.

IQR: Interquartile Range

${ }^{\dagger}$ Social network include those MSM known by recruiter that lived in the metropolitan area of Campinas, that could be contacted personally or by phone by the recruiter, and with whom they talked in the previous month.

$\ddagger$ The nonparametric two-sample test on the equality of medians was used to evaluate differences in median network size.

${ }^{* *} p<0.001 ;{ }^{*} p<0.05$

\section{Sociodemographic Characteristics of MSM}

The sociodemographic profile of the study sample $(n=658)$ and population-based estimates are presented in Table 7. Almost one-third were estimated to be between the ages of 14 and 19 and another quarter were 35 years or older. Over half of MSM had started or completed at least some high school, and 30 percent had started or completed college. Skin color was assessed by self report. About half of the study population was estimated to be white, and approximately one-third brown or mulatto. The majority of MSM were single and over half lived with parents or relatives. Just over one-third of MSM lived in their own house or apartment and one-quarter in rented spaces. Three-quarters resided in Campinas and the remainder in the surrounding metropolitan area, with a median of 16 years of residence in their respective locations. The majority had either formal employment (45 percent) or did not have a job (39 percent) at the time of the survey. Teenagers accounted for 44 percent of those who were unemployed. Based on the Brazilian criterion for purchase power (with class A being the richest and class $\mathrm{E}$ being poorest), the majority were in class B or C.

Most MSM considered religion to be either important or very important in their lives. They primarily reported being Catholic (37 percent), Evangelic or Protestant (14 percent), or having no religion but believing in God (31 percent). 
Table 7 Sociodemographic characteristics of MSM

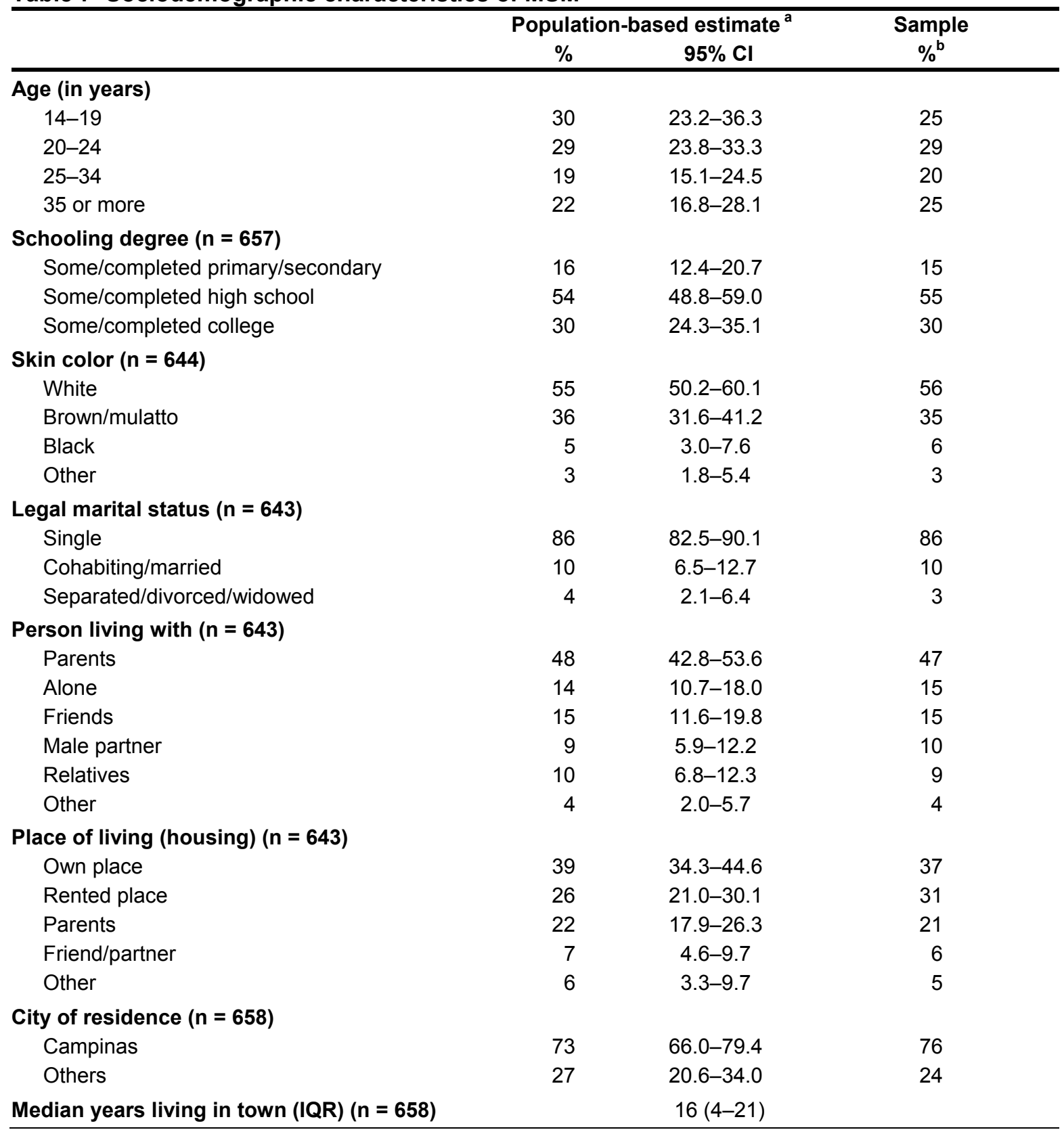




\section{Hgrizons}

Table 7 Sociodemographic characteristics of MSM (continued)

\begin{tabular}{|c|c|c|c|}
\hline & \multicolumn{2}{|c|}{ Population-based estimate $^{a}$} & \multirow{2}{*}{$\begin{array}{c}\text { Sample } \\
\%^{\mathrm{b}}\end{array}$} \\
\hline & $\%$ & $95 \% \mathrm{Cl}$ & \\
\hline \multicolumn{4}{|l|}{ Employment situation $(n=640)$} \\
\hline Formal $^{\mathrm{c}}$ & 45 & $38.5-49.5$ & 47 \\
\hline Informal only & 16 & $12.7-20.1$ & 19 \\
\hline Don't have job & 39 & $34.2-45.3$ & 35 \\
\hline \multicolumn{4}{|c|}{ Brazilian criterion for purchase power $(n=589)$} \\
\hline A class (richest) & 6 & $3.8-8.6$ & 7 \\
\hline $\mathrm{B}$ class & 38 & $31.1-43.2$ & 37 \\
\hline C class & 47 & $40.9-53.2$ & 48 \\
\hline E/D class (poorest) & 9 & $6.5-13.3$ & 9 \\
\hline Median monthly income in Reais (IQR) & \multicolumn{2}{|c|}{$560(300-1,000)$} & \\
\hline Median monthly income in USD (IQR) ${ }^{d}$ & \multicolumn{2}{|c|}{$258(138-460)$} & \\
\hline \multicolumn{4}{|l|}{ Importance of religion/spirituality $(n=644)$} \\
\hline Very important & 52 & $47.2-57.0$ & 51 \\
\hline Important & 39 & $33.8-43.1$ & 39 \\
\hline Somewhat/not important & 10 & $6.7-12.5$ & 10 \\
\hline \multicolumn{4}{|l|}{ Religion ( $n=644$ ) } \\
\hline Catholic & 37 & $32.2-42.4$ & 37 \\
\hline Have no religion but believe in God & 31 & $27.2-36.2$ & 30 \\
\hline Protestant/Evangelic & 14 & $10.5-17.1$ & 15 \\
\hline Kardecist & 7 & $4.3-9.4$ & 6 \\
\hline Candomble/Umbanda & 5 & $2.8-7.7$ & 5 \\
\hline Other & 6 & $3.7-8.0$ & 6 \\
\hline
\end{tabular}

Note: Sample sizes vary slightly because of missing data.

${ }^{a}$ Population-based estimates are based on analysis in RDSAT, which is adjusted for personal network sizes and recruitment patterns.

${ }^{\mathrm{b}}$ Sample percentages represent the proportion of the study population with the characteristic.

${ }^{\mathrm{c}}$ Includes those who responded both formal and informal

${ }^{d}$ Using the average exchange rate of the data collection period (USD $\left.\$ 1=R \$ 0.46\right)$

IQR: Interquartile range

\section{Self-reported Sexual Orientation and Attraction}

Overall estimates and estimates by age groups indicated that the majority of MSM considered themselves homosexual, followed by bisexual (see Table 8 ). Those in the youngest category (14-19 years) were significantly more likely to consider themselves bisexual and less likely to consider themselves homosexual compared to the older age categories. As age increases, self-reported homosexual orientation increases and bisexual orientation decreases. Self-reported sexual attraction followed a similar pattern to sexual orientation. 
Table 8 Distribution of self-reported sexual orientation and sexual attraction by age

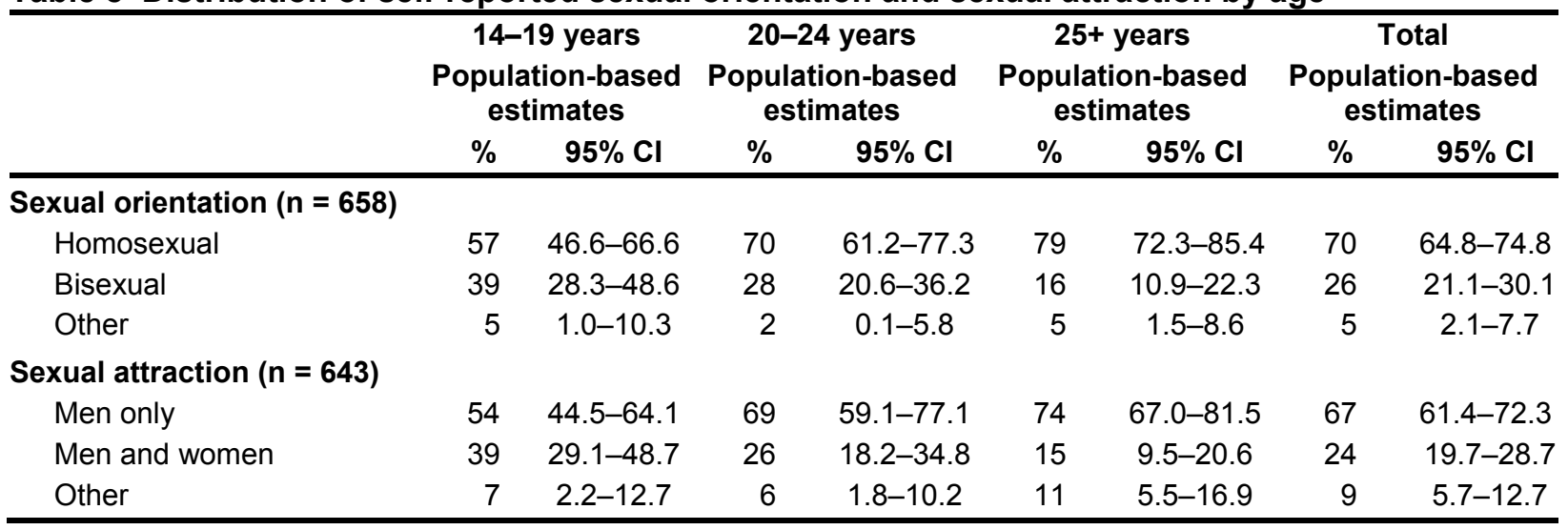

\section{Disclosure and Openness about Sexual Attraction}

Study participants were asked if they had disclosed their sexual attraction to men to anyone and, if so, to whom they had disclosed this information (multiple responses were possible). It was estimated that almost all MSM had disclosed their attraction to men to someone (94 percent). The most common person to whom this attraction was disclosed was a colleague from work ( 73 percent), followed by a relative (other than the mother or father) (59 percent). An estimated half of MSM disclosed to their mothers while only about one-fourth disclosed to their fathers (see Table 9).

The family acceptance of sexual attraction to men (as perceived by the participants) was also analyzed. Almost 40 percent of MSM indicated that their families totally or somewhat approved of their sexual attraction to men, while 27 percent indicated that their families either somewhat or totally disapproved of their attraction to men (see Table 9).

Slightly more than half of MSM had ever participated in a Gay Pride Parade, which could be considered as a proxy for self-acceptance of their homosexual orientation. Among those who had not taken part in a Gay Pride Parade, over half had not disclosed to anyone their sexual attraction to men. 


\section{Hgrizons}

Table 9 Disclosure of sexual attraction to men and family acceptance of disclosure

\begin{tabular}{|c|c|c|}
\hline & \multicolumn{2}{|c|}{ Population-based estimate } \\
\hline & $\%$ & $95 \% \mathrm{Cl}$ \\
\hline \multicolumn{3}{|c|}{ Person to whom disclosed feeling of attraction to men ${ }^{a}$} \\
\hline Someone $(n=622)$ & 94 & $90.6-96.6$ \\
\hline Colleague $(n=564)$ & 73 & $66.2-78.0$ \\
\hline Mother $(n=589)$ & 51 & $45.2-56.5$ \\
\hline Father $(n=490)$ & 27 & $19.7-32.1$ \\
\hline Another relative $(n=613)$ & 59 & $54.6-64.7$ \\
\hline \multicolumn{3}{|l|}{ Family acceptance $(n=566)$} \\
\hline Totally approve & 13 & $9.5-16.8$ \\
\hline Somewhat approve & 24 & $18.7-28.2$ \\
\hline Indifferent & 36 & $30.5-41.5$ \\
\hline Somewhat disapprove & 10 & $7.5-14.0$ \\
\hline Totally disapprove & 17 & $12.9-21.6$ \\
\hline Participation in Gay Pride Parade $(n=643)$ & 54 & $48.3-59.3$ \\
\hline
\end{tabular}

a The ' $n$ 's in the response categories reflect the number of respondents who answered the question.

\section{Exposure to HIV Prevention Activities}

Respondents were asked about HIV prevention activities to which they had been exposed. Approximately one-third had participated in HIV educational activities in the past year (see Table 10). The majority (78 percent) was estimated to have received free condoms in the past year. Approximately 59 percent of MSM received free condoms from a governmental organization (public health posts or public health services); 39 percent at a bar, sauna, or nightclub (which are likely to have come from an NGO), and 35 percent received condoms directly from an NGO. Sex workers received more free condoms in the past 12 months than non-sex workers, but engaged more in URAI and UIAI (data not shown). Only 5 percent of the population of MSM was estimated to be a member of an NGO that works with and for gay men. 
Table 10 Exposure to HIV prevention activities

\begin{tabular}{|c|c|c|}
\hline & \multicolumn{2}{|c|}{$\begin{array}{l}\text { Population-based } \\
\text { estimate }\end{array}$} \\
\hline & $\%$ & $95 \% \mathrm{Cl}$ \\
\hline Participated in HIV/STI-related educational activities past 12 months $(n=643)$ & 30 & $25.7-34.9$ \\
\hline $\begin{array}{l}\text { Frequency of participation in HIV/STI-related educational activities in past } 12 \text { months } \\
(n=640)\end{array}$ & 70 & $65.7-74.9$ \\
\hline None & 7 & $4.6-9.5$ \\
\hline $\begin{array}{l}\text { Few times/once a month } \\
\text { A few times/once a year }\end{array}$ & 23 & $18.6-27.1$ \\
\hline Received educational materials about HIV/STI in past 12 months $(n=643)$ & 55 & $49.8-59.9$ \\
\hline Received free condoms $(n=643)$ & 78 & $73.4-82.4$ \\
\hline Received free condoms from governmental organization in past 12 months $(n=643)$ & 59 & $53.3-64.3$ \\
\hline Received free condoms from NGO in past 12 months $(n=643)$ & 35 & $30.1-39.7$ \\
\hline Received free condoms in nightclubs/saunas/bars in past 12 months $(n=643)$ & 39 & $33.6-43.3$ \\
\hline Member of NGO for gay men $(n=643)$ & 5 & $2.6-7.0$ \\
\hline
\end{tabular}

Note: Sample sizes vary slightly because of missing data.

\section{Experience of Homophobic Abuse}

Table 11 presents MSM's experience of abuse that was perceived by them to be due to homophobia. Population-based estimates indicated that the majority of MSM had experienced some kind of homophobic abuse at least once, and that over two-thirds had experienced it within the past year. Psychological abuse due to homophobia was the most frequent, followed by sexual harassment and physical abuse. Of those who experienced physical abuse or sexual harassment, only 11 percent was estimated to have sought medical attention. Of those who experienced any type of violence, only 6 percent was estimated to have reported it to the police. In addition, approximately 9 percent of MSM had ever experienced homophobic abuse from police.

\section{Childhood Sexual Abuse}

Sexual contact before the age of 13 with someone at least four years older was used as an indicator for possible childhood sexual abuse, as this type of abuse has been shown to be associated with HIV risk behaviors in adult MSM (Carballo-Diéguez and Dolezal 1995; Paul et al. 2001; O'Leary et al. 2003). One-third of the population of MSM was found to have had this experience; of those, only 32 percent (95\% CI: 23.8-40.7) considered themselves to have been sexually abused as a child. Overall, 11 percent (95\% CI: 7.7-14.3) of MSM were estimated to consider themselves victims of sexual abuse as children. 


\section{Hgrizons}

Table 11 MSM's experience of homophobic abuse

\begin{tabular}{|c|c|c|}
\hline & \multicolumn{2}{|c|}{$\begin{array}{l}\text { Population-based } \\
\text { estimate }\end{array}$} \\
\hline & $\%$ & $95 \% \mathrm{Cl}$ \\
\hline Ever experienced any homophobic abuse $(n=636)$ & 85 & $80.4-88.4$ \\
\hline Experienced any homophobic abuse last year $(n=619)$ & 70 & $65.0-75.2$ \\
\hline Ever experienced psychological abuse ${ }^{\dagger}$ due to homophobia $(n=638)$ & 78 & $73.1-82.5$ \\
\hline \multicolumn{3}{|l|}{ Frequency of psychological abuse ${ }^{\dagger}$ due to homophobia last year $(n=618)$} \\
\hline None & 38 & $32.4-43.7$ \\
\hline 1-2 times & 16 & $12.2-19.2$ \\
\hline$>2$ times & 46 & $40.7-51.9$ \\
\hline Ever experienced physical abuse ${ }^{\ddagger}$ due to homophobia $(n=631)$ & 31 & $26.3-35.5$ \\
\hline \multicolumn{3}{|l|}{ Frequency of physical abuse ${ }^{\ddagger}$ due to homophobia last year $(n=623)$} \\
\hline None & 80 & $75.1-84.0$ \\
\hline $1-2$ times & 10 & $7.3-13.0$ \\
\hline$>2$ times & 10 & $6.9-14.0$ \\
\hline Ever experienced sexual harassment due to homophobia $(n=637$ ) & 42 & $37.4-47.4$ \\
\hline \multicolumn{3}{|l|}{ Frequency of sexual harassment due to homophobia past year $(n=624)$} \\
\hline None & 70 & $64.7-73.9$ \\
\hline $1-2$ times & 12 & 8.5-15.6 \\
\hline$>2$ times & 19 & $15.0-22.8$ \\
\hline Ever experienced homophobic abuse from police $(n=635)$ & 9 & $6.1-12.6$ \\
\hline Experienced homophobic abuse from police last year $(n=633)$ & 6 & $3.6-7.9$ \\
\hline $\begin{array}{l}\text { Sought medical help for physical abuse or sexual harassment due to } \\
(n=415)\end{array}$ & 11 & $5.7-17.1$ \\
\hline Ever reported homophobic abuse to police $(n=539)$ & 6 & $3.1-9.3$ \\
\hline
\end{tabular}

Note: Sample sizes vary slightly because of missing data.

* Homophobic abuse was defined as having experienced any physical abuse, psychological abuse, or sexual harassment.

${ }^{\dagger}$ Psychological abuse was defined as being verbally insulted, threatened with physical violence, had personal property damaged, or was chased or followed in the streets.

${ }^{\ddagger}$ Physical abuse was defined as having objects thrown at them, been spat upon, punched, hit, kicked, beaten, or assaulted with a weapon.

\section{Alcohol and Illicit Drug Use}

Table 12 shows alcohol and illicit drug use among MSM in the Campinas metropolitan area. Alcohol was estimated to be used heavily (many times a week or every day) by 17 percent of MSM, while 40 percent used it once a week and 43 percent used it rarely or never. Over half of the population of MSM had ever used any illicit drugs, and approximately one-third reported using an illicit drug in the past six months, with cannabis being the most frequently used drug. An estimated 12 percent were regular users (once a week, several times a week, or every day). Cocaine snorting was the second most commonly used drug, with 6 percent of the population being regular users of the drug in the past six months. Inhalants, crack, ecstasy, and amphetamines were not commonly used. Just over 1 percent of the population was estimated to have ever used injection drugs. Twenty-nine percent (95\% CI: 14.1-45.6) was estimated to have drank or used any drugs during URAI and 15 percent (95\% CI: 6.5-24.9) during UAIA. 
Table 12 Alcohol and illicit drug use among MSM

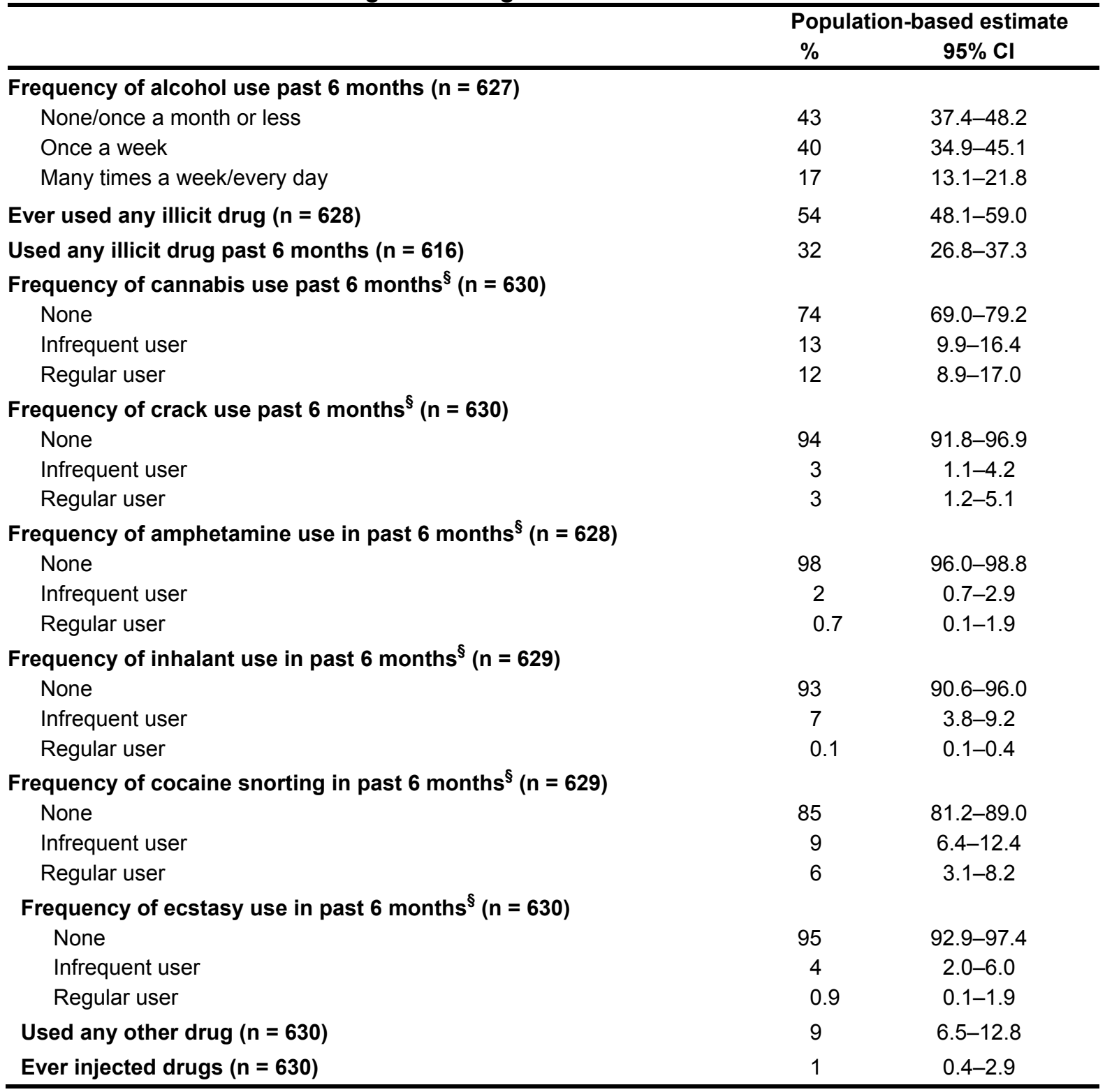

Note: Sample sizes vary slightly because of missing data.

$\S$ Infrequent user = Once a month or less; Frequent user = Once a week, several times a week, or every day.

\section{HIV Testing Behavior}

Approximately half of the population of MSM had ever tested for HIV, the majority of whom received it for free (see Table 13). Slightly more than half (53 percent; 95\% CI: 42.6-67.5) of the MSM who had taken an HIV test in the previous year reported having had their HIV testing in the VCT service in the municipality of Campinas. Among the youngest MSM (14-19 years old), 62 percent (CI: 50-71) had 


\section{Hgrizons}

never been tested for HIV before participating in the study, of whom 46 percent (95\% CI: 31.6-69.8) reported URAI in the past two months.

Although nearly 40 percent of those who had ever been tested had been tested at least two times before, only 42 percent of MSM who had ever tested were tested within the past year. Half perceived themselves to be at low or no risk for HIV infection. Thirty-four percent (95\% CI: 27.9-40.8) of respondents who perceived themselves to be at low or no risk of HIV infection reported having had at least one episode of URAI in the past two months.

Table 13 HIV testing history and self-perception of risk for HIV infection among MSM

\begin{tabular}{|c|c|c|}
\hline & \multicolumn{2}{|c|}{ Population-based estimates } \\
\hline & $\%$ & $95 \% \mathrm{Cl}$ \\
\hline Ever tested for HIV (n = 631) & 58 & $52.1-63.6$ \\
\hline Got HIV test free of charge $(n=374)$ & 82 & $78.4-90.4$ \\
\hline \multicolumn{3}{|l|}{ Number of times tested for HIV $(n=631)$} \\
\hline 0 & 42 & $36.5-48.0$ \\
\hline 1 & 20 & $16.1-24.6$ \\
\hline $2-5$ times & 26 & 21.4-30.9 \\
\hline$>5$ times & 11 & $8.4-15.1$ \\
\hline \multicolumn{3}{|l|}{ Last time tested for HIV $(n=374)$} \\
\hline$<1$ year & 42 & $34.5-50.9$ \\
\hline 1 to 5 years & 41 & $32.9-50.0$ \\
\hline$>5$ years & 12 & $5.7-15.7$ \\
\hline Don't know & 6 & $2.5-9.3$ \\
\hline \multicolumn{3}{|c|}{ Self-perception of risk for HIV infection $(n=625)$} \\
\hline Low/none & 50 & $45.5-55.9$ \\
\hline Moderate/high & 28 & $23.1-32.0$ \\
\hline Don't know & 22 & $17.6-26.2$ \\
\hline
\end{tabular}

Note: Sample sizes vary slightly because of missing data.

\section{HIV and Syphilis Seroprevalence Estimates}

All 658 respondents were tested for syphilis using a rapid syphilis test and 621 (94 percent) were also tested for HIV using rapid HIV tests. It was estimated that 7 percent of the population of MSM was HIVpositive and that 9 percent of the population had been or was infected with syphilis at the time (Table $^{4}$ 14). Among the 49 MSM that tested positive for HIV, 14 already knew of their positive status and 18 reported having received a negative test result in their previous test (ten of these 18 reported taking the HIV test less than one year before the interview). No misreporting was found of HIV positive status. Of the 37 participants who did not accept to be tested for the HIV, nine reported to have previously received a positive result. If those nine cases are added to those who tested positive in the rapid test, the prevalence would be estimated at 8.4 percent (95\% CI: 5.4-11.7).

\footnotetext{
${ }^{4}$ All respondents who tested positive for syphilis by rapid test were also tested using VDRL. The VDRL results indicate that 6.8 percent of the sample was VDRL+ (greater than or equal to a 1:1 dilution) and RDS population-based estimates indicated that 5 percent of the population was VDRL+ (95\% CI: 3.3-7.0).
} 
Table 14 Estimated prevalence of HIV and syphilis using rapid test results

\begin{tabular}{lccc}
\hline & \multicolumn{3}{c}{ Population-based estimate } \\
& \% & $\mathbf{9 5 \%} \mathbf{~ C l}$ \\
\hline HIV-positive $(n=621)$ & 7.4 & $4.7-10.7$ \\
Syphilis-positive* $^{*}(n=658)$ & 8.7 & $6.2-11.5$ \\
\hline
\end{tabular}

${ }^{*}$ Syphilis positive by rapid test, indicating past or current infection

No significant differences were found in the population-based estimates for HIV prevalence of the three age groups analyzed based on overlaps of the $95 \%$ confidence intervals. On the other hand, syphilis prevalence was significantly greater among the oldest MSM (see Table 15).

Table 15 Estimated prevalence of HIV and syphilis by age

\begin{tabular}{ccccc}
\hline & \multicolumn{2}{c}{ HIV } & \multicolumn{2}{c}{ Syphilis } \\
Age (in years) & Population-based estimate & \multicolumn{2}{c}{ Population-based estimate } \\
\hline $14-19(n=162)$ & 4 & $\mathbf{9 5 \%} \mathbf{~ C l}$ & \multicolumn{2}{c}{$\mathbf{9 5 \% ~ C l}$} \\
$20-24(n=186)$ & 4 & $0.6-9.2$ & 3 & $0.5-5.4$ \\
$25+(n=273)$ & 11 & $1.3-7.1$ & 5 & $1.6-10.2$ \\
\hline
\end{tabular}

\section{Self-reported STI Symptoms}

Respondents were asked about any symptoms of STIs they had experienced in the last 12 months. An STI symptom was defined, dichotomously, as having any sores or warts in the genital area, discharge or burning upon urination, discharge or burning at the anus, or any sore around the anus. Slightly more than one-quarter (27 percent, 95\% CI: 22.6-31.6) had experienced some STI symptom in the past 12 months. No statistically significant difference was found among the three age groups (data not shown).

\section{Sexual Behavior}

Table 16 shows the sexual behavior of MSM in the Campinas metropolitan area. The median age of sexual debut of the respondents was 13 years. Estimates indicate that the vast majority were sexually active in the last two months (93 percent; 95\% CI: 90.0-96.0). The median number of sex partners was two (IQR: 1-5). One-third of all MSM had one sex partner, about half had 2-5 sex partners, and nearly 20 percent had six or more partners in the last two months. Just over half reported having had sex in a group, and approximately one-third had done so more than once in the past six months.

About one in ten MSM reported having had a transvestite partner, and about 15 percent reported having had a female sex partner in the past two months. Only 10 percent reported they had not had any male sex partners in the past two months. It was most common for MSM to have either one (38 percent) or 2-5 (41 percent) male sex partners in the last two months. 


\section{Hgrizons}

Among participants who had male sex partners (including transvestites) in the last two months, almost one-third had URAI with one partner and 7 percent had URAI with more than one partner. A similar trend was observed for UIAI. In addition, the number of unprotected sex acts (defined as not using a condom) during at least one occurrence of anal intercourse (insertive or receptive) with single or multiple partners in the past two months was investigated. Nearly 40 percent of MSM reported at least one unprotected (receptive or insertive) anal intercourse during this period.

An estimated 16 percent (CI: 11-22) of MSM had sex with both men and women in the last two months. Among those who had vaginal or anal sex with female partners, it was estimated that 75 percent (CI: $37-$ 91) practiced unprotected anal or vaginal intercourse with female partners at least once in the past two months (data not shown).

MSM's knowledge about the HIV status of sex partners with whom they had unprotected sex was also examined. Of the men who had sex with men who had URAI or UIAI with only one male partner in the past two months, about 10 percent knew that their sex partner was HIV-positive. However, none of the respondents who indicated that their sex partner was HIV-positive declared being HIV-positive themselves. Nearly 30 percent did not know the HIV status of their partner.

Table 16 Sexual behavior of MSM

\begin{tabular}{|c|c|c|}
\hline & \multicolumn{2}{|c|}{$\begin{array}{c}\text { Population-based } \\
\text { estimates }\end{array}$} \\
\hline & $\%$ & $95 \% \mathrm{Cl}$ \\
\hline Median age at first sexual contact with another person (IQR) $(n=640)$ & \multicolumn{2}{|c|}{$13(10-16)$} \\
\hline \multicolumn{3}{|l|}{ Number of sex partners } \\
\hline \multicolumn{3}{|l|}{ Number of sex partners last 2 months $(n=630)$} \\
\hline None & 5 & $2.8-7.9$ \\
\hline 1 partner & 31 & $25.2-35.3$ \\
\hline 2-5 partners & 46 & $42.4-52.2$ \\
\hline $6-10$ partners & 9 & $6.3-11.8$ \\
\hline$>10$ partners & 9 & $6.0-11.3$ \\
\hline \multicolumn{3}{|l|}{ Number of male sex partners last 2 months $(n=636)$} \\
\hline None & 10 & $6.4-13.0$ \\
\hline 1 partner & 38 & $32.1-42.3$ \\
\hline $2-5$ partners & 41 & $36.3-46.2$ \\
\hline $6-10$ partners & 5 & $3.5-7.8$ \\
\hline$>10$ partners & 7 & $4.4-8.9$ \\
\hline \multicolumn{3}{|l|}{ Number of transvestite sex partners last 2 months $(n=638)$} \\
\hline None & 89 & $85.5-92.7$ \\
\hline 1 partner & 6 & $3.5-8.8$ \\
\hline$>1$ partner & 5 & $2.9-6.9$ \\
\hline \multicolumn{3}{|l|}{ Number of female sex partners last 2 months $(n=635)$} \\
\hline None & 84 & $79.5-89.2$ \\
\hline 1 partner & 8 & $4.6-11.5$ \\
\hline$>1$ partner & 8 & $4.8-10.8$ \\
\hline
\end{tabular}


Table 16 Sexual behavior of MSM (continued)

\begin{tabular}{|c|c|c|}
\hline & \multicolumn{2}{|c|}{$\begin{array}{c}\text { Population-based } \\
\text { estimates }\end{array}$} \\
\hline & $\%$ & $95 \% \mathrm{Cl}$ \\
\hline \multicolumn{3}{|l|}{ Group sex } \\
\hline Ever had sex in groups $(n=634)$ & 45 & $39.5-50.5$ \\
\hline \multicolumn{3}{|c|}{ Number of times had sex in groups last 6 months $(n=322)$} \\
\hline None & 43 & $31.3-49.5$ \\
\hline Once & 25 & $20.5-38.4$ \\
\hline Twice or more & 33 & 22.0-39.3 \\
\hline \multicolumn{3}{|l|}{ Unprotected sex } \\
\hline \multicolumn{3}{|c|}{ Number male sex partners ${ }^{\S}$ w/ whom had URAl last 2 months $(n=613)$} \\
\hline Didn't have RAI & 37 & $31.2-41.5$ \\
\hline None & 26 & $21.6-31.2$ \\
\hline 1 partner & 30 & $26.1-35.3$ \\
\hline$>1$ partner & 7 & 4.4-9.6 \\
\hline \multicolumn{3}{|c|}{ Number male sex partners ${ }^{\S} w /$ whom had UIAI last 2 months $(n=619)$} \\
\hline Didn't have IAI & 33 & $27.3-38.1$ \\
\hline None & 30 & $25.7-35.5$ \\
\hline 1 partner & 29 & $24.6-34.4$ \\
\hline$>1$ partner & 8 & $5.0-10.4$ \\
\hline \multicolumn{3}{|c|}{ Number of URAI with male partner ${ }^{\S}(n=631)$} \\
\hline Didn't have RAI & 36 & $31.2-41.1$ \\
\hline None & 25 & 20.9-30.0 \\
\hline Once & 16 & $12.5-19.7$ \\
\hline Twice or more & 23 & $18.6-26.7$ \\
\hline \multicolumn{3}{|c|}{ Number of UIAI with male partner ${ }^{\S}(n=637)$} \\
\hline Didn't have IAI & 32 & $26.6-36.7$ \\
\hline None & 29 & $25.1-34.6$ \\
\hline Once & 14 & $10.7-17.2$ \\
\hline Twice or more & 25 & $20.4-29.3$ \\
\hline \multicolumn{3}{|l|}{ HIV status of sex partners } \\
\hline \multicolumn{3}{|c|}{ HIV status of male single ${ }^{\dagger}$ partner with whom had URAI last 2 months $(n=190)$} \\
\hline HIV-positive & 11 & $3.3-24.7$ \\
\hline Unknown status & 28 & $11.7-30.6$ \\
\hline HIV-negative & 61 & $50.7-80.5$ \\
\hline \multicolumn{3}{|c|}{ HIV status of male single ${ }^{\dagger}$ partner with whom had UIAI last 2 months $(n=176)$} \\
\hline HIV-positive & 10 & $0.6-13.1$ \\
\hline Unknown status & 31 & $21.2-43.7$ \\
\hline HIV-negative & 59 & $51.0-73.0$ \\
\hline
\end{tabular}

Note: Sample sizes vary slightly because of missing data.

${ }^{\S}$ Male partner includes male and transvestite partners.

${ }^{\dagger}$ Male single partner includes those who reported only one male partner in the past 2 months IQR: Interquartile range 


\section{Hgrizons}

\section{Places used to meet male sex partners}

The most common venue used for meeting male sex partners was a nightclub or bar (33 percent) (see Table 17). The internet was used by 12 percent of MSM. Population-based estimates could not be calculated by age group due to small sample size of the strata, but there were significant differences in meeting venues by age of MSM in the study sample. While nightclubs and bars were the most common venue for all age groups, these venues were reported less often among older MSM. Meeting partners at a friend's house or party was more popular among younger men as compared to older men, while saunas were more popular among older MSM.

Table 17 Places where MSM most frequently meet male sex partners, by age ${ }^{\dagger}$

\begin{tabular}{|c|c|c|c|c|c|}
\hline & \multirow{3}{*}{$\begin{array}{c}\text { 14-19 years } \\
\text { Sample } \\
\%\end{array}$} & \multirow{3}{*}{$\begin{array}{c}\text { 20-24 years } \\
\text { Sample }^{a} \\
\%\end{array}$} & \multirow{3}{*}{$\begin{array}{c}\text { 25+ years } \\
\text { Sample }^{a} \\
\%\end{array}$} & \multirow{2}{*}{\multicolumn{2}{|c|}{$\begin{array}{c}\text { Total } \\
\text { Population-based estimates }^{\mathrm{b}}\end{array}$}} \\
\hline & & & & & \\
\hline & & & & $\%$ & $95 \% \mathrm{Cl}$ \\
\hline \multicolumn{6}{|c|}{$\begin{array}{l}\text { Places where participants met male } \\
\text { partners }(n=586)^{*}\end{array}$} \\
\hline Nightclubs/bars & 42 & 31 & 25 & 33 & $26.8-37.6$ \\
\hline Internet & 11 & 14 & 12 & 12 & $8.3-16.0$ \\
\hline Street, public parks & 7 & 6 & 11 & 7 & $4.4-11.0$ \\
\hline Saunas & 1 & 3 & 12 & 6 & $3.9-9.6$ \\
\hline Friends' houses/parties & 11 & 8 & 3 & 5 & $2.7-7.5$ \\
\hline Another place (not specified) & 11 & 14 & 15 & 13 & $10.4-18.1$ \\
\hline Nowhere & 17 & 24 & 22 & 23 & $18.5-27.7$ \\
\hline
\end{tabular}

${ }^{\dagger}$ Population-based estimates are unavailable for age strata due to small sample size of the strata.

${ }^{a}$ Sample percentages represent the proportion of the study population with the characteristic.

${ }^{b}$ Population-based estimates are based on analysis in RDSAT, which is adjusted for personal network sizes and recruitment patterns.

* Differences in the sample proportions by age were statistically significant $(p<0.001)$

\section{Commercial Sex Work}

\section{Involvement in commercial sex}

Respondents were asked if they had sex in exchange for money, gifts, or drugs in the past two months. Only an estimated 5 percent of MSM had paid anyone for sex in the past two months (see Table 18). However, 28 percent were estimated to have ever received payment for sex, and 15 percent had received payment for sex in the past two months, the vast majority of whom were paid by men in exchange for sex. However, only 8 percent of MSM considered themselves to be commercial sex workers, with half of those who received payment for sex in the past two months not considering themselves to be sex workers. 
Table 18 Involvement of MSM in commercial sex work

\begin{tabular}{|c|c|c|}
\hline & \multicolumn{2}{|c|}{ Population-based estimate } \\
\hline & $\%$ & $95 \% \mathrm{Cl}$ \\
\hline Paid anyone for sex in past 2 months $^{*}(n=633)$ & 5 & $2.8-7.6$ \\
\hline Paid man to have sex in past 2 months $(n=633)$ & 3 & $1.4-5.0$ \\
\hline Paid woman to have sex in past 2 months $(n=633)$ & 2 & $0.7-3.8$ \\
\hline Paid transvestite to have sex in past 2 months $(n=633)$ & 1 & $0.1-1.6$ \\
\hline Ever received payment for sex $(n=636)$ & 28 & 23.9-33.8 \\
\hline Received payment from anyone to have sex in past 2 months $(n=631)$ & 15 & $11.1-19.0$ \\
\hline Received payment from man to have sex in past 2 months $(n=632)$ & 15 & 10.9-18.7 \\
\hline Received payment from woman to have sex in past 2 months $(n=633)$ & 3 & $1.2-4.6$ \\
\hline Received payment from transvestite to have sex in past 2 months $(n=634)$ & 2 & $0.9-3.9$ \\
\hline Consider self commercial sex worker $(n=635)$ & 8 & $4.8-11.6$ \\
\hline
\end{tabular}

Note: Sample sizes vary slightly because of missing data.

* Payment includes exchange of money, drugs, or gifts for sex

\section{Comparison of MSM who sold sex and those who did not in the past two months}

Of the 631 respondents, 106 reported that they had received payment in money, drugs, or gifts for sex in the past two months. Those who did and did not receive payment for sex were similar in age, marital status, median income, and median social network size (results not shown). Level of purchasing power was borderline statistically significant with those selling sex having lower purchasing power. Compared to those who did not sell sex, MSM who sold sex had significantly less education and were significantly more likely to be mullato/brown in color than to be white (see Table 19).

Self-reported sexual orientation also differed significantly between MSM who sold sex and those who did not. MSM who sold sex were significantly less likely to consider their sexual orientation to be homosexual than men who did not sell sex (52 percent vs. 73 percent) (see Table 19). 


\section{Hgrizons}

Table 19 Comparison of the sociodemographic characteristics of MSM who sold sex in the past two months with those who did not*

\begin{tabular}{|c|c|c|c|c|}
\hline & \multicolumn{4}{|c|}{ 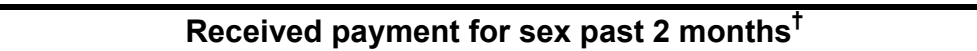 } \\
\hline & \multirow{2}{*}{\multicolumn{2}{|c|}{$\begin{array}{c}\text { Yes }(n=106) \\
\text { Population-based estimates }\end{array}$}} & \multirow{2}{*}{\multicolumn{2}{|c|}{$\begin{array}{l}\qquad \text { No }(n=525) \\
\text { Population-based estimates }\end{array}$}} \\
\hline & & & & \\
\hline & $\%$ & $95 \% \mathrm{Cl}$ & $\%$ & $95 \% \mathrm{Cl}$ \\
\hline \multicolumn{5}{|l|}{ Schooling degree } \\
\hline Some/complete primary/secondary & 41 & $28.5-55.6$ & 10 & $6.4-13.8$ \\
\hline Some/complete high school & 46 & $32.2-59.5$ & 55 & $49.4-61.1$ \\
\hline Some/complete college & 13 & $5.0-21.4$ & 35 & $28.7-41.2$ \\
\hline \multicolumn{5}{|l|}{ Brazilian criterion purchase power } \\
\hline Class $A / B$ & 35 & $18.9-45.5$ & 44 & $37.3-51.1$ \\
\hline Class C & 43 & $29.7-60.1$ & 48 & $41.3-54.6$ \\
\hline Class D/E & 22 & $11.2-37.3$ & 8 & $4.8-11.5$ \\
\hline \multicolumn{5}{|l|}{ Color } \\
\hline White & 32 & $19.5-44.0$ & 60 & $54.4-64.9$ \\
\hline Black & 6 & $0.6-12.7$ & 5 & $3.0-8.0$ \\
\hline Mullato/brown & 54 & $41.4-67.9$ & 33 & $28.1-38.2$ \\
\hline Other & 8 & $1.3-17.9$ & 2 & $0.7-3.2$ \\
\hline \multicolumn{5}{|l|}{ Sexual orientation } \\
\hline Homosexual & 52 & $39.5-66.2$ & 73 & $67.5-77.8$ \\
\hline Heterosexual & 11 & $3.2-18.3$ & 3 & $0.8-6.4$ \\
\hline Bisexual & 37 & $23.6-51.3$ & 24 & $19.6-28.7$ \\
\hline
\end{tabular}

${ }^{\dagger}$ Sample size varies slightly due to missing data.

*Bold type data indicates significant difference between those who did and did not receive payment for sex in the past 2 months at $p<0.05$.

Drug and alcohol abuse were also compared between those who sold sex and those who did not in the past two months (see Table 20). A significantly greater proportion of MSM who sold sex drank alcohol at least several times a week than those who did not sell sex (39 percent vs. 13 percent). Use of any illicit drugs in the past six months was significantly higher among those who sold sex (56 percent vs. 27 percent), as was the use of crack and cocaine. Those selling sex were also significantly more likely to have been incarcerated compared to those not selling sex (14 percent vs. 3 percent).

MSM who sold sex had unprotected anal intercourse with more partners than those not selling sex; those selling sex were more likely to have had URAI with more than one partner in the past two months (22 percent vs. 5 percent) and UIAI with more than one partner in the past two months (21 percent vs. 5 percent). Those who sold sex also had more unprotected anal and vaginal intercourse (UAVI) with women than those not selling sex ( 23 percent vs. 6 percent). 
Table 20 Comparison of risk behaviors of MSM who sold sex in the past two months with those who did not*

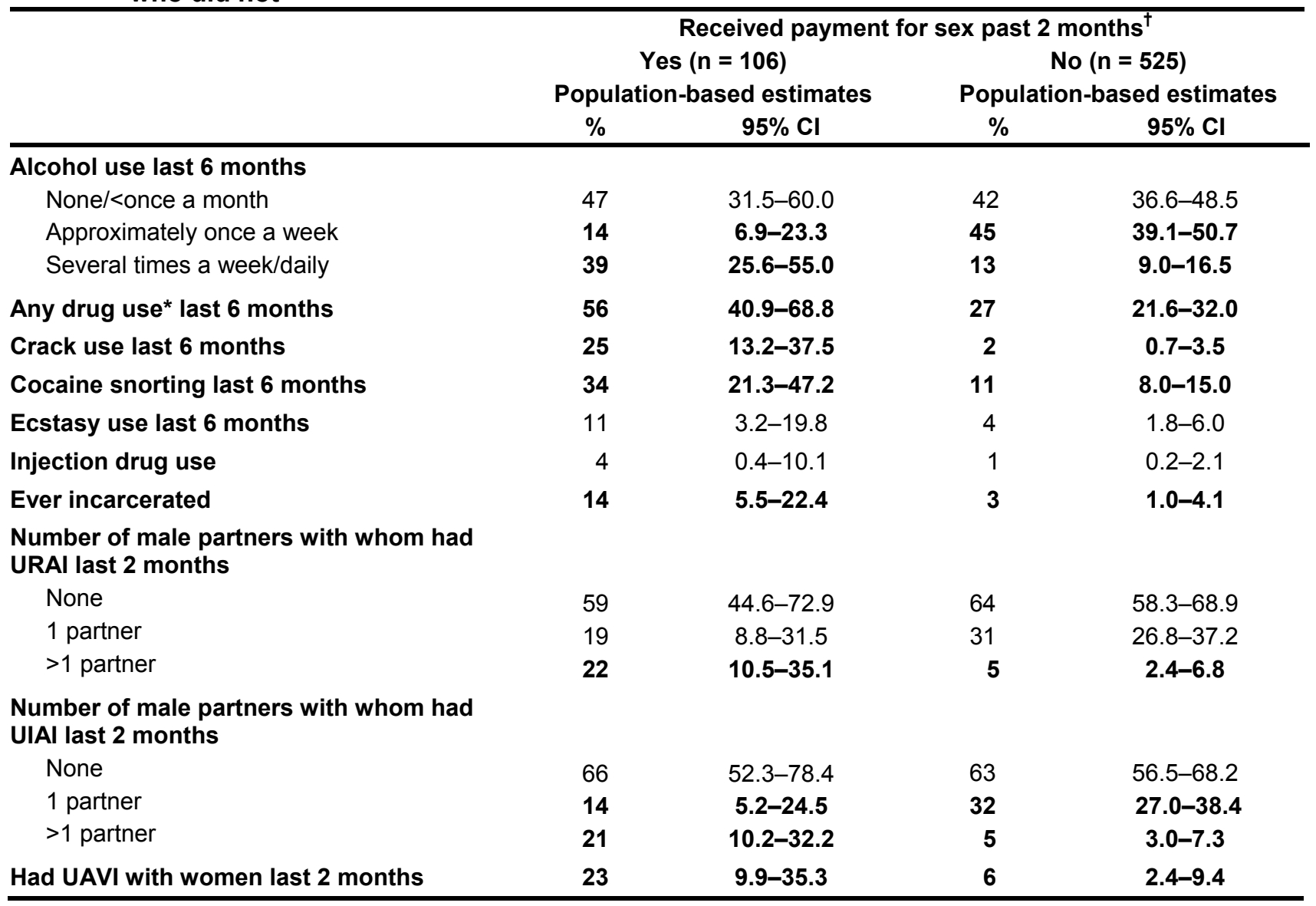

${ }^{\dagger}$ Sample size varies slightly due to missing data.

* Any drug use includes smoking of cannabis or crack, taking amphetamines or ecstasy, snorting inhalants or cocaine, using any other drugs, or injecting any non-prescribed drugs.

*Bold type data indicates significant difference between those who did and did not receive payment for sex in the past 2 months.

Similar proportions of MSM (approximately 60 percent) who had sold sex and who had not sold sex in the last two months had ever tested for HIV (see Table 21). Based on the syphilis test results from this study, a significantly greater proportion of MSM who had sold sex in the past two months tested positive for syphilis than those who had not sold sex (20 percent vs. 7 percent). Although not significantly different, those who sold sex were slightly more likely to test HIV-positive and to have experienced an STI symptom in the past 12 months compared to MSM who did not sell sex in the last 2 months. Risk perception was similar between the two groups (data not shown). 


\section{Hgrizons}

Table 21 HIV testing history and seroprevalence of HIV and syphilis of MSM who sold sex and who did not sell sex in past two months*

\begin{tabular}{|c|c|c|c|c|}
\hline & \multicolumn{4}{|c|}{ 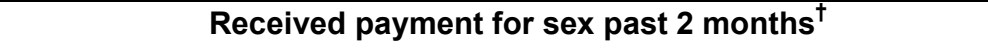 } \\
\hline & \multirow{2}{*}{\multicolumn{2}{|c|}{$\begin{array}{l}\text { Yes }(n=106) \\
\text { Population-based estimates }\end{array}$}} & \multirow{2}{*}{\multicolumn{2}{|c|}{$\begin{array}{l}\text { No }(n=525) \\
\text { Population-based estimates }\end{array}$}} \\
\hline & & & & \\
\hline & & & & \\
\hline Ever took HIV test & 62 & $46.9-75.3$ & 57 & $51.2-63.0$ \\
\hline Tested positive for HIV & 14 & $2.9-27.3$ & 6 & $3.2-8.7$ \\
\hline Tested positive for syphilis & 20 & $11.3-31.6$ & 7 & 4.3-9.1 \\
\hline Had an STI symptom past 12 months & 40 & $27.5-54.4$ & 24 & $20.1-29.3$ \\
\hline
\end{tabular}

† Sample size varies slightly due to missing data.

*Bold type data indicates significant difference between those who did and did not receive payment for sex in the past 2 months.

MSM who had sold sex in the past two months were significantly more likely to have experienced psychological abuse, physical abuse, and abuse from police in the past 12 months compared to those who had not sold sex (see Table 22). Additionally, MSM who had sold sex in the past two months were estimated more likely to have had sexual contact with someone at least four years older than themselves as a child (before the age of 13 years) than those who had not sold sex.

Table 22 Experience of homophobic abuse and childhood sexual abuse among MSM who sold sex and MSM who did not sell sex in the past two months*

\begin{tabular}{|c|c|c|c|c|}
\hline & \multicolumn{4}{|c|}{ 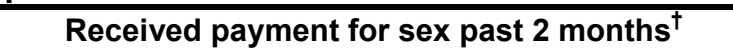 } \\
\hline & \multicolumn{2}{|c|}{$\begin{array}{c}\text { Yes }(n=106) \\
\text { Population-based } \\
\text { estimates }\end{array}$} & \multicolumn{2}{|c|}{$\begin{array}{c}\text { No }(n=525) \\
\text { Population-based } \\
\text { estimates }\end{array}$} \\
\hline & $\%$ & $95 \% \mathrm{Cl}$ & $\%$ & $95 \% \mathrm{Cl}$ \\
\hline Any homophobic abuse ${ }^{a}$ last year & 83 & $71.1-92.8$ & 66 & $60.8-72.2$ \\
\hline Psychological abuse due to homophobia last year & 81 & $68.8-91.0$ & 58 & $52.4-64.5$ \\
\hline Physical abuse due to homophobia last year & 48 & $33.1-60.2$ & 15 & $11.6-19.9$ \\
\hline Sexual harassment due to homophobia last year & 37 & $24.1-50.4$ & 28 & $23.6-33.7$ \\
\hline Abuse from police due to homophobia last year & 16 & $7.0-25.4$ & 4 & $2.1-6.3$ \\
\hline $\begin{array}{l}\text { Had sexual contact } w / \text { someone } \geq 4 \text { years older before } \\
13 \text { years old }\end{array}$ & 54 & $40.3-67.5$ & 30 & $24.6-34.9$ \\
\hline Consider self abused as child & 20 & $9.2-31.4$ & 9 & $6.0-12.2$ \\
\hline
\end{tabular}

${ }^{\dagger}$ Sample size varies slightly due to missing data.

${ }^{a}$ Homophobic abuse was defined as having experienced any physical abuse, psychological abuse and sexual harassment.

*Bold type data indicates significant difference between those who did and did not receive payment for sex in the past 2 months. 


\section{Factors Associated with URAI}

Multivariate logistic regression analysis was conducted on unweighted data to examine factors associated with URAI, one of the most important behaviors that put MSM at high risk for HIV and STIs. Table 23 presents multivariate models for all sexually active MSM, including those who had live-in MSM partner (Model 1) and excluding MSM who had live-in male partner (Model 2).

In Model 1, those living with male partner were found to be about five times more likely to have had URAI in the past two months (AOR 5.29; 95\% CI 2.61-10.73) compared to those who did not live with a male partner. Upon further examination of those living with a male partner, the study found that among those with live-in partners $(\mathrm{n}=58), 37.5$ percent had more than one partner in the past two months and 9 percent reported having URAI with more than one partner in this period. Model 1 also indicates that MSM who had ever suffered psychological homophobic violence were two times more likely to have engaged in URAI in the past two months (AOR 2.05; 95\% CI 1.22-3.47) and those participating in HIV educational activities in the past 12 months were less likely to have had URAI as compared to those that had not participated in these activities (AOR 0.60; 95\% CI 0.40-0.89).

In order to evaluate the predictors for URAI excluding those with a live-in male or transvestite partner, a second model is also presented in Table 23. In Model 2, experience of psychological abuse and participation in HIV prevention educational activities remained significant and the adjusted odds ratios were similar to the first model. Additionally, two variables that had borderline significance in Model 1 became significant when those living with a male partner were excluded. In Model 2, MSM who had more than two partners were 1.5 times more likely to have had URAI than those with 1-2 partners (AOR $1.53 ; 95 \%$ CI 1.02-2.29), and MSM with less than 11 years of education were 1.5 times more likely to have had URAI than those with more education (AOR 1.58; 95\% CI 1.02-2.45). 


\section{Hgrizons}

Table 23 Multivariate logistic regression model for factors associated with URAI among MSM in Campinas

Model 1

Including MSM with live-in MSM partner $(\mathbf{n}=528)^{\ddagger}$

Adjusted $\mathrm{OR}^{\dagger} \quad 95 \% \mathrm{Cl}^{\dagger}$
Model 2

Excluding MSM with live-in MSM partner $(n=478)^{\ddagger}$

Adjusted OR ${ }^{\dagger} \quad 95 \% \mathrm{Cl}^{\dagger}$

\begin{tabular}{|c|c|c|c|c|}
\hline \multicolumn{5}{|l|}{$\overline{\text { Age }}$} \\
\hline $14-24$ & 1.00 & - & 1.00 & - \\
\hline $25+$ & 0.73 & $0.49-1.09$ & 0.74 & $0.48-1.11$ \\
\hline \multicolumn{5}{|l|}{ City } \\
\hline Campinas & 1.00 & - & 1.00 & - \\
\hline Other & 1.06 & $0.69-1.62$ & 1.08 & $0.69-1.67$ \\
\hline \multicolumn{5}{|l|}{ Sexual orientation } \\
\hline Homosexual & 1.15 & $0.73-1.80$ & 1.11 & $0.69-1.77$ \\
\hline Bisexual/other & 1.00 & - & 1.00 & - \\
\hline \multicolumn{5}{|l|}{ Schooling degree } \\
\hline$<11$ yrs & 1.48 & $0.98-2.25^{\Phi}$ & 1.58 & $1.02-2.45^{*}$ \\
\hline$>12 \mathrm{yrs}$ & 1.00 & - & 1.00 & - \\
\hline \multicolumn{5}{|l|}{ Religion } \\
\hline Evangelic/Protestant & 0.60 & $0.35-1.05$ & 0.58 & $0.33-1.01^{\Phi}$ \\
\hline Others & 1.00 & - & 1.00 & - \\
\hline \multicolumn{5}{|c|}{ Disclosed sexual attraction to mother } \\
\hline Yes & 1.29 & $0.88-1.89$ & 1.31 & $0.88-1.95$ \\
\hline No & 1.00 & - & 1.00 & - \\
\hline \multicolumn{5}{|c|}{ Used crack past 6 months } \\
\hline Yes & 2.57 & $0.90-7.35$ & 2.41 & $0.84-6.88$ \\
\hline No & 1.00 & - & 1.00 & - \\
\hline \multicolumn{5}{|l|}{ Live with MSM partner } \\
\hline Yes & 5.29 & $2.61-10.73^{* * *}$ & - & - \\
\hline No & 1.00 & - & - & - \\
\hline \multicolumn{5}{|l|}{ Number of sex partners } \\
\hline $1-2$ & 1.00 & - & 1.00 & - \\
\hline$>2$ & 1.44 & $0.97-2.13$ & 1.53 & $1.02-2.29^{*}$ \\
\hline \multicolumn{5}{|c|}{ Received payment for sex past 2 months } \\
\hline Yes & 1.16 & $0.67-2.01$ & 1.22 & $0.69-2.13$ \\
\hline No & 1.00 & - & 1.00 & - \\
\hline \multicolumn{5}{|c|}{$\begin{array}{l}\text { Ever suffered psychological abuse due to } \\
\text { homophobia }\end{array}$} \\
\hline Yes & 2.05 & $1.22-3.47^{\star *}$ & 1.89 & $1.08-3.33^{*}$ \\
\hline No & 1.00 & - & 1.00 & - \\
\hline \multicolumn{5}{|c|}{$\begin{array}{l}\text { Participated in educational activities past } 12 \\
\text { months }\end{array}$} \\
\hline Yes & 0.60 & $0.40-0.89^{*}$ & 0.63 & $0.42-0.96^{*}$ \\
\hline No & 1.00 & - & 1.00 & - \\
\hline
\end{tabular}

${ }^{* \star *} p<0.0001,{ }^{* *} p<0.01,{ }^{*} p<0.05,{ }^{\Phi}$ borderline significance; ${ }^{\ddagger}$ Sample size varies slightly due to missing data.

† Reported for variables that remained in the reduced logistic regression model predicting URAI, adjusted by other variables in the model, including age, city and sexual orientation. Model demonstrated adequate fit based on the goodness-of-fit test $(p>0.05)$. All variables that remained in the model were checked for colinearity but none was found. 


\section{Discussion}

This study has identified some important subgroups of MSM in the metropolitan area of Campinas that are at increased risk for HIV infection. However, before discussing the implications of the findings, some limitations should be pointed out.

First, although the study was designed to reach MSM from the entire metropolitan area of Campinas, recruitment was strongly concentrated in the city of Campinas ( 76 percent of all participants resided in Campinas); the rest of the sample resided in six of the 19 municipalities of the area. Recruitment was concentrated in the city of Campinas possibly due to several factors: i) RDS methodology relies on recruiting social contacts of participants, and the majority of seeds were from Campinas, ii) Campinas is the center of culture and entertainment in the area, and iii) the study site was centrally located in the city of Campinas, making it more challenging for those outside of the city to enroll in the study. Consequently, the sample likely best represents MSM who belong to a network, have their social and occupational activities in the city of Campinas, or who reside in the city of Campinas, instead of the larger metropolitan area of Campinas.

Second, the study likely disproportionately recruited more MSM who were comfortable with their sexual orientation. When comparing disclosure rates of the study sample to the disclosure rates of their peers (as reported by the participants), study participants were more likely to have disclosed their sexual orientation to family members than peers in their network ( 95 percent vs. 54 percent). This suggests that MSM who were comfortable disclosing their sexual orientation may have been more likely to participate in the study than those less comfortable with disclosure. Qualitative assessments also confirmed this finding.

Finally, the sample may have over-sampled those who were motivated to participate in the study due to the offer of free and confidential HIV testing. The possibility of having an HIV rapid test, although it was optional, may have influenced the recruitment process. Seventy-two percent of participants indicated that they participated in the study due to the opportunity to take an HIV test. Participants who reported participating in the study primarily because of the HIV test had similar sexual risk behavior to those who participated for other reasons. However, the participants who reported HIV testing as their main reason for enrolling in the study were younger and less likely to have ever been tested for HIV before compared to those who were not motivated by the HIV testing to participate in it. Therefore, the offer of HIV testing may have resulted in the recruitment of a young population of MSM in this study.

In sum, due to the study design, the study likely accessed young MSM who were more likely to disclose their sexual orientation, and those who lived in or were linked to people who live in the city of Campinas. This should be kept in mind when considering the implications of the study findings.

\section{Low Levels of Disclosure of Sexual Orientation}

This study found that one-quarter of the MSM identified themselves to be bisexual, which is slightly higher than observed in previous Brazilian studies of populations of MSM (estimated at 15 percent) (Kerr-Pontes 1999; Brasil 2000, 2005). The higher percentage in this study could be explained by the larger proportion of adolescents (14-19 years old), since this age group was more likely to report being bisexual than the older age groups (39 percent vs. 16 percent). Bisexual orientation may also have been 


\section{Hgrizons}

over-reported, as some of the MSM may have feared disclosing their homosexual orientation. Lastly, the higher rate of bisexual orientation found in this study may also reflect the high percentage of young MSM in the study, since younger MSM are likely going through a transitional stage within a sequential model of sexual identity development during which sexual questioning and experimentation with both oppositesex and same-sex partners is not uncommon and may take place before consistently self-identifying as lesbian, gay, or bisexual persons (Rosario et al. 2006).

Although this study may have accessed the MSM who were more comfortable with disclosure of their sexual orientation, the results indicated that those who identified themselves as bisexuals were less likely to mention their sexual attraction to men to anyone and suffered higher rates of family disapproval of their sexual attraction to men. Studies have shown that the fear of social retaliation due to sexual orientation may lead many gay and bisexual men to identify as heterosexual (Brooks et al. 2005; Díaz et al. 2001). Moreover, the non-disclosure among gay or bisexual young men may prevent them from seeking VCT or other HIV prevention services due to HIV-related stigma and discrimination (Kegeles, Hays and Coates 1996; Brooks et al. 2005). Therefore, it is imperative to implement interventions which take into account factors that can hinder and prevent utilization of effective prevention programs for MSM, including sexual identity, disclosure, self-esteem, and HIV-related stigma and discrimination.

\section{Importance of Participation in HIV Prevention Activities and Access to Condoms}

Although only one-third of MSM indicated they had participated in HIV prevention activities in the past 12 months, the study found that participation in such activities was associated with higher condom use during receptive anal sex. This finding is similar to that found among MSM in Nairobi, Kenya (OnyangoOnyango-Ouma, Birungi and Geibel 2005) and highlights the importance of increasing exposure to HIV prevention programs among the population.

Receipt of free condoms was fairly high (nearly 80 percent). In Brazil, the promotion of condom use is a widespread strategy for HIV/STI control, and it has increased by almost 50 percent between 1998 and 2005 among Brazilians in general (Berquó and Barbosa 2007). In Campinas, the public health services were responsible for 60 percent of the free condoms received by MSM in this study. It is important to note that those who received free condoms were significantly more likely to have participated in HIVrelated discussions in the past 12 months. This was markedly observed among MSM sex workers whose participation in HIV talks or workshops was greater than among those not involved in commercial sex.

\section{History of HIV Testing and Self-perception of Risk}

The HIV testing rate observed among MSM in this study (58 percent had ever been tested) is lower than that observed in other Brazilian studies with similar populations (70 percent) (IBOPE 2002; Brasil 2005), but much higher than that observed among the general sexually active Brazilian male population (estimated at 21 percent) (Brasil 2006b). The HIV testing rate was much lower among the younger MSM (14-19 years old), which is similar to findings from other national and international studies (IBOPE 2002; Brasil 2005; Choi et al. 2006). Low HIV testing rates among this age group are particularly worrisome especially when half of these younger MSM reported engaging in URAI in the two months prior to the survey. 
HIV risk perceptions were inconsistent with MSM's risk behaviors. Among those who had never been tested for HIV, almost half perceived themselves at low risk even when over one-third reported having URAI during the previous two months. These findings are consistent with findings from other studies with MSM (MacKellar et al. 2005, 2006), suggesting the need for prevention providers to intensify efforts to assess potential risks and recommend testing for men in this population, especially younger ones.

\section{Sexual Behavior and Condom Use}

Unprotected sex with male or transvestite partners was high in this study. Almost one-third of MSM reported URAI with one MSM partner and seven percent had URAI with more than one MSM partner. Unlike other studies, which have reported lower levels unprotected sex during receptive intercourse than during insertive intercourse (Brasil 2000; Ma et al. 2007; Koblin et al. 2006; Onyango-Ouma, Birungi and Geibel 2005), this study found similar levels of unprotected sex for insertive anal intercourse and receptive anal intercourse.

Upon further examining factors associated with the risky behavior of URAI, multivariate analysis indicated that living with a male or tranvestite partner was an important independent predictor of URAI. Cohabiting may be a reasonable proxy for steady or main partnership. Among those who live with male or transvestite partners, nearly 40 percent reported having had sex with more than one partner in the past two months, 8 percent of whom reported unprotected anal intercourse in the same period with more than one partner. Despite the small number of cases, this finding suggests that non-monogamous relationships may be common, and unprotected anal sex is practiced in concurrent partnerships. In a sample of MSM from a northeast Brazilian city, Gondim and Kerr-Pontes (2000) observed that 31 percent of the MSM who reported a steady partnership with a man also had sex with other sexual male partners.

The study findings are consistent with previous studies that have found a strong association between unprotected anal intercourse and steady partnership among MSM (Brasil 2000, 2005; da Silva et al. 2005; MacKellar et al. 2005; Folch et al. 2006; Sanchez et al. 2006; Hart, Peterson and Community Intervention Trial for Youth Study Team 2004; Davidovich, de Wit and Stroebe 2004). Given these results as well as findings from recent studies that suggest that a large majority of new HIV infections among younger MSM might be attributed to transmission from steady sexual partners (Davidovich et al. 2001; Xiridou et al. 2003), HIV prevention programs for MSM must encourage positive changes in sexual behaviors with the promotion of consistent condom use, knowing one's HIV status and that of one's sex partner(s), and the enhancement of negotiation skills for safer sexual practices among steady partners such as "negotiated safety" (Kippax et al. 1997; Davidovich, de Wit and Stroebe 2004; Piaseczna et al. 2001).

Having multiple sex partners was also found to be common among MSM. More than 40 percent of MSM had sex with 2-5 partners in the last two months, and around 20 percent had sex with more than five partners. Having more than two partners in the past two months was found to be significantly associated with URAI among MSM who did not live with their partners. This finding has been reported in other studies with MSM (Kerr-Pontes 1999; Koblin et al. 2003).

\footnotetext{
${ }^{5}$ The practice between two people of the same HIV serostatus agreeing to have unprotected anal intercourse after ensuring both partners have been tested for HIV and re-tested after the 3-month window period, and agreeing to abstain from sex with others or using a condom with others.
} 


\section{Hgrizons}

Additionally, having sex with both men and women in the past two months was not uncommon (16 percent), and it was reported even among those who did not identify themselves as bisexuals.

Furthermore, condom use with female partners was low; 75 percent of those who had vaginal or anal sex with female partners had unprotected sex at least once in the past two months. A recent survey with MSM from a metropolitan area located in the Brazilian central-west region found similar results (Brasil 2005). Among those who had unprotected sex with a female partner in the past two months, slightly more than half also had unprotected anal intercourse with at least one male partner in the same period. High rates of unprotected sex with both male and female partners of MSM have been reported in other studies in Brazil (Kerr-Pontes 1999) and elsewhere (Choi et al. 2004; He et al. 2006; Sanchez et al. 2006; Tabet et al. 2002). Some studies have suggested reasons MSM engage in risky behaviors simultaneously with both men and women, including low perception of HIV risk infection with vaginal sex compared to anal sex with male partners (Gondim and Kerr-Pontes 2000), low self-perceived risk by not considering themselves as gay or homosexual (Jarama et al. 2005), or fear of their female partners finding out about their sexual behavior with men (O'Leary and Jones 2006). The findings of concurrent partnerships and unsafe sex with both male and female partners in this study suggest a potential bridge of STI/HIV infection from MSM to the other populations, and vice versa.

\section{HIV Status of Sex Partners}

An important finding from this study was the low level of knowledge of partners' HIV serostatus. Around 30 percent of MSM engaged in unprotected anal intercourse with sexual partners whose HIV status they did not know. Of those who had URAI with single or multiple MSM partners and UIAI with a single MSM partner, only 60 percent knew that their sex partner was HIV-negative. Interestingly, a reverse proportion was observed for those who practiced insertive sex with more than one partner in the past two months, with 62 percent reporting to be unaware of their partners' HIV serostatus. This finding may suggest what some authors have called "seropositioning" (deciding to practice insertive or receptive anal sex depending on the HIV status of the partner) (Truong et al. 2006). In other words, MSM who had multiple partners whose HIV status they did not know may have deliberately chosen to practice insertive intercourse knowing that risk of HIV infection would be greater if they were to have receptive sex.

Although this study found that a small proportion (10 percent) of MSM who reported having unprotected anal intercourse had unprotected sex with an HIV-positive male or transvestite partner, it is noteworthy that all of them reported being HIV-negative or having an unknown HIV status. We do not know whether such situations were intentional or not. However, it is important to be aware that intentional unprotected sex, known as "barebacking" or "bareback sex," does occur among some MSM (Mansergh et al. 2002; Parsons and Bimbi 2007) and should be considered in HIV prevention efforts.

These findings support the need for addressing self-perceived risk and perceptions of risk of sex partners when counseling MSM on sexual risk reduction, which could strongly contribute to their ability to negotiate protective sexual practices with partners. 


\section{Male Sex Workers}

In this study, a relatively high proportion of MSM was estimated to have received payment (drugs, money, or gifts) for sex in their lifetime (28 percent) or in the past two months (15 percent). However, in contrast, only 8 percent actually identified themselves as sex workers.

Self-reported sexual orientation differed significantly between MSM who engaged in commercial sex from those who did not, with a higher proportion of those engaged in commercial sex identifying themselves as bisexuals or heterosexuals. This has also been reported in the international literature (Finlinson et al. 2006; Mariño, Minichiello and Disogra 2003; Kelly et al. 2001; Newman, Rhodes and Weiss 2004). Homosexual or bisexual self-identification is more likely to be related to the sexual practice as opposed to sexual identity (Finlinson et al. 2006; Parker 1991). Among a sample of Puerto Rican drug users involved in male sex work, Finlinson et al. (2006) observed that the study participants identified themselves as straight men with a strong desire to distance themselves from men who they perceived to be effeminate or who participated in receptive anal sex.

Study analysis found that MSM who received payment for sex were a high-risk group. They were more socioeconomically disadvantaged, and more likely to have suffered homophobic abuse and consumed alcohol and illicit drugs, such as crack and cocaine, compared to those not selling sex. Additionally, a significantly higher proportion of MSM who sold sex reported unprotected anal intercourse with more than one partner in the past two months. Further, MSM who sold sex were significantly more likely to have reported sex with women in the past 2 months compared to those who did not, and had more unprotected anal and vaginal intercourse (UAVI) with women compared to those not selling sex, suggesting a potential bridge for HIV transmission to women.

MSM who are sex workers seem to be at highest risk for HIV and STI infections as compared to female sex workers and to non-sex worker MSM (Dandona et al. 2006; Belza 2005; Estcourt et al. 2000). In the present study, higher HIV and syphilis prevalence was found among those who sold sex in the past two months when compared to those who did not.

These findings support the need to increase interventions efforts with male sex workers in the metropolitan region of Campinas. Programs targeting this population must include harm reduction strategies for alcohol and drug abuse, and address their social vulnerability to homophobic discrimination and violence, including that perpetrated by police authorities.

\section{Experience of Homophobic Abuse}

One of the most striking findings of this study is the high frequency of homophobic abuse experienced by this population. Roughly five out of six MSM have suffered some kind of homophobic abuse in their life time, and 70 percent had experienced it within the last year alone, with psychological abuse being the most common form of aggression suffered. These findings are consistent with the little data that exists on homophobic behavior in Brazil, primarily from police departments and LGBTTT organizations (Carrara and Ramos 2004; Mott 2006). These data, including this study's findings, may be an underestimation given that these incidents often go unreported.

Convenience sampling surveys conducted at Gay Pride Parades in major cities including São Paulo have also reported high rates of homophobic abuse: 60 percent of gay participants had ever suffered verbal 


\section{Hgrizons}

aggression or threat of physical aggression due to their sexual orientation, and 16 percent had ever suffered physical violence. Rates are much higher for transgenders, with 85 percent reporting experience of verbal aggression and 60 percent reporting experience of physical abuse in their lifetime (Facchini, França and Venturi 2007). The higher prevalence of homophobic violence found in this study may be due, in part, to the higher rates of disclosure of sexual orientation in the study population, since "coming out" has been found to be associated with greater exposure to homophobic discrimination and violence (Rosario, Schrimshaw and Hunter 2006; Huebner, Rebchook and Kegeles 2004; Herek 1991).

The impact the discrimination and violence on the mental health status of MSM has been documented in several studies (Mays and Cochran 2001; Díaz et al. 2001; Clements-Nolle et al. 2001; Herek 1991). These negative consequences include depression, low self-esteem, anxiety, insomnia, suicidal ideation and attempts, substance abuse, and higher sexual risk behaviors (Ortiz-Hernández and Torres 2005; Clements-Nolle et al. 2001; Rosário et al. 2006; Herek 1991; Thiede et al. 2003; Celentano et al. 2006; Koblin et al. 2006; Ortiz-Hernández and Torres 2005; Diaz et al. 2001; Rosario et al. 2006; Wilson and Yoshikawa 2004; Jarama et al. 2005). In the current study, use of illicit drugs in the past six months was significantly associated with having suffered verbal or physical abuse in the past 12 months.

These findings clearly support the need for policies to take strong action against discrimination and violence toward LGBTTT and for HIV prevention interventions to consider the social-cultural attitudes towards homosexuality that exist in the larger society.

\section{Alcohol and Drug Abuse}

The prevalence of alcohol use in the past six months was high ( 88 percent) and slightly higher than that observed in a national study with MSM from a metropolitan area of Brazil (Brasil 2005) and in the general male population in Brazil (77 percent) (Galduróz et al. 2005). Additionally, the prevalence of heavy drinkers (consuming alcohol many times a week or everyday) in the current study was higher than that observed in previous studies with young MSM (Thiede et al. 2003).

More than half of MSM reported ever using any illicit drug, and 32 percent had used them in the past six months. These proportions were much higher than the estimated 19 percent prevalence of ever using any illicit drug among the Brazilian general population (Galduróz et al. 2005). Marijuana was the most commonly used drug in the previous six months, which is similar to findings from other studies with MSM (Brasil 2005; Thiede et al. 2003; Stall et al. 2001; Operario et al. 2006; Rusch et al. 2004). The use of snorted cocaine was much higher than that estimated for the Brazilian male population (aged 15-49 years-old) (Szwarcwald et al. 2005), but similar to those observed among other MSM populations (Thiede et al. 2003; Stall et al. 2001; Operario et al. 2006; Rusch et al. 2004). Injection drug use was rare in this population.

\section{HIV and Syphilis Prevalence}

HIV prevalence was estimated at 7.4 percent by rapid test. However, it should be noted that participants who already knew they were HIV-positive did not take the HIV test for the study. Taking these positive MSM into account, the estimated HIV prevalence of the study population would be 8.4 percent. This is consistent with findings from a previous study conducted in the city of São Paulo, which reported an HIV seroprevalence of 11 percent (Brasil 2000). The HIV prevalence estimated from this study may be 
conservative, as the poorest segments of the study population, known to have higher prevalence rates, may be underrepresented in the study. The estimated prevalence for MSM is much higher than the rate for the adult male population in Brazil, estimated at 0.8\% (Szwarcwald and Souza Junior 2006)

An important finding of this study was the high number of MSM who did not know their HIV status. The majority of MSM (35 out of 49) who tested positive for HIV were unaware of their infection. Additionally, of those who tested positive, 18 had previously tested negative for HIV infection, and, of these, 10 reported taking the HIV test less than one year before the interview. A recent study with MSM from five metropolitan areas in the United States showed that 48 percent of MSM who tested HIVpositive were unaware of their HIV infection (CDC 2005). The study reported that reasons for not having tested for HIV were fear of receiving a positive test result and concerns about disclosing a positive serostatus. Increasing the uptake of HIV testing should be a priority for interventions targeting MSM, as it has been demonstrated that knowing one's serostatus may reduce HIV transmission through positive behavior change (Weinhardt et al. 1999).

The estimated HIV prevalence of 4 percent in the adolescent (ages 14-19) study population is extremely high compared to the general population and the average age of sexual debut was 13 years. These results confirm the importance of this young population in the dynamics of the HIV epidemic in Brazil. Generally, in the North American context, indicators also suggest high HIV prevalence among young MSM, especially those in their early twenties (Koblin et al. 2000), and particularly among AfricanAmericans, Hispanic, and mixed ethnicity men (Valleroy et al. 2000). Although a striking finding, this high prevalence was not surprising, as Brazil has witnessed a continuous decrease of the median age in sexual debut in the general population (Berquó 2000; Abramovay, Castro and da Silva 2004; Heilborn et al. 2006), and condom use is still low. For these reasons, all campaigns directed to adolescents and young MSM should be complemented with aggressive free condom distribution to avoid or bypass barriers for condoms use by adolescents. In this sense, evidence-based prevention programs for young MSM should be urgently implemented in the country. Prevention programs targeted at young men based on peer outreach, social network-level approaches, and publicity campaigns have been shown to lead to HIV risk reduction (Kegeles, Hays and Coates 1996; Amirkhanian et al. 2005). Additionally, prevention strategies should consider the age-differences in venues attended by MSM to meet sex partners, considering that the majority of the young MSM reported seeking sexual partners in nightclubs or bars, while internet-based HIV prevention campaign should be considered for all MSM, as it was the second most reported place for sexual encounters.

The estimated syphilis prevalence in the current study was high ( 9 percent), but slightly lower than the 16 percent previously reported for this population in Brazil (Brasil 2000), and much higher than that observed among heterosexual male population such as truck drivers, estimated at 4.5 percent (Chinaglia et al. 2007) or blood donors (1 percent) (Martelli et al. 1999). The syphilis prevalence reported in our and the other studies represent both recent and old infections. Increasing outbreaks of syphilis among MSM have been reported in major U.S. cities (CDC 2003), European countries, and Australia (Nicoll and Hamers 2002). The high syphilis prevalence found may be due in part to the fact that the rapid syphilis test does not differentiate between current and past infection. Overall, 52 percent of the study group with a positive rapid test for syphilis reported having had syphilis in the past. Despite the difficulty of distinguishing new infections from infections that were either not initially identified or did not respond to treatment, it is important to emphasize that the prevalence among the adolescents studied was estimated to be 3 percent. Among these adolescents, the positive result on the rapid test is likely a more recent infection, as they have been sexually active for a shorter period of time. This information again highlights 


\section{Hgrizons}

the need for interventions targeting very young MSM, since syphilis infection facilitates acquisition and transmission of HIV infection (Buchacz et al. 2005; Ruan et al. 2007; Lama et al. 2006).

Just recently, the National STD and AIDS Program of Brazil added syphilis and HIV testing as part of its forthcoming second generation behavioral surveillance with MSM in the country.

\section{Concluding Remarks}

This study has provided important insights into the social and behavioral characteristics of the population of MSM in the metropolitan area of Campinas as well as that of the diverse sub-populations of the mostat-risk men. The study has also identified other underlying factors that increase the vulnerability of MSM to HIV infection. The results indicate that the sub-populations of MSM who are most likely to practice unprotected receptive anal intercourse include younger MSM, those who engage in sex work, MSM in stable partnerships (living with MSM partner), and those who have been victims of homophobic violence.

HIV seroprevalence of 7.4 percent among MSM is high, especially when compared to that of the general population. However, an even more critical finding was the high percentage of MSM who did not know their HIV status. Clearly, increasing the uptake of HIV testing must be a priority for interventions targeted at MSM, as knowing one's HIV serostatus may reduce HIV transmission through positive behavior change (Weinhardt et al. 1999).

HIV prevalence for very young MSM was strikingly high for the Brazilian context. Thus, adolescent MSM should be a priority group for prevention activities in the country. Prevention programs for young MSM must also take into account sexuality and gay identity, as this study found that younger MSM were less likely than older men to identify themselves as homosexual. Additionally, younger MSM in Campinas meet their MSM sex partners in different venues than older MSM, suggesting that different strategies should be considered to reach different age groups.

MSM who were commercial sex workers were also identified as a high-risk group in this study. They are socially more vulnerable due to their lower socioeconomic status, lower levels of education, ethnicity, and history of homophobic abuse, making them even more susceptible to HIV infection, as unequal power dynamics make it difficult for them to negotiate safer sex. Male sex workers and their clients must also be a focus of HIV interventions.

Prevention programs must also address high-risk sexual behaviors within stable partnerships. The findings from this study indicate that MSM in stable partnerships are five times more likely to have unprotected receptive anal sex than those who are not in stable relationships, and more than one-third of those in stable partnerships were estimated to have engaged in unprotected sex with more than one partner in the previous two months.

The astonishingly high levels of homophobic abuse that MSM experience provides strong evidence for prioritizing and supporting initiatives of non-governmental organizations for gay men and for the Brazilian Federal Government's plan to reduce homophobia and discrimination against gays, lesbians, transgenders, and bisexuals. Societal homophobia is a major barrier for MSM in accessing prevention services. Advocacy for greater acceptance by all sectors of society is urgently needed. 
The data from this study suggest the importance of HIV prevention programs that address not only sexual risk reduction, but also other social and cultural factors such as their vulnerability to homophobic violence, social construction of sexual identity, social norms regarding sexuality, and condom use within their social networks.

However, it was encouraging to find that most MSM in the studied area had received free condoms in the past 12 months. Although only one-third indicated they had participated in an HIV prevention educational activity in the past 12 months, the study found that participation in such activities was associated with higher condom use. Therefore, greater effort in trying to reach MSM with educational activities should be a priority, especially those most at risk. In addition, efforts should be made to describe and disseminate those educational activities which are shown to be successful.

After having identified the characteristics and extent of risky sexual practices of MSM, valid HIV and syphilis prevalence rates, and the sub-populations of MSM who are at most risk for HIV, it is clear that the decision of the Brazilian government to prioritize the HIV epidemic among MSM in its most recent prevention campaigns is an appropriate and timely one. 


\section{Hgrizons}

\section{References}

Abramovay, M., M. G. Castro, and L. B. da Silva. 2004. Juventudes e Sexualidade [Youths and Sexuality]. Brasília: UNESCO Brasil.

Amirkhanian, Y. A. et al. 2005. "A randomized social network HIV prevention trial with young men who have sex with men in Russia and Bulgaria," AIDS 19(16): 1897-1905.

Belza, M.J. 2005. "Risk of HIV infection among male sex workers in Spain," Sexually Transmitted Infections 81(1): $85-88$.

Berquó, E. 2000. Comportamento sexual da população brasileira e percepções acerca do HIV/Aids [Sexual behaviors of the Brazilian population and perceptions of HIV/AIDS]. Brasília: Brazil, Ministério da Saúde.

Berquó, E. and R. M. Barbosa. 2007. "Relatório de Pesquisa. Comportamento sexual da população brasileira e percepções acerca do HIV/Aids, 1998-2005 [Research report: Sexual behaviors of the Brazilian population and perceptions of HIV/AIDS, 1998-2005]." Ministério da Saúde.

Brasil. 2006a. Ministério da Saúde. "Boletim epidemiológico Aids e DST [Epidemiological AIDS and STD Bulletin]," Ano III, n¹, 01 a 26 semanas epidemiológias-janeiro a junho de 2006.

Brasil. 2006b. Ministério da Saúde. "Pesquisa de conhecimento, atitudes e práticas na população brasileira de 15 a 54 anos, 2004 [Report on knowledge, attitudes, and practices of Brazilian population 15 to 54 years of age, 2004]." Brasília, Brasil: Ministério da Saúde.

Brasil. 2005. Universidade de Brasília. "Comportamento sexual e cidadania junto à população de homens que fazem sexo com homens do Distrito Federal [Sexual behavior and citizenship of men who have sex with men in the Federal District].” Brasília, Brazil: Univerisidade de Brasília.

Brasil. 2000. Bela Vista e Horizonte: Estudos comportamentais e epidemiológicos entre homens que fazem sexo com homens [Bela Vista and Horizonte: Behavioral and epidemiological studies among men who have sex with men]. Brasília: Ministério da Saúde.

Brooks, R. A. et al. 2005. "Preventing HIV among Latino and African American gay and bisexual men in a context of HIV-related stigma, discrimination, and homophobia: perspectives of providers," AIDS Patient Care STDS 19(11): 737-744.

Buchacz, K. et al. 2005. "Syphilis epidemics and human immunodeficiency virus (HIV) incidence among men who have sex with men in the United States: implications for HIV prevention," Sexually Transmitted Diseases 32(10 Suppl): S73-79.

Carballo-Diéguez, A. and C. Dolezal. 1995. "Association between history of childhood sexual abuse and adult HIVrisk sexual behavior in Puerto Rican men who have sex with men," Child Abuse and Neglect 19(5): 595-605.

Carrara, S. and S. Ramos. 2005. "Política, Direitos, Violência e Homossexualidade. Pesquisa $9^{\circ}$ Parada do Orgulho GLTB - Rio 2004 [Politics, Rights, Violence and Homosexuality. Survey conducted during the 9th GLTB Pride Parade - Rio de Janeiro, 2004].” Rio de Janeiro: CEPESC.

Celentano, D. D. et al. 2006. "Associations between substance use and sexual risk among very young men who have sex with men," Sexually Transmitted Diseases 33(4): 265-271. 
Centers for Disease Control and Prevention. 2005. "HIV prevalence, unrecognized infection, and HIV testing among men who have sex with men - five U.S. cities, June 2004-April 2005," Morbidity and Mortality Weekly Report 54 (24): 597-601.

2003. "HIV/STD risks in young men who have sex with men who do not disclose their sexual orientationsix cities, 1994-2000," Morbidity and Mortality Weekly Report 52(5): 81-87.

. 2001. "Revised guidelines for HIV counseling, testing, and referral," Morbidity and Mortality Weekly Report 50: 1-57.

1999. "Protocol for rapid test intervention session (revised 2/4/99). RESPECT-2: Single session counseling protocol—Rapid Test." http://www.cdc.gov/hiv/projects/respect-2/counseling.htm, accessed in 12/09/05.

Chinaglia, Magda et al. 2007. "Reaching truckers in Brazil with non-stigmatizing and effective HIV/STI services," Horizons Final Report. Washington, DC: Population Council.

Choi, K. H. et al. 2004. "High levels of unprotected sex with men and women among men who have sex with men: a potential bridge of HIV transmission in Beijing, China," AIDS Education and Prevention 16(1): 19-30.

Choi, K. H. et al. 2006. "Lack of HIV testing and awareness of HIV infection among men who have sex with men, Beijing, China," AIDS Education and Prevention 18(1): 33-43.

Clements-Nolle, K. et al. 2001. "HIV prevalence, risk behaviors, health care use, and mental health status of transgender persons: implications for public health intervention," American Journal Public Health 91: 915-921.

Dandona, L. et al. 2006. "How much attention in needed towards men who sell sex to men for HIV prevention in India," BMC Public Health 6: 31.

da Silva, C. G. et al. 2005. "Optimistic perception of HIV/AIDS, unprotected sex and implications for prevention among men who have sex with men, Sao Paulo, Brazil," AIDS 19(Suppl 4): S31-36.

Davidovich, U. et al. 2001. "Increase in the share of steady partners as a source of HIV infection: a 17-year study of seroconversion among gay men," AIDS 15(10): 1303-1308.

Davidovich U, J. B. de Wit, and W. Stroebe. 2004. "Behavioral and cognitive barriers to safer sex between men in steady relationships: implications for prevention strategies" AIDS Education and Prevention 16(4): 304-314.

Díaz, R. M. et al. 2001. "The impact of homophobia, poverty, and racism on the mental health of gay and bisexual Latino men: findings from 3 US cities,” American Journal of Public Health 91(6): 927-932.

Estcourt, C.S. et al. 2000. "HIV, sexually transmitted infections, and risk behaviors in male commercial sex workers in Sydney," Sexually Transmittd Infections 76(4): 294-298.

Facchini, R., I. L. França, and G. Venturi. 2007. "Sexualidade, Cidadania e Homofobia. Pesquisa da $10^{a}$ Parada do Orgulho GLBT de São Paulo - 2006 [Sexuality, Citizenship and Homophobia. Survey conducted during the 10th GLTB Pride Parade - São Paulo, 2006].” São Paulo: APOGLBT.

Finlinson, H. A. et al. 2006. "Sexual identity formation and Aids prevention: an exploratory study of non-gayidentified Puerto Rican MSM from working class neighborhood,” AIDS Behavior 10(5): 531-539. 


\section{Hgrizons}

Folch, C. et al. 2006. "Factors associated with unprotected sexual intercourse with steady male, casual male, and female partners among men who have sex with men in Barcelona, Spain," AIDS Education and Prevention 18(3): $227-242$.

Galduróz, J. C. et al. 2005. "Household survey on drug abuse in Brazil: study involving the 107 major cities of the country-2001," Addictive Behaviors 30(3): 545-556.

Gondim, R. G. and L. Kerr-Pontes. 2000. "Male/bisexuality: a study about unprotected sexual intercourse in Fortaleza, Brazil,” Revista Brasileira de Epidemiologia 3(1-3): 38-49.

Hart, T., J. L. Peterson, and Community Intervention Trial for Youth Study Team. 2004. "Predictors of risky sexual behavior among young African American men who have sex with men," American Journal of Public Health 94(7): $1122-1124$.

Heckathorn, D. 1997. "Respondent-driven sampling: A new approach to the study of hidden populations," Social Problems 44(2): 174-99.

Heckathorn, D. et al. 2002. "Extensions of respondent-driven sampling: A new approach to the study of injection drug users aged 18-25," AIDS and Behavior 6(1): 55-67.

Heilborn, Maria Luiza et al. 2006. O Aprendizado da Sexualidade: Reprodução e Rrajetórias Sociais de Jovens Brasileiros. [Learning Sexuality: Reproduction and Social Development of Brazilian Youths]. Rio de Janeiro: Garamond.

Herek, G. M. 1991. "Stigma, prejudice, and violence against lesbians and gay men," in Gonsiorek, JC and Weinrich, JD (Eds). Homosexuality: Research Implications for Public Policy. Newbury Park, CA: Sage.

Hosmer, D. W. and S. Lemeshow. 1989. Applied Logistic Regression. New York: Wiley \& Sons; 1989.

Huebner, D. M., G. M. Rebchook, and S. M. Kegeles. 2004. "Experiences of harassment, discrimination, and physical violence among young gay and bisexual men," American Journal of Public Health 2004; 94 (7): 1200-03.

IBOPE. 2002. "Pesquisa de Opinião Publica sobre homossexuais masculinos [Public opinion survey on homosexual men].” São Paulo: IBOPE.

[IBGE] Fundação IBGE. “Censo demográfico 2000 [Demographic census 2000].” Rio de Janeiro (11 Recenseamento Geral do Brasil).

Jarama, S. L. et al. 2005. "Psychosocial, behavioral, and cultural predictors of sexual risk for HIV infection among Latino men who have sex with men," AIDS and Behavior 9(4): 513-523.

Kegeles, S. M., R. B. Hays, and T. J. Coates. "The Mpowerment Project: a community-level HIV prevention intervention for young gay men," American Journal of Public Health 86(8): 1129-1136.

Kelly, J. A. et al. 2001. "HIV risk behavior and risk-related characteristics of young Russian men who exchange sex for money or valuables from other men," AIDS Education and Prevention 13(2): 175-188.

Kerr-Pontes, L. R. S. et al. 1999. "Self-reported sexual behavior and HIV risk taking among men who have sex with men in Fortaleza, Brazil,” AIDS 13(6): 709-717.

Kippax, S. et al. 1997. "Sexual negotiation in the AIDS era: negotiated safety revisited," AIDS 11(2): 191-197. 
Koblin, B. A. et al. 2000. "High prevalence of HIV infection among young men who have sex with men in New York City," AIDS 14(12): 1793-1800.

Koblin, B. A. et al. 2003. "High-risk behaviors among men who have sex with men in 6 US cities: baseline data from the EXPLORE Study," American Journal of Public Health 93(6): 926-32. Erratum in: American Journal of Public Health 2003, 93(8): 1203.

Koblin, B. A. et al. 2006. "Violence and HIV-related risk among young men who have sex with men," AIDS Care 18(8): 961-967.

Lama, J. R. et al. 2006. "Association of herpes simplex virus type 2 infection and syphilis with human immunodeficiency virus infection among men who have sex with men in Peru," Journal of Infectious Diseases 194(10): 1459-1466.

Lepkowski, J. M. 1991. "Sampling the difficult-to-sample,” American Institute of Nutrition 416-423.

Lignani, L. Jr. et al. 2000. "Sexually transmitted diseases in homosexual and bisexual males from a cohort of human immunodeficiency virus negative volunteers (Project Horizonte), Belo Horizonte, Brazil," Memórias do Instituto Oswaldo Cruz 95(6): 783-785.

Luna, E. J. and M. A. Veras. 2002. "AIDS research in men who have sex with men in Brazil: a review," meeting abstract, XIV International AIDS Conference, Barcelona, Spain, July 7-12.

Ma, X. et al. 2007. "Trends in prevalence of HIV, Syphilis, Hepatitis C, Hepatitis B, and sexual behavior among men who have sex with men," Journal of Acquired Immune Deficiency Syndrome 45(5): 581-587.

MacKellar, D. A. et al. 2005. "Unrecognized HIV infection, risk behaviors, and perceptions of risk among young men who have sex with men," Journal of Acquired Immune Deficiency Syndrome 38(5): 603-614.

MacKellar, D. A. et al. 2006. "Perceptions of lifetime risk and actual risk for acquiring HIV among young men who have sex with men," AIDS Behavior 11(2): 263-270.

Mansergh, G. et al. 2002. "Barebacking" in a diverse sample of men who have sex with men," AIDS 16(4): 653659.

Marins, J. R. et al. 2003. "Dramatic improvement in survival among adult Brazilian AIDS patients," AIDS 17(11): $1675-1682$.

Mariño, R., V. Minichiello, and C. Disogra. 2003. "Male sex workers in Córdoba, Argentina: sociodemographic characteristics and sex work experiences," Pan American Journal of Public Health/Revista Panamericana de Salud Pública 13 (5): 311-319.

Martelli, C.M. et al. 1999. "Anti-HBc testing for blood donations in areas with intermediate hepatitis B endemicity," Pan American Journal of Public Health/Revista Panamericana de Salud Pública 6(1): 69-73.

Mays, V. M. and S. D. Cochran. 2001. "Mental health correlates of perceived discrimination among lesbian, gay, and bisexual adults in the United States," American Journal of Public Health 91(11): 1869-1876.

Mott, L. 2006. "Homo-afetividade e direitos humanos [Homo-affection and human rights]," Revista Estudos Feministas 14(2): 509-521. 


\section{Hgrizons}

Newman, P. A., F. Rhodes, and R. E. Weiss. "Correlates of sex trading among drug-using men who have sex with men," American Journal of Public Health 94(11): 1998-2003.

Nicoll, A. and F. F. Hamers. 2002. "Are trends in HIV, gonorrhoea, and syphilis worsening in western Europe?" British Journal of Medicine 324(7349): 1324-7.

O'Leary, A. and K. T. Jones. 2006. "Bisexual men and heterosexual women: how big is the bridge? How can we know?" Sexually Transmitted Diseases 33(10): 594-5.

O'Leary, A. et al. 2003. "Childhood sexual abuse and sexual transmission risk behaviour among HIV-positive men who have sex with men," AIDS Care 15(1): 17-26.

Onyango-Ouma, W., Harriet Birungi, and Scott Geibel. 2005. "Understanding the HIV/STI risks and prevention needs of men who have sex with men in Nairobi, Kenya," Horizons Final Report. Washington, DC: Population Council.

Operario, D. et al. 2006. "Prevalence and correlates of substance use among young Asian Pacific Islander men who have sex with men," Prevention Science 7(1): 19-29.

Ortiz-Hernández, L. and Torres, M. I. G. 2005. "Efectos de la violencia y la discriminación en la salud mental de bisexuales, lesbianas y homosexuales de la Ciudad de México" [Effects of violence and discrimination on the mental health of bisexuals, lesbians, and gays in Mexico City] Cad Saude Publica 21 (3): 913-925.

Parker, R.G. 1991. Bodies, Pleasures and Passions: Sexual Cultures in Contemporary Brazil. Boston: Beacon Press.

Parsons, J. T. and D. S. Bimbi. 2007. "Intentional unprotected anal intercourse among sex who have sex with men: barebacking — from behavior to identity," AIDS Behavior 11(2): 277-287.

Paul, J. P. et al. 2001. "Understanding childhood sexual abuse as a predictor of sexual risk-taking among men who have sex with men: The Urban Men's Health Study," Child Abuse and Neglect 25(4): 557-84.

Piaseczna, M. A. et al. 2001. "Longitudinal patterns of sexual behavior and condom use in a cohort of HIV-negative gay and bisexual men in Vancouver, British Columbia, Canada, 1995-2000," Journal of Acquired Immune Deficiency Syndrome 28(2): 187-193.

Robinson, W. T. et al. 2006. "Recruiting injection drug users: a three-site comparison of results and experiences with respondent-driven and targeted sampling procedures," Journal of Urban Health 83(7): 129-138.

Rosario M, E. W. Schrimshaw, and J. Hunter. 2006. "A model of sexual risk behaviors among young gay and bisexual men: longitudinal associations of mental health, substance abuse, sexual abuse, and the coming-out process," AIDS Education and Prevention 18(5): 444-460.

Rosario M, et al. 2006. "Sexual identity development among gay, lesbian, and bisexual youths: consistency and change over time," Journal of Sex Research 43(1): 46-58.

Ruan, Y. et al. 2007. "Relationship between syphilis and HIV infections among men who have sex with men in Beijing, China," Sexually Transmitted Diseases 34(8): 592-597.

Rusch, M. et al. 2004. "Unprotected anal intercourse associated with recreational drug use among young men who have sex with men depends on partner type and intercourse role," Sexually Transmitted Diseases 31(8): 492-498. 
Salganik, M. J. and D. Heckathorn. 2004. "Sampling and estimation in hidden populations using respondent-driven sampling," Sociological Methodology 34: 193-239.

Sanchez, T. et al. 2006. "Human immunodeficiency virus (HIV) risk, prevention, and testing behaviors-United States, National HIV Behavioral Surveillance System: men who have sex with men, November 2003-April 2005," Morbidity and Mortality Weekly Report Surveillance Summary 55(6): 1-16. Erratum in: Morbidity and Mortality Weekly Report 2006, 55(27): 752.

Semaan, S. et al. 2002. "Street and network sampling in evaluation studies of HIV risk-reduction interventions," AIDS Review 4(4): 213-223.

Stall, R. et al. 2001. "Alcohol use, drug use and alcohol-related problems among men who have sex with men: the Urban Men's Health Study,” Addiction 96 (11): 1589-1601.

Sudman, S., M. G. Sirken, and D. C. Charles. 1988. "Sampling rare and elusive populations," Science 240: 991-6.

Sutmoller, F. et al. 1997. "The Rio de Janeiro HIV vaccine site-I. Recruitment strategies and socio-demographic data of a HIV negative homosexual and bisexual male cohort in Rio de Janeiro, Brazil," Memórias do Instituto Oswaldo Cruz 92(1): 39-46.

Sutmoller. F. et al. 2002. "Human immunodeficiency virus incidence and risk behavior in the 'Projeto Rio': results of the first 5 years of the Rio de Janeiro open cohort of homosexual and bisexual men, 1994-98," International Journal of Infectious Diseases 6(4): 259-265.

Szwarcwald, C. L. 2000. "Estimativa da proporção de infectados pelo HIV para homens de 18 a 59 anos segundo a orientação sexual, 1998 [Estimate proportion of HIV infected men aged 18 to 59 by sexual orientation, 1998]." report prepared for the Brazilian Ministry of Health.

Szwarcwald, C. L. et al. 2005. "Knowledge, practices and behaviours related to HIV transmission among the Brazilian population in the 15-54 years age group, 2004," AIDS 19(Suppl 4): S51-58.

Szwarcwald, C. L. and P. R. B. Souza Junior. 2006. "Estimativa da prevalência do HIV na população Brasileira de 15 a 49 anos, 2004 [Estimated HIV prevalence in the Brazilian population aged 15 to 49, 2004]," Boletim Epidemiológico-Aids e DST 3(1): 11-15.

Tabet, S. et al. 2002. "HIV, syphilis and heterosexual bridging among Peruvian men who have sex with men," AIDS 16(9): 1271-1277.

Thiede, H. et al. 2003. "Regional patterns and correlates of substance use among young men who have sex with men in 7 US urban areas," American Journal of Public Health 93(11): 1915-1921.

Thompson, S. K. and O. Frank. 2000. "Model-based estimation with link-tracing sampling designs," Survey Methodology 26(1): 87-98.

Truong, H. M. et al. 2006. "Increases in sexually transmitted infections and sexual risk behaviour without a concurrent increase in HIV incidence among men who have sex with men in San Francisco: a suggestion of HIV serosorting?" Sexually Transmitted Infections 82(6): 461-466. Erratum in: Sexually Transmitted Infections 2007, 83(1): 76 .

Valleroy, L. A. et al. 2000. "HIV prevalence and associated risks in young men who have sex with men. Young Men's Survey Study Group,” Journal of the American Medical Association 284(2): 198-204. 


\section{Hgrizons}

Waldo, C. R. et al. 2000. "Very young gay and bisexual men are at risk for HIV infection: The San Francisco Bay Area Young Men's Survey II,” Journal of Acquired Immune Deficiency Syndrome 24(2): 168-174.

Weinhardt, L. S. et al. 1999. "Effects of HIV counseling and testing on sexual risk behavior: a meta-analytic review of published research, 1985-1997," American Journal of Public Health 89: 1397-1405.

Wilson, P. A. and H. Yoshikawa. 2004. "Experiences of and responses to social discrimination among Asian and Pacific Islander gay men: their relationship to HIV risk," AIDS Education and Prevention 16(1): 68-83.

Xiridou, M. et al. 2003. "The contribution of steady and casual partnerships to the incidence of HIV infection among homosexual men in Amsterdam," AIDS 17(7): 1029-1038.

Yoshikawa, H. et al. 2004. "Do family and friendship networks protect against the influence of discrimination on mental health and HIV risk among Asian and Pacific Islander gay men?" AIDS Education and Prevention 16(1): 84100 . 


\section{Appendix 1 - Recruitment Coupon (front and back side)}

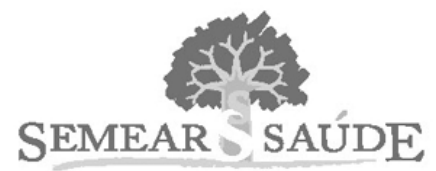

\section{Obrigado por participar!}

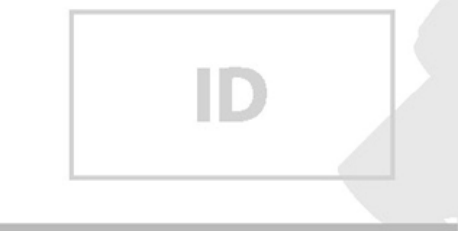

Fique com esta parte e pegue seu brinde até
Participando você estará dando sua contribuição para melhorar

a saúde da comunidade!

SEMEAR SAÚDE
Endereço: Rua 10 de setembro, 148, centro, Campinas (perto do SENAC)

Telefone: 0800-770 0220 (Se preferir, telefone para ser atendido com hora marcada)

Horário de funcionamento: De segunda à sexta-feira das 13 às $\mathbf{2 0}$ horas, sábado das $\mathbf{1 0}$ às $\mathbf{1 7}$ horas

Atenção: Convite válido entre os dias

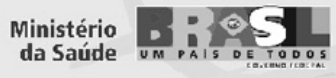

Population Council

\section{Traga este convite e, se você puder participar da pesquisa, você irá:}

- responder uma entrevista confidencial e anônima (leva de 30 a 40 minutos)

- fazer um teste anônimo para sífilis e, se você também quiser, para HIV

- receber o resultado dos testes em 20 minutos

- se quiser, receber vacina contra Hepatite B (se tiver, traga seu cartão de vacinação)

- ganhar um brinde.

\section{Destaque esta parte e entregue-a a seu convidado}

Endereço: Rua 10 de setembro, 148 , centro, Campinas (perto do SENAC)

\section{Telefone: $0800-7700220$}

(Se preferir, telefone para ser atendido com hora marcada)

Horário de funcionamento: De segunda à sexta-feira das 13 às 20 horas, sábado das 10 às 17 horas 


\section{Hgrizons}

\section{Appendix 2 Tables of Full Results}

For readers who are interested in comparing the population-based estimates and the sample percentages, these tables report both of these figures and correspond to the tables in the main report.

Table 8 Distribution of self-reported sexual orientation and sexual attraction by age

\begin{tabular}{|c|c|c|c|c|c|c|c|c|}
\hline & \multicolumn{2}{|c|}{$14-19$ years } & \multicolumn{2}{|c|}{$20-24$ years } & \multicolumn{2}{|l|}{$25+$ years } & \multicolumn{2}{|l|}{ Total } \\
\hline & $\begin{array}{c}\text { Population- } \\
\text { based } \\
\text { estimates }^{\text {b }} \\
\%(95 \% \mathrm{Cl})\end{array}$ & $\underset{\%^{\mathrm{a}}}{\text { Sample }}$ & $\begin{array}{c}\text { Population- } \\
\text { based } \\
\text { estimates } \\
\%(95 \% \mathrm{Cl})\end{array}$ & $\underset{\%^{\mathrm{a}}}{\text { Sample }}$ & $\begin{array}{c}\text { Population- } \\
\text { based } \\
\text { estimates } \\
\%(95 \% \mathrm{Cl})\end{array}$ & $\underset{\%^{\mathrm{a}}}{\text { Sample }}$ & $\begin{array}{c}\text { Population- } \\
\text { based } \\
\text { estimates } \\
\%(95 \% \mathrm{Cl})\end{array}$ & $\underset{\%^{\mathrm{a}}}{\text { Sample }}$ \\
\hline \multicolumn{9}{|c|}{$\begin{array}{l}\text { Sexual orientation } \\
(n=658)\end{array}$} \\
\hline Homosexual & $56.5(46.6-66.6)$ & 61.1 & $69.5(61.2-77.3)$ & 74.2 & $79.0(72.3-85.4)$ & 79.1 & $69.8(64.8-74.8)$ & 73.1 \\
\hline Bisexual & $38.6(28.3-48.6)$ & 36.5 & $28.3(20.6-36.2)$ & 23.7 & $16.2(10.9-22.3)$ & 15.6 & $25.5(21.1-30.1)$ & 23.2 \\
\hline Other & $4.9(1.0-10.3)$ & 2.4 & $2.2(0.1-5.8)$ & 2.1 & $4.8(1.5-8.6)$ & 5.3 & $4.7(2.1-7.7)$ & 3.6 \\
\hline \multicolumn{9}{|l|}{$\begin{array}{l}\text { Sexual attraction } \\
(n=643)\end{array}$} \\
\hline Men only & $54.4(44.5-64.1)$ & 57.7 & $68.5(59.1-77.1)$ & 72.8 & $74.1(67.0-81.5)$ & 76.7 & $67.0(61.4-72.3)$ & 70.8 \\
\hline Men and & $38.7(29.1-48.7)$ & 38.0 & $25.9(18.2-34.8)$ & 21.8 & $15.0(9.5-20.6)$ & 14.4 & $24.0(19.7-28.7)$ & 22.5 \\
\hline $\begin{array}{l}\text { women } \\
\text { Other }\end{array}$ & $6.9(2.2-12.7)$ & 4.3 & $5.6(1.8-10.2)$ & 5.3 & $10.9(5.5-16.9)$ & 8.9 & $9.0(5.7-12.7)$ & 6.7 \\
\hline
\end{tabular}

${ }^{a}$ Sample percentages represent the proportion of the study population with the characteristic.

${ }^{\mathrm{b}}$ Population-based estimates are based on analysis in RDSAT, which is adjusted for personal network sizes and recruitment patterns. 
Table 9 Disclosure of sexual attraction to men and family acceptance of disclosure

\begin{tabular}{|c|c|c|}
\hline & \multicolumn{2}{|l|}{ Total } \\
\hline & $\begin{array}{c}\text { Population-based } \\
\text { estimate }^{b} \\
\%(95 \% \text { Cl })\end{array}$ & $\begin{array}{c}\text { Sample }^{a} \\
\%\end{array}$ \\
\hline \multicolumn{3}{|c|}{ Person to whom disclosed feeling of attraction to men $^{c}$} \\
\hline Someone $(n=622)$ & $94.0(90.6-96.6)$ & 95.8 \\
\hline Colleague $(n=564)$ & $73.1(66.2-78.0)$ & 78.9 \\
\hline Mother $(n=589)$ & $50.9(45.2-56.5)$ & 56.2 \\
\hline Father $(n=490)$ & $26.7(19.7-32.1)$ & 33.5 \\
\hline Another relative $(n=613)$ & $59.1(54.6-64.7)$ & 64.9 \\
\hline \multicolumn{3}{|l|}{ Family acceptance $(n=566)$} \\
\hline Totally approve & $12.5(9.5-16.8)$ & 13.9 \\
\hline Somewhat approve & $24.0(18.7-28.2)$ & 25.1 \\
\hline Indifferent & $36.4(30.5-41.5)$ & 35.8 \\
\hline Somewhat disapprove & $10.1(7.5-14.0)$ & 10.1 \\
\hline Totally disapprove & $17.0(12.9-21.6)$ & 15.0 \\
\hline Participation in Gay Pride Parade $(n=643)$ & $53.8(48.3-59.3)$ & 62.8 \\
\hline
\end{tabular}

${ }^{a}$ Sample percentages represent the proportion of the study population with the characteristic.

${ }^{\mathrm{b}}$ Population-based estimates are based on analysis in RDSAT, which is adjusted for personal network sizes and recruitment patterns.

${ }^{c}$ The 'n's in the response categories reflect the number of respondents who answered the question.

Table 10 Exposure to HIV prevention activities

\begin{tabular}{|c|c|c|}
\hline & $\begin{array}{c}\text { Population-based } \\
\text { estimate }^{\mathrm{b}} \\
\%(95 \% \mathrm{Cl})\end{array}$ & $\begin{array}{l}\text { Sample } \\
\%^{\mathrm{a}}\end{array}$ \\
\hline $\begin{array}{l}\text { Participated in HIVISTI-related educational activities past } 12 \text { months } \\
(n=643)\end{array}$ & $30.0(25.7-34.9)$ & 33.7 \\
\hline $\begin{array}{l}\text { Frequency of participation in HIVISTI-related educational activities in past } \\
12 \text { months }(n=640)\end{array}$ & $70.4(65.7-74.9)$ & 66.6 \\
\hline None & $7.0(4.6-9.5)$ & 7.5 \\
\hline Few times/once a month & $22.6(18.6-27.1)$ & 25.9 \\
\hline A few times/once a year & & \\
\hline Received educational materials about HIVISTI in past 12 months ( $n=643$ ) & $54.7(49.8-59.9)$ & 58.2 \\
\hline Received free condoms $(n=643)$ & $78.3(73.4-82.4)$ & 81.9 \\
\hline $\begin{array}{l}\text { Received free condoms from governmental organization in past } 12 \\
\text { months }(n=643)\end{array}$ & $58.9(53.3-64.3)$ & 62.0 \\
\hline Received free condoms from NGO in past 12 months $(n=643)$ & $34.9(30.1-39.7)$ & 39.5 \\
\hline $\begin{array}{l}\text { Received free condoms in nightclubs/saunas/bars in past } 12 \text { months } \\
(n=643)\end{array}$ & $38.5(33.6-43.3)$ & 44.6 \\
\hline Member of NGO for gay men $(n=643)$ & $4.9(2.6-7.0)$ & 10.0 \\
\hline
\end{tabular}

${ }^{a}$ Sample percentages represent the proportion of the study population with the characteristic.

${ }^{b}$ Population-based estimates are based on analysis in RDSAT, which is adjusted for personal network sizes and recruitment patterns. 


\section{Hgrizons}

Table 11 MSM's experience of homophobic abuse

\begin{tabular}{|c|c|c|}
\hline & $\begin{array}{c}\text { Population- } \\
\text { based estimate }^{\mathrm{b}} \\
\%(95 \% \mathrm{Cl})\end{array}$ & $\underset{\%^{a}}{\text { Sample }}$ \\
\hline Ever experienced any homophobic abuse ${ }^{*}(n=636)$ & $84.5(80.4-88.4)$ & 86.5 \\
\hline Experienced any homophobic abuse last year $(n=619)$ & $69.5(65.0-75.2)$ & 72.4 \\
\hline Ever experienced psychological abuse ${ }^{\dagger}$ due to homophobia $(n=638)$ & $77.6(73.1-82.5)$ & 80.9 \\
\hline \multicolumn{3}{|l|}{$\begin{array}{l}\text { Frequency of psychological abuse }{ }^{\dagger} \text { due to homophobia last year } \\
(n=618)\end{array}$} \\
\hline None & $38.4(32.4-43.7)$ & 35.3 \\
\hline $1-2$ times & $15.5(12.2-19.2)$ & 15.2 \\
\hline$>2$ times & $46.1(40.7-51.9)$ & 49.5 \\
\hline Ever experienced physical abuse ${ }^{\ddagger}$ due to homophobia $(n=631)$ & $30.6(26.3-35.5)$ & 34.4 \\
\hline \multicolumn{3}{|l|}{ Frequency of physical abuse ${ }^{\ddagger}$ due to homophobia last year $(n=623)$} \\
\hline None & $79.9(75.1-84.0)$ & 76.9 \\
\hline $1-2$ times & $10.0(7.3-13.0)$ & 11.6 \\
\hline$>2$ times & $10.1(6.9-14.0)$ & 11.6 \\
\hline Ever experienced sexual harassment due to homophobia $(n=637)$ & $41.8(37.4-47.4)$ & 45.2 \\
\hline \multicolumn{3}{|l|}{$\begin{array}{l}\text { Frequency of sexual harassment due to homophobia past year } \\
(n=624)\end{array}$} \\
\hline None & $69.5(64.7-73.9)$ & 67.3 \\
\hline $1-2$ times & $11.9(8.5-15.6)$ & 12.9 \\
\hline$>2$ times & $18.7(15.0-22.8)$ & 19.7 \\
\hline Ever experienced homophobic abuse from police $(n=635)$ & $9.1(6.1-12.6)$ & 10.4 \\
\hline Experienced homophobic abuse from police last year $(n=633)$ & $5.6(3.6-7.9)$ & 6.3 \\
\hline $\begin{array}{l}\text { Sought medical help for physical abuse or sexual harassment due to } \\
\text { homophobia }(n=415)\end{array}$ & $10.9(5.7-17.1)$ & 11.1 \\
\hline Ever reported homophobic abuse to police $(n=539)$ & $5.6(3.1-9.3)$ & 6.1 \\
\hline
\end{tabular}

\footnotetext{
${ }^{a}$ Sample percentages represent the proportion of the study population with the characteristic.

${ }^{b}$ Population-based estimates are based on analysis in RDSAT, which is adjusted for personal network sizes and recruitment patterns.

* Homophobic violence was defined as having experienced any physical abuse, psychological abuse and sexual harassment.

${ }^{\dagger}$ Psychological abuse was defined as being verbally insulted, threatened with physical violence, had personal property damaged, or was chased or followed in the streets.

${ }^{\ddagger}$ Physical abuse was defined as having objects thrown at them, been spat upon, punched, hit, kicked, beaten, or assaulted with a weapon.
} 
Table 12 Alcohol and illicit drug use among MSM

\begin{tabular}{|c|c|c|}
\hline & $\begin{array}{c}\text { Population-based } \\
\text { estimate } \\
\%(95 \% \mathrm{Cl})\end{array}$ & $\underset{\%^{\mathrm{a}}}{\text { Sample }}$ \\
\hline \multicolumn{3}{|l|}{ Frequency of alcohol use past 6 months $(n=627)$} \\
\hline None/once a month or less & $42.6(37.4-48.2)$ & 38.9 \\
\hline Once a week & $40.2(34.9-45.1)$ & 43.8 \\
\hline Many times a week/every day & $17.2(13.1-21.8)$ & 17.2 \\
\hline Ever used any illicit drug $(n=628)$ & $53.5(48.1-59.0)$ & 57.6 \\
\hline Used any illicit drug past 6 months $(n=616)$ & $32.2(26.8-37.3)$ & 33.4 \\
\hline \multicolumn{3}{|c|}{ Frequency of cannabis use past 6 months $^{\S}(n=630)$} \\
\hline None & $74.3(69.0-79.2)$ & 73.2 \\
\hline Infrequent user & $13.3(9.9-16.4)$ & 14.9 \\
\hline Regular user & $12.4(8.9-17.0)$ & 11.9 \\
\hline \multicolumn{3}{|l|}{ Frequency of crack use past 6 months ${ }^{\S}(n=630)$} \\
\hline None & $94.4(91.8-96.9)$ & 95.1 \\
\hline Infrequent user & $2.5(1.1-4.2)$ & 2.4 \\
\hline Regular user & $3.0(1.2-5.1)$ & 2.5 \\
\hline \multicolumn{3}{|c|}{ Frequency of amphetamine use in past 6 months ${ }^{\S}(n=628)$} \\
\hline None & $97.5(96.0-98.8)$ & 97.0 \\
\hline Infrequent user & $1.8(0.7-2.9)$ & 2.5 \\
\hline Regular user & $0.7(0.1-1.9)$ & 0.3 \\
\hline \multicolumn{3}{|c|}{ Frequency of inhalant use in past 6 months $^{\S}(n=629)$} \\
\hline None & $93.4(90.6-96.0)$ & 94.0 \\
\hline Infrequent user & $6.5(3.8-9.2)$ & 5.7 \\
\hline Regular user & $0.1(0.1-0.4)$ & 0.2 \\
\hline \multicolumn{3}{|c|}{ Frequency of cocaine snorting in past 6 months $^{\S}(n=629)$} \\
\hline None & $85.1(81.2-89.0)$ & 84.0 \\
\hline Infrequent user & $9.2(6.4-12.4)$ & 10.3 \\
\hline Regular user & $5.6(3.1-8.2)$ & 5.6 \\
\hline \multicolumn{3}{|c|}{ Frequency of ecstasy use in past 6 months $^{\S}(n=630)$} \\
\hline None & $95.2(92.9-97.4)$ & 94.6 \\
\hline Infrequent user & $4.0(2.0-6.0)$ & 4.6 \\
\hline Regular user & $0.9(0.1-1.9)$ & 0.8 \\
\hline Used any other drug $(n=630)$ & $9.4(6.5-12.8)$ & 9.4 \\
\hline Ever injected drugs $(n=630$ ) & $1.3(0.4-2.9)$ & 1.6 \\
\hline
\end{tabular}

${ }^{a}$ Sample percentages represent the proportion of the study population with the characteristic.

${ }^{\mathrm{b}}$ Population-based estimates are based on analysis in RDSAT, which is adjusted for personal network sizes and recruitment patterns.

$\S$ Infrequent user = Once a month or less; Frequent user = Once a week, several times a week, or every day. 


\section{Hgrizons}

Table 13 HIV testing history and self-perception of risk for HIV infection among MSM

\begin{tabular}{|c|c|c|}
\hline & $\begin{array}{c}\text { Population-based estimates }^{\mathrm{b}} \\
\%(95 \% \mathrm{Cl})\end{array}$ & $\begin{array}{c}\text { Sample } \\
\%^{\mathrm{a}}\end{array}$ \\
\hline Ever tested for HIV $(n=631)$ & $57.6(52.1-63.6)$ & 59.3 \\
\hline Got HIV test free of charge $(n=374)$ & $82.2(78.4-90.4)$ & 79.4 \\
\hline \multicolumn{3}{|l|}{ Number of times tested for HIV $(n=631)$} \\
\hline 0 & $42.4(36.5-48.0)$ & 40.7 \\
\hline 1 & $20.1(16.1-24.6)$ & 19.5 \\
\hline $2-5$ times & $26.4(21.4-30.9)$ & 26.5 \\
\hline$>5$ times & $11.1(8.4-15.1)$ & 13.3 \\
\hline \multicolumn{3}{|l|}{ Last time tested for HIV $(n=374)$} \\
\hline$<1$ year & $42.0(34.5-50.9)$ & 50.8 \\
\hline 1 to 5 years & $40.6(32.9-50.0)$ & 36.6 \\
\hline$>5$ years & $11.6(5.7-15.7)$ & 6.9 \\
\hline Don't know & $5.8(2.5-9.3)$ & 5.6 \\
\hline \multicolumn{3}{|c|}{ Self-perception of risk for HIV infection $(n=625)$} \\
\hline Low/None & $50.1(45.5-55.9)$ & 50.4 \\
\hline Moderate/high & $27.7(23.1-32.0)$ & 30.1 \\
\hline Don't know & $22.1(17.6-26.2)$ & 19.5 \\
\hline
\end{tabular}

${ }^{a}$ Sample percentages represent the proportion of the study population with the characteristic.

${ }^{b}$ Population-based estimates are based on analysis in RDSAT, which is adjusted for personal network sizes and recruitment patterns.

Table 14 Estimated prevalence of HIV and syphilis using rapid test results

\begin{tabular}{lcr}
\hline & $\begin{array}{c}\text { Population-based } \\
\text { estimate }^{\mathbf{b}} \\
\%(95 \% \mathrm{Cl})\end{array}$ & $\begin{array}{c}\text { Sample } \\
\%^{\mathrm{a}}\end{array}$ \\
\hline HIV positive $(\mathrm{n}=621)$ & $7.4(4.7-10.7)$ & 7.9 \\
Syphilis positive $^{*}(\mathrm{n}=658)$ & $8.7(6.2-11.5)$ & 11.5 \\
\hline
\end{tabular}

${ }^{a}$ Sample percentages represent the proportion of the study population with the characteristic.

${ }^{b}$ Population-based estimates are based on analysis in RDSAT, which is adjusted for personal network sizes and recruitment patterns.

* Syphilis positive by rapid test, indicating past or current infection

Table 15 Estimated prevalence of HIV and syphilis by age

\begin{tabular}{|c|c|c|c|c|}
\hline \multirow[b]{2}{*}{ Age (in years) } & \multicolumn{2}{|l|}{ HIV } & \multicolumn{2}{|l|}{ Syphilis } \\
\hline & $\begin{array}{c}\text { Population-based } \\
\text { estimate }^{b} \\
\%(95 \% \mathrm{Cl})\end{array}$ & $\underset{\%^{\mathrm{a}}}{\text { Sample }}$ & $\begin{array}{c}\text { Population-based } \\
\text { estimate }^{b} \\
\%(95 \% \mathrm{Cl})\end{array}$ & $\underset{\%{ }^{\mathrm{a}}}{\text { Sample }}$ \\
\hline $14-19(n=162)$ & $4.0(0.6-9.2)$ & 2.5 & $2.8(0.5-5.4)$ & 4.8 \\
\hline $20-24(n=186)$ & $3.8(1.3-7.1)$ & 5.4 & $5.2(1.6-10.2)$ & 5.8 \\
\hline $25+(n=273)$ & $11.4(6.4-17.4)$ & 12.8 & $15.0(10.2-21.1)$ & 18.9 \\
\hline
\end{tabular}

${ }^{a}$ Sample percentages represent the proportion of the study population with the characteristic.

${ }^{\mathrm{b}}$ Population-based estimates are based on analysis in RDSAT, which is adjusted for personal network sizes and recruitment patterns. 
Table 16 Sexual behavior of MSM

\begin{tabular}{|c|c|c|}
\hline & $\begin{array}{c}\text { Population-based } \\
\text { estimates } \\
\%(95 \% \mathrm{Cl})\end{array}$ & $\underset{\%^{\mathrm{a}}}{\text { Sample }}$ \\
\hline Median age at first sexual contact with another person (IQR) $(n=640)$ & - & $13(10-16)$ \\
\hline \multicolumn{3}{|l|}{ Number of sex partners } \\
\hline \multicolumn{3}{|l|}{ Number of sex partners last 2 months $(n=630)$} \\
\hline None & $5.2(2.8-7.9)$ & 4.6 \\
\hline 1 partner & $30.8(25.2-35.3)$ & 28.9 \\
\hline 2-5 partners & $46.4(42.4-52.2)$ & 44.1 \\
\hline $6-10$ partners & $8.9(6.3-11.8)$ & 9.5 \\
\hline$>10$ partners & $8.7(6.0-11.3)$ & 12.8 \\
\hline \multicolumn{3}{|l|}{ Number of male sex partners last 2 months $(n=636)$} \\
\hline None & $9.5(6.4-13.0)$ & 7.5 \\
\hline 1 partner & $37.6(32.1-42.3)$ & 32.8 \\
\hline 2-5 partners & $40.7(36.3-46.2)$ & 42.0 \\
\hline $6-10$ partners & $5.4(3.5-7.8)$ & 7.1 \\
\hline$>10$ partners & $6.8(4.4-8.9)$ & 10.5 \\
\hline \multicolumn{3}{|l|}{ Number of transvestite sex partners last 2 months $(n=638)$} \\
\hline None & $89.3(85.5-92.7)$ & 91.4 \\
\hline 1 partner & $6.0(3.5-8.8)$ & 4.2 \\
\hline$>1$ partner & $4.8(2.9-6.9)$ & 4.4 \\
\hline \multicolumn{3}{|l|}{ Number of female sex partners last 2 months $(n=635)$} \\
\hline None & $84.4(79.5-89.2)$ & 86.8 \\
\hline 1 partner & $7.9(4.6-11.5)$ & 6.0 \\
\hline$>1$ partner & $7.7(4.8-10.8)$ & 7.2 \\
\hline \multicolumn{3}{|l|}{ Group sex } \\
\hline Ever had sex in groups $(n=634)$ & $44.7(39.5-50.5)$ & 51.3 \\
\hline \multicolumn{3}{|l|}{ Number times had sex in groups last 6 months $(n=322)$} \\
\hline None & $42.7(31.3-49.5)$ & 43.8 \\
\hline Once & $24.7(20.5-38.4)$ & 24.8 \\
\hline Twice or more & $32.6(22.0-39.3)$ & 31.4 \\
\hline \multicolumn{3}{|l|}{ Unprotected sex } \\
\hline \multicolumn{3}{|l|}{ Number male sex partners ${ }^{\S}$ w/ whom had URAI last 2 months $(n=613)$} \\
\hline Didn't have RAI & $36.5(31.2-41.5)$ & 33.3 \\
\hline None & $26.1(21.6-31.2)$ & 27.7 \\
\hline 1 partner & $30.1(26.1-35.3)$ & 30.8 \\
\hline$>1$ partner & $7.2(4.4-9.6)$ & 8.2 \\
\hline \multicolumn{3}{|l|}{ Number male sex partners ${ }^{\S} w /$ whom had UIAI last 2 months $(n=619)$} \\
\hline Didn't have IAI & $32.8(27.3-38.1)$ & 30.7 \\
\hline None & $30.4(25.7-35.5)$ & 32.5 \\
\hline 1 partner & $29.4(24.6-34.4)$ & 28.4 \\
\hline$>1$ partner & $7.5(5.0-10.4)$ & 8.4 \\
\hline \multicolumn{3}{|l|}{ Number of URAI with male partner ${ }^{\S}(n=631)$} \\
\hline Didn't have RAI & $36.1(31.2-41.1)$ & 32.3 \\
\hline None & $25.0(20.9-30.0)$ & 27.1 \\
\hline Once & $15.6(12.5-19.7)$ & 15.8 \\
\hline Twice or more & $23.3(18.6-26.7)$ & 24.7 \\
\hline
\end{tabular}




\section{Hgrizons}

Number of UIAI with male partner ${ }^{\S}(n=637)$

Didn't have IAI

$32.3(26.6-36.7)$

29.8

None

$29.1(25.1-34.6)$

Once

$13.8(10.7-17.2)$

13.2

Twice or more

$24.8(20.4-29.3)$

25.3

HIV status of sex partners

HIV status of male single ${ }^{\dagger}$ partner with whom had URAI last 2 months $(n=190)$

HIV-positive

$11.0(3.3-24.7) \quad 7.4$

Unknown status

$28.0(11.7-30.6) \quad 31.0$

HIV-negative

$61.1(50.7-80.5)$

61.6

HIV status of male single ${ }^{\dagger}$ partner with whom had UIAI last 2 months $(n=176)$

HIV-positive

$10.4(0.6-13.1) \quad 6.2$

Unknown status

$30.7(21.2-43.7) \quad 33.5$

HIV-negative

$59.0(51.0-73.0)$

60.2

${ }^{a}$ Sample percentages represent the proportion of the study population with the characteristic.

${ }^{\mathrm{b}}$ Population-based estimates are based on analysis in RDSAT, which is adjusted for personal network sizes and recruitment patterns.

${ }^{\S}$ Male partner includes male and transvestite partners.

${ }^{\dagger}$ Male single partner includes those who reported only one male partner in the past 2 months

IQR: Interquartile range

Table 17 Places where MSM most frequently meet male sex partners, by age ${ }^{\dagger}$

\begin{tabular}{|c|c|c|c|c|c|}
\hline $\begin{array}{l}\text { Places where participants } \\
\text { met male partners }(n=586)^{*}\end{array}$ & $\begin{array}{c}\text { 14-19 } \\
\text { years } \\
\text { Sample } \\
\%^{\mathrm{a}}\end{array}$ & $\begin{array}{c}20-24 \\
\text { years } \\
\text { Sample } \\
\%^{\mathrm{a}}\end{array}$ & $\begin{array}{c}25+ \\
\text { years } \\
\text { Sample } \\
\%^{\mathrm{a}}\end{array}$ & $\begin{array}{l}\text { Total } \\
\text { Population-based } \\
\text { estimates }^{\text {b }} \\
\%(95 \% \mathrm{Cl})\end{array}$ & $\begin{array}{c}\text { Sample } \\
\%^{\mathrm{a}}\end{array}$ \\
\hline Nightclubs/bars & 41.9 & 31.4 & 25.2 & $33.2(26.8-37.6)$ & 31.1 \\
\hline Internet & 11.2 & 13.6 & 12.0 & $11.9(8.3-16.0)$ & 12.3 \\
\hline Street, public parks & 7.0 & 5.9 & 10.6 & $7.2(4.4-11.0)$ & 8.4 \\
\hline Saunas & 0.7 & 2.9 & 12.4 & $6.4(3.9-9.6)$ & 6.8 \\
\hline Friends' houses/parties & 11.2 & 8.3 & 3.3 & $4.9(2.7-7.5)$ & 6.6 \\
\hline Another place (not specified) & 11.2 & 14.2 & 14.9 & $13.3(10.4-18.1)$ & 13.8 \\
\hline Nowhere & 16.8 & 23.7 & 21.5 & $23.0(18.5-27.7)$ & 21.0 \\
\hline
\end{tabular}

${ }^{\dagger}$ Population-based estimates are unavailable for age strata due to small sample size of the strata.

${ }^{a}$ Sample percentages represent the proportion of the study population with the characteristic.

${ }^{\mathrm{b}}$ Population-based estimates are based on analysis in RDSAT, which is adjusted for personal network sizes and recruitment patterns.

${ }^{*}$ Differences in the sample proportions by age were statistically significant $(p<0.001)$ 
Table 18 Involvement of MSM in commercial sex work

\begin{tabular}{|c|c|c|}
\hline & $\begin{array}{c}\text { Population-based } \\
\text { estimate }^{\mathrm{b}} \\
\%(95 \% \mathrm{Cl})\end{array}$ & $\begin{array}{c}\text { Sample } \\
\%^{\mathrm{a}}\end{array}$ \\
\hline Paid anyone for sex in past 2 months $^{*}(n=633)$ & $4.9(2.8-7.6)$ & 5.2 \\
\hline Paid men to have sex in past 2 months $(n=633)$ & $2.9(1.4-5.0)$ & 4.0 \\
\hline Paid woman to have sex in past 2 months $(n=633)$ & $2.1(0.7-3.8)$ & 1.3 \\
\hline Paid transvestite to have sex in past 2 months $(n=633)$ & $0.5(0.1-1.6)$ & 0.5 \\
\hline Ever received payment for sex $(n=636)$ & $28.3(23.9-33.8)$ & 32.4 \\
\hline Received payment from anyone to have sex in past 2 months $(n=631)$ & $14.8(11.1-19.0)$ & 16.8 \\
\hline Received payment from men to have sex in past 2 months $(n=632)$ & $14.6(10.9-18.7)$ & 16.8 \\
\hline Received payment from woman to have sex in past 2 months $(n=633)$ & $2.7(1.2-4.6)$ & 2.5 \\
\hline Received payment from transvestite to have sex in past 2 months $(n=634)$ & $2.3(0.9-3.9)$ & 2.2 \\
\hline Consider self as commercial sex worker $(n=635)$ & $8.0(4.8-11.6)$ & 8.5 \\
\hline
\end{tabular}

${ }^{a}$ Sample percentages represent the proportion of the study population with the characteristic.

${ }^{\mathrm{b}}$ Population-based estimates are based on analysis in RDSAT, which is adjusted for personal network sizes and recruitment patterns.

${ }^{*}$ Payment includes exchange of money, drugs, or gifts for sex 


\section{Hgrizons}

Table 19 Comparison of the sociodemographic characteristics of MSM who sold sex in the past two months with those who did not

\begin{tabular}{|c|c|c|c|c|}
\hline & \multicolumn{4}{|c|}{ 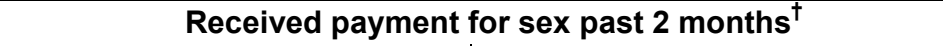 } \\
\hline & \multicolumn{2}{|c|}{ Yes $(n=106)$} & \multicolumn{2}{|c|}{ No $(n=525)$} \\
\hline & $\begin{array}{c}\text { Population-based } \\
\text { estimates } \\
\%(95 \% \mathrm{CI})\end{array}$ & $\underset{\%^{a}}{\text { Sample }}$ & $\begin{array}{c}\text { Population- } \\
\text { based estimates }^{b} \\
\%(95 \% \mathrm{Cl})\end{array}$ & $\underset{\%^{a}}{\text { Sample }}$ \\
\hline \multicolumn{5}{|l|}{ Schooling degree } \\
\hline $\begin{array}{l}\text { Some/complete } \\
\text { primary/secondary }\end{array}$ & $41.1(28.5-55.6)$ & 36.8 & $10.0(6.4-13.8)$ & 9.2 \\
\hline Some/complete high school & $45.6(32.2-59.5)$ & 48.1 & $55.2(49.4-61.1)$ & 56.7 \\
\hline Some/complete college & $13.3(5.0-21.4)$ & 15.1 & $34.7(28.7-41.2)$ & 34.2 \\
\hline \multicolumn{5}{|c|}{ Brazilian criteria purchase power } \\
\hline Class A/B & $35.2(18.9-45.5)$ & 39.6 & $44.2(37.3-51.1)$ & 44.2 \\
\hline Class C & $43.3(29.7-60.1)$ & 42.7 & $48.0(41.3-54.6)$ & 48.7 \\
\hline Class D/E & $21.6(11.2-37.3)$ & 17.7 & $7.7(4.8-11.5)$ & 7.0 \\
\hline \multicolumn{5}{|l|}{ Color } \\
\hline White & $31.9(19.5-44.0)$ & 35.8 & $60.4(54.4-64.9)$ & 60.7 \\
\hline Black & $5.7(0.6-12.7)$ & 4.7 & $5.1(3.0-8.0)$ & 6.1 \\
\hline Mullato/brown & 54.0 (41.4-67.9) & 54.7 & 32.6 (28.1-38.2) & 31.0 \\
\hline Other & $8.4(1.3-17.9)$ & 4.7 & $1.9(0.7-3.2)$ & 2.1 \\
\hline \multicolumn{5}{|l|}{ Sexual orientation } \\
\hline Homosexual & $52.1(39.5-66.2)$ & 56.6 & 72.5 (67.5-77.8) & 76.2 \\
\hline Heterosexual & $10.6(3.2-18.3)$ & 8.5 & $3.3(0.8-6.4)$ & 1.9 \\
\hline Bisexual & $37.3(23.6-51.3)$ & 32.1 & 24.3 (19.6-28.7) & 21.7 \\
\hline
\end{tabular}

${ }^{\dagger}$ Sample size varies slightly due to missing data.

${ }^{\text {a }}$ Sample percentages represent the proportion of the study population with the characteristic.

${ }^{\mathrm{b}}$ Population-based estimates are based on analysis in RDSAT, which is adjusted for personal network sizes and recruitment patterns.

Bold type data indicates significant difference between those who did and did not receive payment for sex in the past 2 months. 
Table 20 Comparison of risk behaviors of MSM who sold sex in the past two months with those who did not

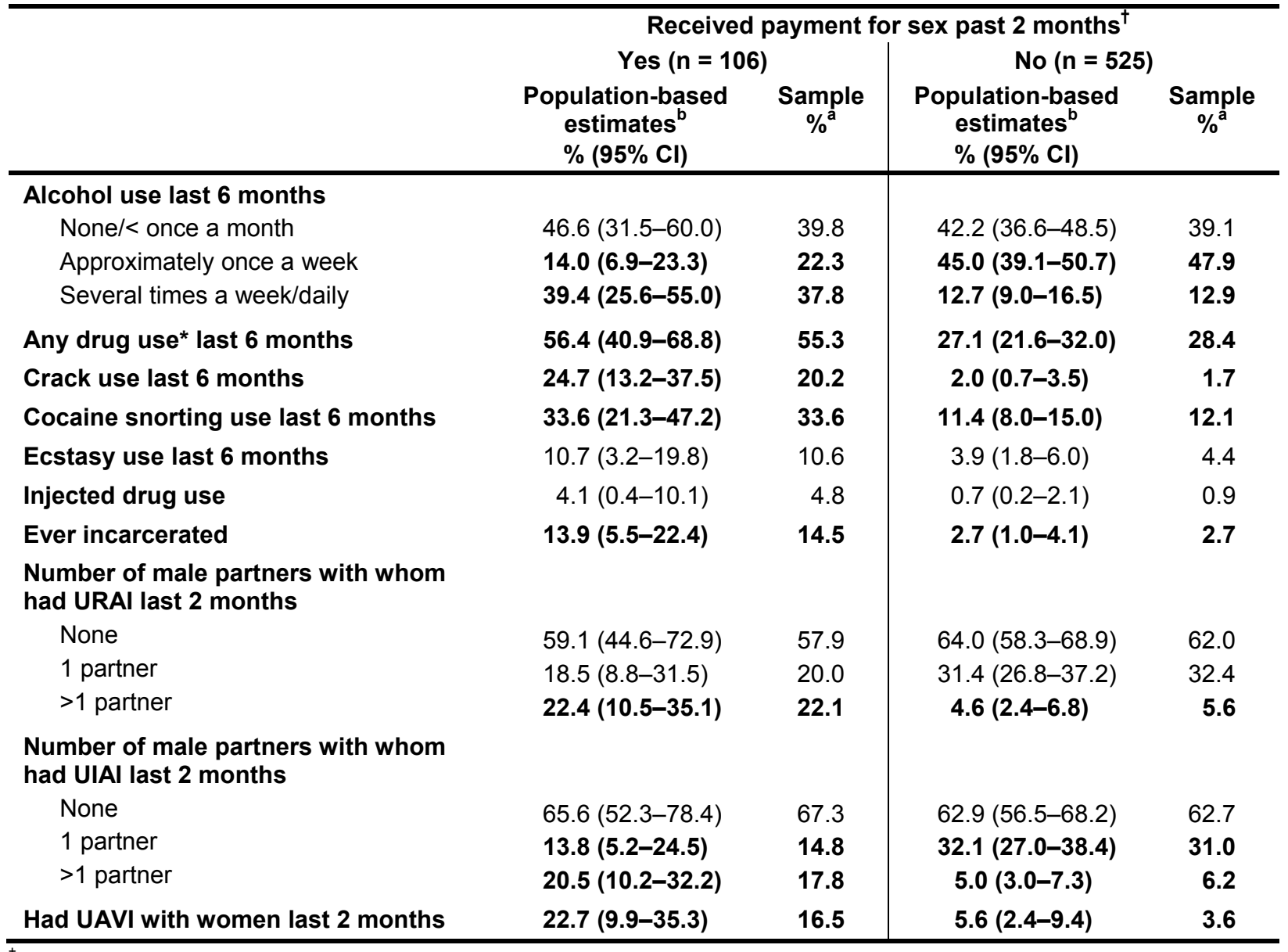

${ }^{\dagger}$ Sample size varies slightly due to missing data.

${ }^{\text {a }}$ Sample percentages represent the proportion of the study population with the characteristic.

${ }^{\mathrm{b}}$ Population-based estimates are based on analysis in RDSAT, which is adjusted for personal network sizes and recruitment patterns.

* Any drug use includes smoking of cannabis or crack, taking amphetamines or ecstasy, snorting inhalants or cocaine, using any other drugs or injecting any non-prescribed drugs.

Bold type data indicates significant difference between those who did and did not receive payment for sex in the past 2 months. 


\section{Hgrizons}

Table 21 HIV testing history and seroprevalence of HIV and syphilis of MSM who sold sex and who did not sell sex in past two months

\begin{tabular}{|c|c|c|c|c|}
\hline & \multicolumn{4}{|c|}{ 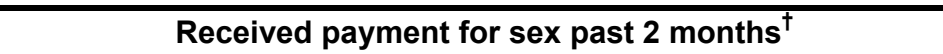 } \\
\hline & \multicolumn{2}{|c|}{ Yes $(n=106)$} & \multicolumn{2}{|c|}{ No $(n=525)$} \\
\hline & $\begin{array}{c}\text { Population-based } \\
\text { estimates } \\
\%(95 \% \mathrm{CI})\end{array}$ & $\underset{\%^{\mathrm{a}}}{\text { Sample }}$ & $\begin{array}{c}\text { Population-based } \\
\text { estimates } \\
\%(95 \% \mathrm{Cl})\end{array}$ & $\begin{array}{c}\text { Sample } \\
\%^{\mathrm{a}}\end{array}$ \\
\hline Ever took HIV test & $61.8(46.9-75.3)$ & 59.0 & $56.6(51.2-63.0)$ & 59.0 \\
\hline Tested positive for HIV result & $13.5(2.9-27.3)$ & 13.0 & $5.5(3.2-8.7)$ & 5.8 \\
\hline Tested positive for syphilis result & $19.7(11.3-31.6)$ & 23.6 & $6.5(4.3-9.1)$ & 8.7 \\
\hline Had an STI symptom past 12 months & $40.4(27.5-54.4)$ & 37.1 & $23.9(20.1-29.3)$ & 26.6 \\
\hline
\end{tabular}

Table 22 Experience of homophobic violence and childhood sexual abuse among MSM who sold sex and MSM who did not sell sex in the past two months

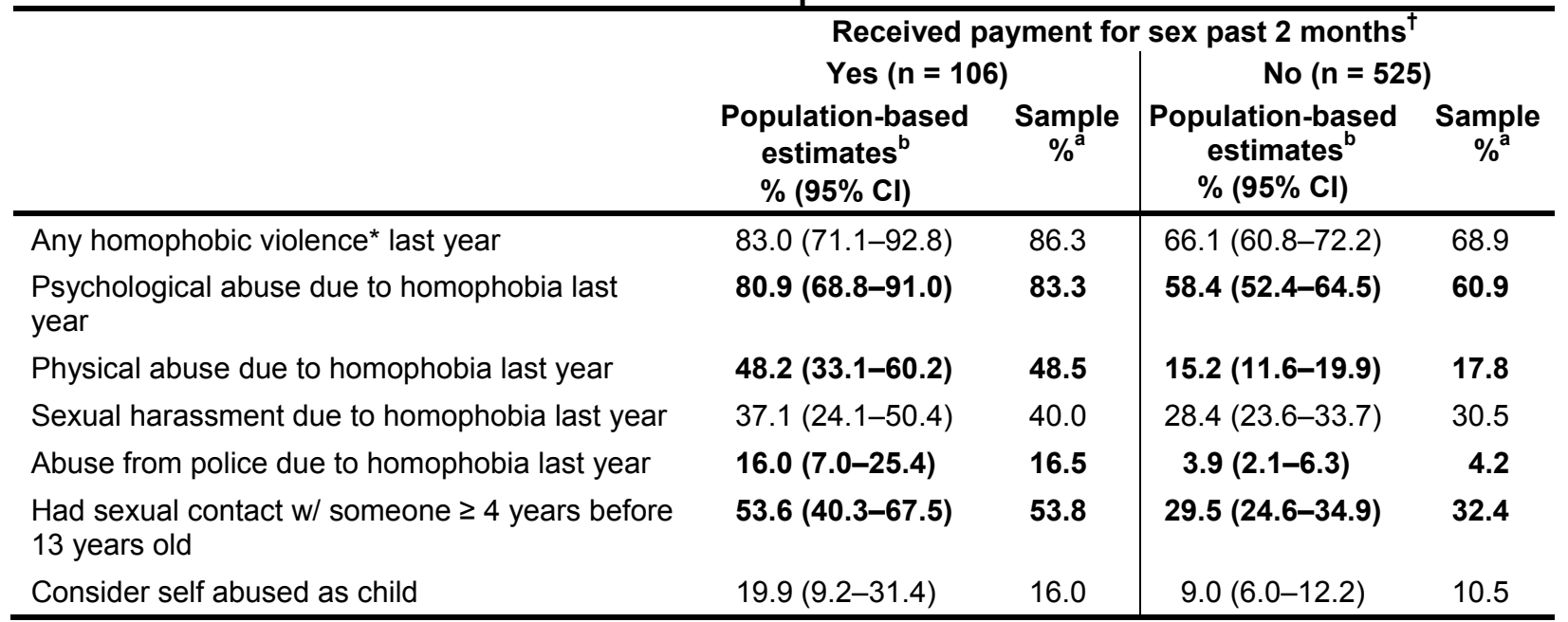

${ }^{\dagger}$ Sample size varies slightly due to missing data.

a Sample percentages represent the proportion of the study population with the characteristic.

${ }^{b}$ Population-based estimates are based on analysis in RDSAT, which is adjusted for personal network sizes and recruitment patterns.

*Homophobic violence was defined as having experienced any physical abuse, psychological abuse and sexual harassment. Bold type data indicates significant difference between those who did and did not receive payment for sex in the past 2 months. 


\section{Hgrizons}

Horizons is a global operations research program designed to:

- Identify and test potential strategies to improve HIV/AIDS prevention, care, and support programs and service delivery.

- Disseminate best practices and utilize findings with a view toward scaling up successful interventions.

\section{(2) Population Council}

Horizons is implemented by the Population Council in collaboration with

- International Center for Research on Women (ICRW)

- International HIV/AIDS Alliance

- PATH

- Tulane University

- Family Health International (FHI)

- Johns Hopkins University

For more information, please contact:

Horizons Program, Communications Unit 4301 Connecticut Avenue, NW Suite 280 Washington, DC 20008 USA

Tel: 202-237-9400

Fax: 202-237-8410

Email: horizons@popcouncil.org www.popcouncil.org/horizons 